\title{
Open heart surgery in the elderly patient
}

Citation for published version (APA):

Heijmeriks, J. (2000). Open heart surgery in the elderly patient. [Doctoral Thesis, Maastricht University]. Datawyse / Universitaire Pers Maastricht. https://doi.org/10.26481/dis.20000707jh

Document status and date:

Published: 01/01/2000

DOI:

10.26481/dis.20000707jh

Document Version:

Publisher's PDF, also known as Version of record

\section{Please check the document version of this publication:}

- A submitted manuscript is the version of the article upon submission and before peer-review. There can be important differences between the submitted version and the official published version of record.

People interested in the research are advised to contact the author for the final version of the publication, or visit the DOI to the publisher's website.

- The final author version and the galley proof are versions of the publication after peer review.

- The final published version features the final layout of the paper including the volume, issue and page numbers.

Link to publication

\footnotetext{
General rights rights.

- You may freely distribute the URL identifying the publication in the public portal. please follow below link for the End User Agreement:

www.umlib.nl/taverne-license

Take down policy

If you believe that this document breaches copyright please contact us at:

repository@maastrichtuniversity.nl

providing details and we will investigate your claim.
}

Copyright and moral rights for the publications made accessible in the public portal are retained by the authors and/or other copyright owners and it is a condition of accessing publications that users recognise and abide by the legal requirements associated with these

- Users may download and print one copy of any publication from the public portal for the purpose of private study or research.

- You may not further distribute the material or use it for any profit-making activity or commercial gain

If the publication is distributed under the terms of Article $25 \mathrm{fa}$ of the Dutch Copyright Act, indicated by the "Taverne" license above, 
Open heart surgery in the elderly patient 
(1) Jan Heigmeriks, Maastricht 2000

ISBN 9052782792

Vormgeving en druk: Datawyse / Universitaire Pers Maastricht

Financial support by the Nederlandse Hartstichting, Stichting RESCAR and the Wijnand M. Pon Stichting Leusden for the publication of this thesis is gratefully acknowledged. 


\title{
Open heart surgery in the elderly patient
}

\author{
PROEFSCHRIFT \\ ter verkrijging van de graad van doctor \\ aan de Universiteit Maastricht, \\ op gezag van de Rector Magnificus, \\ Prof. dr. A.C. Nieuwenhuijzen Kruseman, \\ volgens het besluit van het College van Decanen, \\ in het openbaar te verdedigen \\ op vrijdag 7 juli 2000 om 16.00 uur \\ door
}

JAN HEIJMERIKS

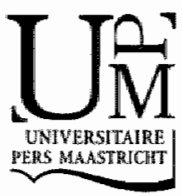


PROMOTOR

Prof. dr. H.J.J. Wellens

\section{BEOORDELINGSCOMMISSIE}

Prof. dr. M.J.A.P. Daemen (voorzitter)

Prof. dr. L. Eijsman (Universiteit van Amsterdam)

Prof. dr. S. de Lange

Prof. dr. K.I. Lie (Universiteit van Amsterdam)

Dr. J. Maessen

Address for correspondence:

Boven I] ziekenhuis

dept. of candiology

Statenjachtstraat I

1034 CS Amsterdam 
Voor Jeannette,

Christian, Anne

en... 


\section{Table of contents}

\section{CHAPTER 1}

Introduction

\section{CHAPTER 2}

Review of the literature

\section{CHAPTER 3}

The Mastricht study

\section{CHAPTER 4}

Coronary antery bypass surgery

\section{CHAPTER 5}

Valvular surgery

\section{CHAPTER 6}

Prophylactic $\beta$-blocking therapy for atrial fibrillation post cardiac surgery. Incidence and impact of contraindications for $\beta$-blockade, and the efficacy of low dose Sotalol in different age groups.

\section{CHAPTER 7}

Comparison of quality of life after coronary and/or valvular surgery in patients $>75$ years of age to younger patients.

\section{CHAPTER 8}

The incidence and consequences of mental disturbances in elderly patients post cardiac surgery. A comparison with younger patients.

\section{CHAPTER 9}

Observations on the effect of cardiac surgery on long-term survival patterns. A comparison with the general population.

\section{CHAPTER 10}




\section{CHAPTER 11}

Summary

CHAPTER 12

Samenvatting

Dankwoord

Publications

Curriculum Vitae 



\section{Introduction}

Open heart surgery in elderly patients was in the past associated with a high mortality rate. Keon et al reported in a retrospective study covering 3 decades a drop in mortality from $28 \%$ in 1970 to $12 \%$ in 1980 to $5 \%$ in 1990 in parients aged 70 years or over. In comparison to the younger patient with cardiac surgery the mortality decreased from $7 \%$ to $4 \%$ in the last 30 years ${ }^{4}$. Factors explaining this spectacular improvement include: 1) improved anaesthesiological and surgical techniques and skills, 2) improved postoperative care, and 3) better selection of candidates, using a risk profile.

Because of lower mortality rates and the increased capacity to perform open heart surgery, the number of elderly patients operated upon has gradually increased during the last decade. Several studies indicated a 4-6 times increase of elderly patients operated over a 7-13 year period (1981-1987, and 1979-1992) 2;3. Also at our institution, where cardiac surgery started in 1986, the percentage of elderly patients being operated have increased more than 3 fold since the first year. However as shown in figure 1 , during the last 5 years no further increase has been observed, with approximately $10 \%$ of all patients undergoing open heart surgery being 75 years or older.

This increase is expected to continue when we realize that demographic developments according to the Eurostat forecasting model ${ }^{4}$ indicate that the percentage of people aged 65 and older will increase from $15.2 \%$ in 1995 to $19.2-19.5 \%$ in 2020 , and that people aged 80 and older will increase from $3.8 \%$ in 1995 to $4.9-5.5 \%$ in 2020 .

There are because of ethical difficulties no randomized studies that compare the benefit of cardiac surgery versus conservative treatment in elderly patients. Ko et $\mathrm{al}^{5}$ studied retrospectively 65 octogenarians that had bypass surgery $(\mathrm{n}=36)$ or were treated conservatively $(n=29)$. The surgically treated patients had more severe coronary artery disease and anginal complaints. The mortality after 3 years was $22.6 \%$ in the surgical group, compared to $44.8 \%$ in the conservatively treated group, suggesting a benefit from bypass surgery.

In this regard it is important to know the general life expectancy in the elderly in the different age groups. Table 1 shows the situation in the Netherlands (CBS, $1995)^{6 ; 7}$ 


\section{$\%$ procedures $\geq 75$ years old}

Academic Hosputa Maastricht

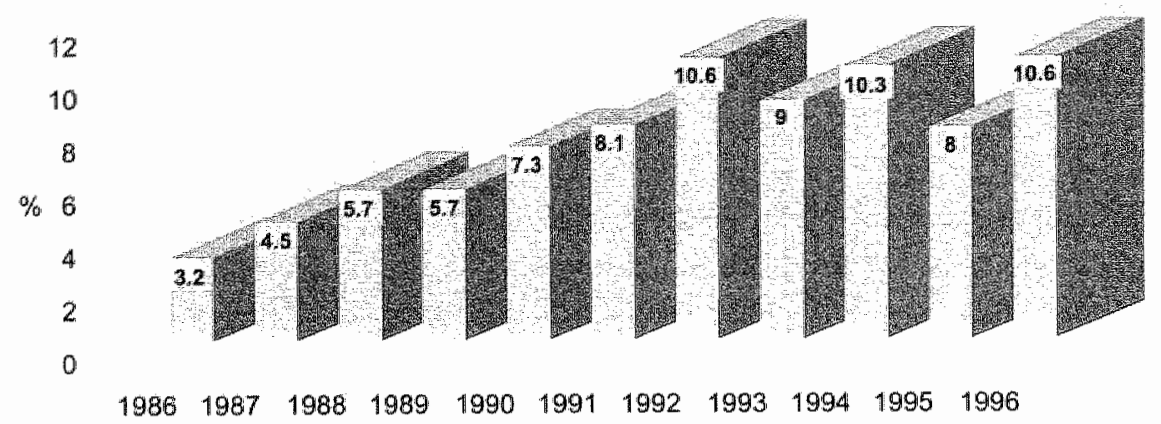

Filgure 1.1. Percentage of patients aged 75 years and alder, umdergoing open heart surgery.

Table 1.1. Life expectancy in different age and gender groups.

\begin{tabular}{llll}
\hline & $65 y$ & $75 y$ & $85 y$ \\
\hline male & $14.2 y$ & $8.5 y$ & $4.7 y$ \\
female & $18.8 y$ & $11.3 y$ & $5.8 y$ \\
\hline
\end{tabular}

Recent studies show that the longevity in elderly patients after open heart surgery is similar or even better than the theoretical life expectancy. ${ }^{8-14}$

Although current mortality rates are rather low $3 ; 15-17$, several studies indicate that there is a higher morbidity post surgery in elderly patients. ${ }^{2 ; 18-20}$ That results in a longer duration of hospital stay, higher costs, and therefore a worse cost/benefit ratio. ${ }^{21}$ Not only mortality but also quality of life is important for determining the success of the operation.

Many studies suggest that there is a clear improvement of quality of life ${ }^{22}$ after open heart surgery in elderly patients. ${ }^{23-29}$ However most of these studies are retrospective and without a control group. Results are therefore not very reliable because these studies are done quite late after the operation in a selected group which is still alive at that time. Until now no prospective studies were done comparing quality of life in both elderly and younger patients before and after open heart surgery. ${ }^{30}$

One of the greatest problems is the selection of elderly patients likely to benefit from open heart surgery. There are several factors that influence the risk of an operation. ${ }^{31-35}$ These risk factors can be divided in cardiac factors, like poor LV function, manifest heart failure, concomitant severe mitral incompetence and the 
need for emergency cardiac surgery. Among the known non-cardiac riskfactors are kidney function disturbances, chronic obstructive pulmonary disease, cerebrovascular disease, ${ }^{36-40}$ diabetes melitus and advanced age ${ }^{4-49}$ In addition there are perioperative riskfactors like complexity of the operation, 5.51 type of valve used, ${ }^{52-60}$ longer aortic cross clamp time, and the need for inotropic support. Also the amount and type of cardiac protection tluids used during the operation is important for outcome. ${ }^{61-63}$ Some of these factors however are not known at the time of patient selection. This makes the preoperative riskfactors most important.

All patients operated nowadays are considered to be "vital", and are without serious concomitant disease resulting in a shortened life expectancy. However, because of the process of aging ${ }^{64}$ the elderly patient has a higher incidence of riskfactors than the younger patient. In the elderly patient the decision to perform surgery is than often based on the inability to find a satisfactory conservative approach ${ }^{65}$ This explains why elderly patients referred for surgery are frequently more disabled and have more advanced cardiac disease than younger patients. The purpose of our study is to compare the results of open heart surgery in patients older than 75 years with younger patients. Short-and long-term results will be related to pre-operative findings. The outcome will include medical data (morbidity and mortality), quality of life data (prospectively assessed with validated questionnaires), and cost aspects (admission duration and readmissions). The purpose if our study is to investigate the possibility to divide patients in three categories: 1) patients in whom cardiac surgery is beneficial, 2) patients where cardiac surgery is of questionable benefit, 3) patients where cardiac surgery is not beneficial. If possible, such a ranking could help in future selection of patients for open heart surgery.

The first part of this thesis (chapter 2) will describe a review of the current literature concerning open heart surgery in elderly patients. The next chapter (3) describes the methods and patient population of the prospective study we performed in 600 patients. In chapter 4 the results of our study with coronary bypass surgery are discussed. Chapter 5 shows our results of valve surgery and combined valve and coronary surgery. Since atrial fibrillation is an important complication of open heart surgery, especially in elderly patients, having a high incidence resulting in prolongation of the admission duration, a separate chapter deals with this problem (chapter 6). In Chapter 7 differences are described in quality of life following open heart surgery in different age groups. The next chapter (8) deals about the incidence and consequences of mental confusion post cardiac surgery in the elderly. Chapter 9 compares the life expectancy in the first years following surgery of different age groups to that of the general population. The general discussion is in chapter 10. Finally in chapter 11 the results and conclusions of this thesis are described in a summary. 


\section{REFERENCES}

1. Keon WJ: Operative results and risk factors over the past three decades, in Walter PJ (ed): Coronary bypass surgery in the eldenly. Kluwer Academic Publishers, 1995, pp 27-40

2. Acinapura AJ, Rose DM, Cunningham JN, Jr., Jacobowitz IJ, Kramer MD, Zisbrod Z: Coronary artery bypass in Sepruagenarians. Analysis of mortality and morbidity. Cinculation 1988:78:1-179-J-184

3. Curtis J, Walls JT, Boley TM, Schmaltz RA, Demmy TL, Salan N: Coronary revascullarization in the elderly: determinants of operative mortalicy. Am. Thordc. Surg. $1994 ; 58: 1069-1072$

4. Schneider M: Demographic and economic trends in Europe and the need for coronary bypass surgery, in Walter P] (ed): Corontary bypass surgery in the elderly. the Netherlands, Kluwer Academic Publishers, 1995, pp 3-12

5. Ko W, GoldJP, Lazzaro R, ZelanolA, Lang S, Isom OW, Krieger KH: Survival analysis of octogenarian patients with coronary artery disease managed by elective coronary artery bypass strgery versus conventional medical treatment. Circulation 1992;86: $11191-11197$

6. Nusselder WJ, Bos van den GAM, Lenjor ME, Sonsbeek van JLA, Velden van der J: Prevalentiecijfers en gezonde levensverwachting, in Nusselder WJ (ed): Gezonde. levensvevtuading en het effect van dhromishe zideten. Central bureau woor de statistiek (CBS), 1995, pp $51-76$

7. MackenbergJP, Kunst AE, Looman CWN, Beeck van EF: Regionale sterfueverschillen in Nederland. Een overzicht van enkele recente onderzoeken. T. Soc. Gezondheidsz. $1992 ; 70: 396-404$

8. Cane ME, Chen C, Bailey BM, Femandez J, Laub GW, Anderson WA, McGrath LB: CABG in octogenarians: early and late events and actuarial survival in comparison with a matched population. Ans. Thorac Sug. 1995;60:1033-1037

9. Haman EL, Burke J: Efect of age on mortality in coronary artery bypass surgery in New York, 199!-1992. Am.Heart J. 1994;128:1184-1191

10. Subayi JB, de Brux JL, Delhumeau A, Lotfi N, Moreau X, Cottineau C, Bukowski JG, Corbea J], Pillet J: [Cardiac surgery in aged patients: immediate and medium tem results in 100 patients over 75 years of age/ Chirurgie cardiaque chez les patients ages; resultats immediats ef a moyen terme chaz 100 patients ages de 75 ans et plus. Antr.Mal. Coen, Vaiss 1994;87:1671-1677

11. Ruygrok PN, Barret-Boyes BG, Agnew TM, Whidlock RML: Long-tem follow-up after homograft aortic vallve replacement in elderly patients. The Thoraxcentre Joumal $1994,6: 8-13$

12. Ganver CC, Nichols RD, Cooler SD, Heisey DM, Murray EL, Kroncke GM: Influence of increasing age on long-term survival after coronary antery bypass grafting. Ann. Thowa. Swr. 1996,62:1123-1127 
13. Elayda MA, Hall RJ, Reul RM, Alonzo DM, Gillette N, Reu GI, Jr. Cooley DA: Aortic valve replacement in patients 80 years and older. Operative risks and long-term results. Circulation 1993;88:1111-6

14. Freman WK, SchaffHV, O'Brien PC, Orzulak TA, Naessens JM, Tajk AJ Cardiac surgery in the octogenarian: perioperative outcome and clinical follow-up. J.A.m. Coll Cardiol. 1991;18:29-35

15. He GW, Acuf TE, Ryan WH, Bowman RT, Douthit MB, Mack MJ: Deteminants of operative mortality in elderly patients undergoing coronary artery bypass grafting. Emphasis on the influence of internal mammary artery grafting on montality and morbidity. J. Thorac Cardionas. Surg. 1994;108:73-8:

16. Tsai T-P, Chaux A, Kass RM, Gray RJ, Matloff JM: Aortocoronary bypass surgery in septuagenarians and octogenarians, J. Cardiowas, Sumg. 1989;30:364-368

17. Levinon JR, Akins CW, Buckley M], Newell JB, Palacios IF, Block JC, Fifer MA: Octogenarians with aortic stenosis: Outcome after aortic valve replacement. Cirmbatom $1989 ; 80: 149-156$

18. Deiwick M, Möllhoff T, Budde T, Scheld $\mathrm{HH}$ : Cardiac surgery in patients aged 80 years and above: does outcome justify significant perioperative morbidity? Cardiology in the elderly 1995;3:381-386

19. Katz NM, Hannan RL, Hopkins RA, Wallace RB. Cardiac operations in patients aged 70 years and over: mortality, length of stay, and hospital charge. Amn. Thorte. Sumg. $1995 ; 60: 96-100$

20. Tsai TP, Nessim S, Kass RM, Chaux A, Gray RJ, Khan SS, Blanche C, Utey C, Matloft JM: Morbidity and mortality after coronary artery bypass in octogenarians. Ann. Thorac.Sung. 1991;51:983-986

21. Peigh PS, Swartz MT, Vaca KJ, Lohmann DP, Naunheim KS: Effect of advancing age on cost and outcome of coronary artery bypass grafting. Am. Thow. Surg. 1994,58; $1362-1366$

22. Mayou R, Bryant B: Quality of life in cardiovascular disease. Br. Heart J. 1993,69: $460-466$

23. Bunzel $B$, Eckersberger $F$ : Changes in life quality after aortoconomary bypass and walve replacement: A subjective criterion for assessing operative vesults. THORAC. CARDIOYASC.SURG. $1987 ; 35: 242-247$

24. Fitzpatrick R, Fletcher A, Gore S, Jones D, Spiegelhater D, Cox D: Quality of life measures in health care. I: Applications and issues in assessment. BMy. 1992:305: $1074-1077$

25. Jaeger AA, Hatky MA, Paul SM, Gonter SR: Functional capacity aftere cardiac surgery in elderly patients. J.Aw. Coll Cardiol. 1994:24:104m108

26. Kumar $\mathbb{P}$, Zehr KJ, Chang A, Cameron DE, Baumgartner WA: Quality oflife in octogenarians after open heart surgery. Chest 1995,108:9 19-926

27. Magni G, Unger HP. Valfe C, et al Psychosocial outcome one year after heart surgery. A prospective study. Anh Intem. Med. 1987;147:473m477 
28. Oxman TE, Freman DH, Jr., Manheimer ED: Lack of social participation or religious strength and comfort as risk factors for death after cardiac surgery in the elderly. Psydosom Med. 1995;57:5-15

29. Underwood MJ, Firmin RK Jehu D: Aspects of psychological and social morbidity in patients awaiting coronary artery bypass grafting. Br. Heart J. 1993;69:382-384

30. Gurwitz JH, Col NE, Avorn J: The exclusion of the elderly and women from clincal trials in acute myocardial infarction [see comments]. JAMA 1992;268:1417-1422

31. Antona CA, Pompilio G, Musumeci S, Arena V, Polvani G, Dainese L, Biglioli P: Matched comparison of patients older than 75 years versus a control group undergoing myocardial revascularisation: an assessment of operative risk. Cardiology in the elderly $1994 ; 2: 395-400$

32. Aranki SF, Rizzo RJ, Couper GS, Adans DH, Collins JJ, Jr., Gildea JS, Kinchla NM, Cohn LH: Aortic valve replacement in the elderly: Effect of gender and coronary artery disease on operative mortality. Circulation 1993;88:17-23

33. Logeais $Y$, Langanay $T$, Roussin $R$, Leguenier $A$, Rioux $C$, Chaperon J, de Place $C$. Mabo P, Pony JC, Daubert JC, et al: Surgery for aortic stenosis in elderly patients. A study of surgical risk and predictive factors. Circulation 1994:90:2891-2898

34. Weintrab WS: Coronary operations in octogenarians: can we select the partients? [editorial; comment]. Ann. Thork Surg. 1995;60:875-876

35. Williams DB, Carrillo RG, Trad EA, Wyatt CH, Grahowksi R, Wittels SH, Ebra G: Determinants of operative mortality in octogenarians undergoing coronary bypass. Ann. Thorac. Surg. 1995;60;1038-1043

36. Berens ES, Kouchoukos NT, Murphy SF, Wareing TH: Preoperative carotid artery screening in elderly patients tndergoing cardiac surgery. J.VASC.SURG. 1992;15: 313-323

37. Faggioli GL, Curl GR, Ricotta J]: The role of carotid screening before coronary artery bypass. J. Vas. Surg. 1990;12:724-731.

38. Ivey TD, Strandness E. Williams DB, et al: Management of patients with carotid bruir undergoing cardiopulmonary bypass. J. Thorac Cardionasc Surg. 1984;87:183-189

39. Johnsson P. Norving B, Nilsson B, Stähl E: Risk of cerebral complications during coronary artery bypass graft surgery in patients with previous cerebrovascular symptoms or carotid disease. Cardiology in the elderly 1993;1:15-21

40. Wareing TH. Daily BB, Murphy SF: Spectrum and management of coexistent carotid arterial disease in elderly cardiac surgical patiencs. Cardiology in the dderly 1994;2: $462-467$

41. Bashour TT, Hanna ES, Myler RK, Mason DT, Ryan C, Feeney J, Iskikian J, Wald SH, Antonini $\mathrm{C}, \mathrm{Sr}$., Malabed LL: Cardiac surgery in patients over the age of 80 years. Clin. Cardiol 1990;13:267-270

42. Edmunds LH, Jr., Stephenson LW, Edie RN, Ratcliffe MB: Open-heart surgery in octogenarians. NEW ENGL J.MED. 1988;319:131-136

43. Iskandrian AS, Segall BL: Should cardiac surgery be perfomed in octogenarians? J.Am. Coll. Cardiol 1991;18:36-37 
44. Ko W, Krieger KH, Lazenby WD, Shin YT, Goldstein M, Lazzaro R, Isom OW: Isolated coronary artery bypass grafting in one hundred consecutive octogenarian patients: A multivariate analysis. J. Thora Cardovar. Sums. 1991;102:532-538

45. Naunheim KS, Kern MJ, McBride LR, et al: Coronary artery bypass surgery in patients aged 80 years or older. An.J. Cardiol. 1987,59:804-807

46. Petersion ED, Cowper PA, Jollis JG, Bebchuk JD, DeLong ER, Muhlbaier LH, Mark $D B$, Pryor DB: Outcomes of coronary artery bypass graft surgery in 24,461 patients aged 80 years or older. Cirmation 1995;92:II85-91

47. Shah VZ, Rosenfeldt FL, Parkin GW, Ugoni AM, Habersberger PG, Gooper E: Cardiac surgery in the very elderly. Med.J.Aust. 1994;1.60:332-334

48. Tsai TP, Matloff JM, Gray RJ, et al: Cardiac surgery in the octogenarian. J. Thorac Cardiovasc.Surg. 1986:91:924-928

49. Utley JR, Leyland SA: Coronary artery bypass grafting in the octogenarian. J. Thord: Cardiovac. Surg. 1991;101:866-870

50. Adkins MS, Amalfitano D, Harnum NA, Laub GW, MoGrath LB: Efticacy of combined coronary revascularization and valve procedures in octogenarians. Chest 1995;108: $927-931$

51. Tsai TP, MatloffM. Chaux A, et al: Combined valve and coronary artery bypass proce dures in septuagenarians and octogenarians: Results in 120 patients. Am. Thorat. Surg. 1986:42:681-684

52. Antunes $\mathrm{MJ}$ : Valve replacement in the elderly. Is the mechanical valve a good altemative? J. Thorac Cardionasc. Surg. 1989;98:485-491

53. Cammack PL, Edie RN, Edmunds LH, Jr.: Bar calcification of the mitral anulus. A risk factor in mitral valve operations. J. Thowac. Cardiovasc. Surg. 1987;94:399-404

54. Deleuze P, Loisance DY, Besnainou F, Hillion ML, Aubry P, Bloch G, Cachera JP. Severe aortic stenosis in octogenarians: Is operation an acceptable alternative? Anw. Thorac. Surg. 1990;50:226-229

55. Fiore AC, Naunhem KS, Barner HB, Pennington DG, McBride LR, Kaiser GC, Willman VL: Valve replacement in the octogenarian. Am. Thowa.\$ag. 1989:48: $104-108$

56. Frenes SE, Goldman BS, LanovJ. Weisel RD, David TE, Salerno T: Valvular surgery in the elderly. Circulation 1989,80:177-190

57. Gardner Ty Mitral valve surgery in the elderly. Cardology in the elderly 1994:2:457-461

58. Jamieson WR, Munro AI, Burr LH, Germann E, Miyagishima RT, Ling H: Influence of coronary artery bypass and age on clinical perfomance after aortic and mitual valve replacement with biological and mechanical prostheses. Circulation 1995;92:11 101-106

59. Jones EL, Weintrab WS, Craver JM, Guyton RA, Shen Y: Interaction of age and coronary disease after valve replacement: Implications for valve selection. Am. Thorac. Surg. 1994,58:378-385

60. Rabinov M, David TE: Aortic valve surgery in the elderly. Cardiology in the elderly $1994 ; 2: 448-456$ 
61. Caldatone CA, Krukenkamp IB, Bums PG, Gaudette GR, Schuman J, Levitsky S: Blood cardioplegia in the senescent heart J. Thorac Cardiovasc. Surg. 1995;109:269-274

62. Chitwood WR, Jr. Wixon CL, Notton TO. Lust RM: Complex valve operations: antegrade versus retrograde cardioplegia? Ann. Thowa. Sug. 1995;60:815-818

63. Kato NS, Buckberg GD: Myocardial protection for coronary antery disease. Cown Antery Dis $1993,4,682-696$

64. Sollott SJ, Lakatta EG: Normal aging changes in the cardiovascular system. Cardiology in the elderly $1993,1: 349-358$

65. Cosgrove DM: Surgical myocardial revascularization. Cardiology in the elderly 1993;1: $71-76$ 


\section{Review of the literature}

The number of elderly patients that are undergoing open heart surgery has been increasing during the last decade. Most studies that have been performed in the past to evaluate the results of open heart surgery in elderly patients are retrospective, and mostly limited to mortality data and morbidity. The mortality figures in these studies show a wide range varying between $0 \%$ and $29 \%$, depending on the type of operation, risk factors, age of patients studied, and institution. In a retrospective study performed at our institution in 1991 (Ter Woorst F.J., unpublished) in which 186 patients aged 75 years and older were studied, with either coronary bypass surgery, valvular surgery or combined valvular and coronary surgery, the surgical mortality (within one month following surgery) was only $2.3 \%$. These patients were operated during a four year period, which equals 47 patiencs each year.

The majority of retrospective studies that have been performed include patients over a time period varying from 3 to 16 years (table $1-3$ ). When calculating the number of old patients that are operated in one year in these studies, the number is surprisingly low in many studies, varying between three and 126 cases each year, with a median of 25 cases. The conclusions from these studies are that results are favorable in elderly patients. This could suggest that several centers have strong selection criteria for open heart surgery in the elderly, thereby limiting the number of patients that have been operated.

In table 2.1 studies are listed that included only coronary bypass surgery. Table 2.2 shows studies with valve surgery and/or combined valvular with coronary surgery. Table 2.3 lists the studies that included all types of open heart surgery in elderly patients.

Factors that influence operative mortality are related to the actual condition of the patient. Important factors are: decreased kidney function, low LVEF/congestive failure, advanced age, emergency procedures. In table 2.4 an overview is given of several studies with the riskfactors that were found. All prospective studies are included in that table. Many studies also mention perioperative riskfactors for mortality. These include a prolonged perfusion-or aortic cross clamp time, need for inotropic support, prolonged mechanical ventilation after surgery and IABP use. Since these riskfactors are of not much help in pre-operative selecting patients, they are not reviewed here. 


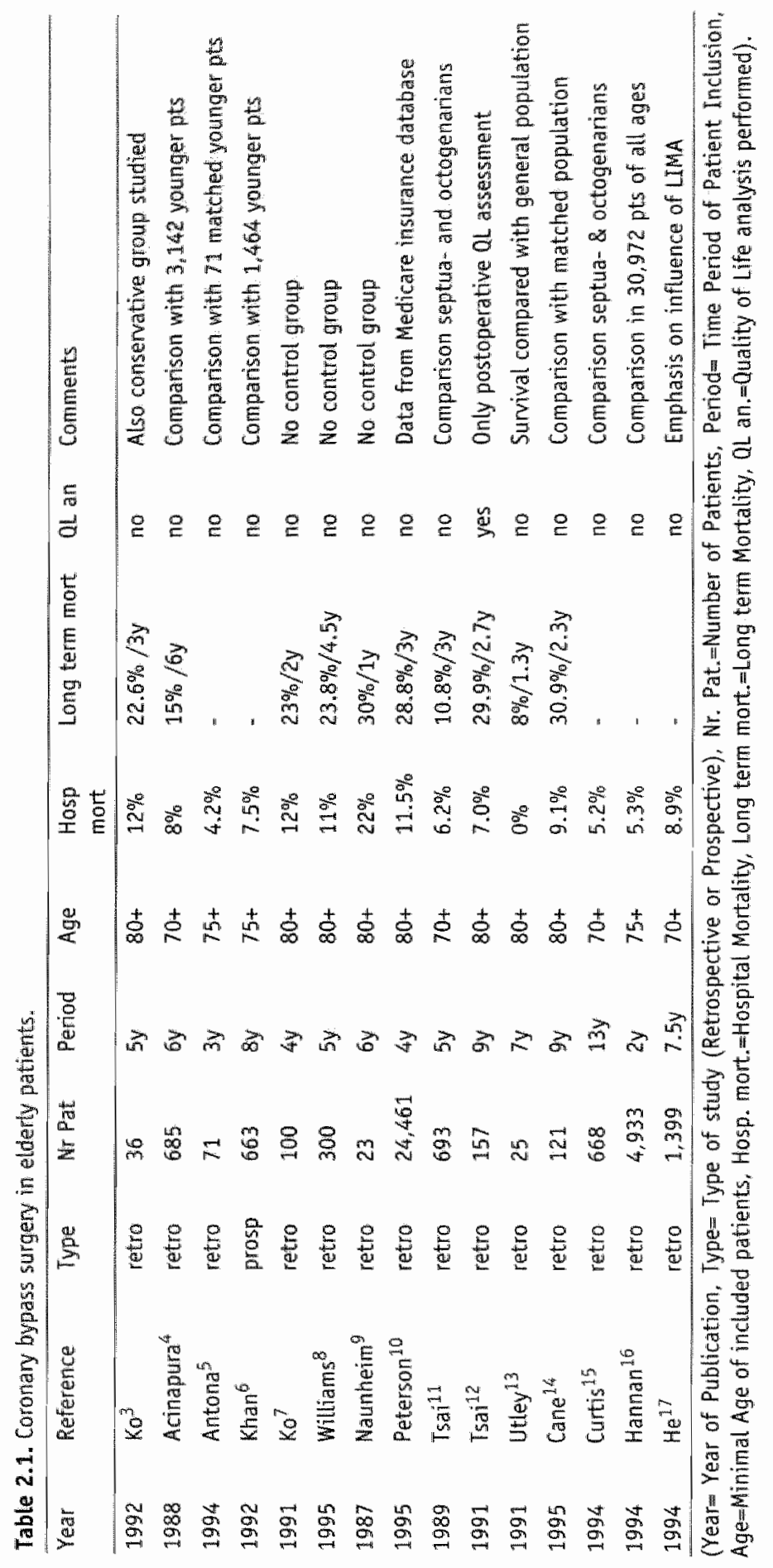




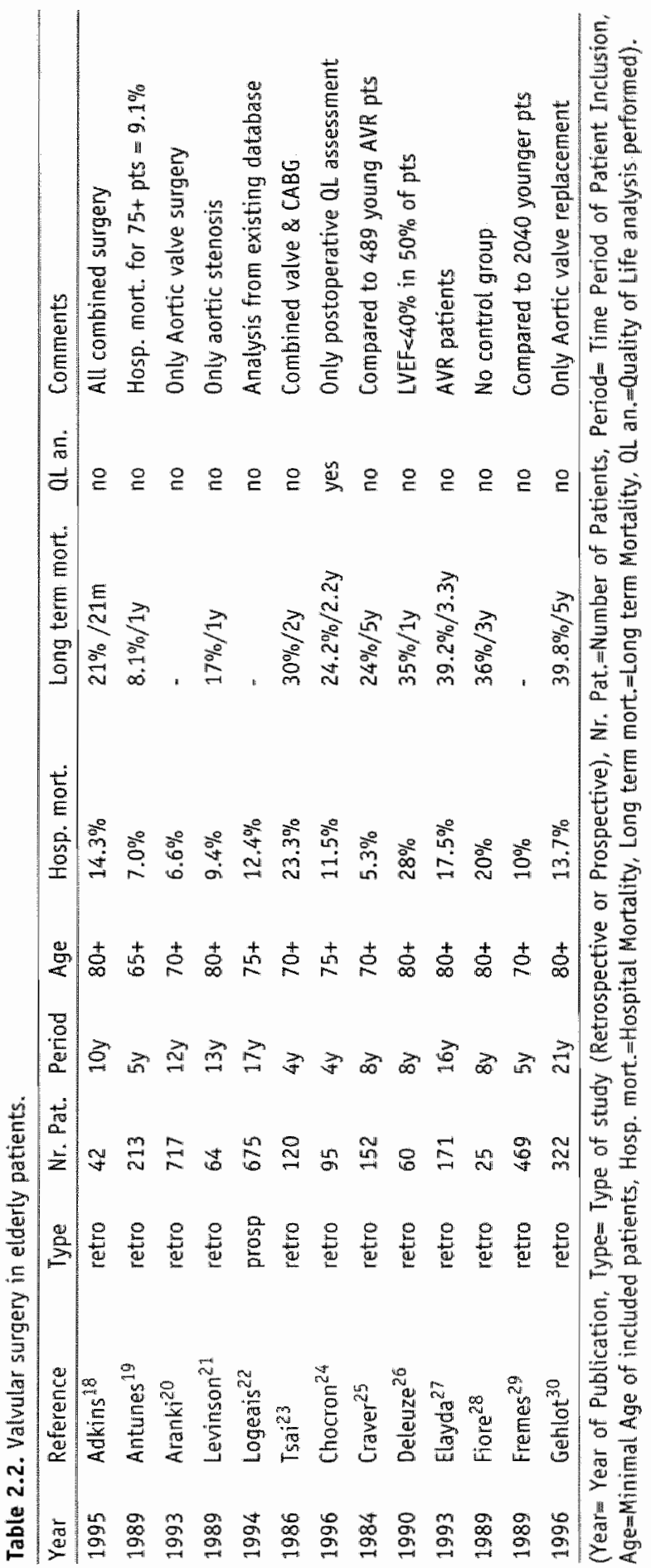




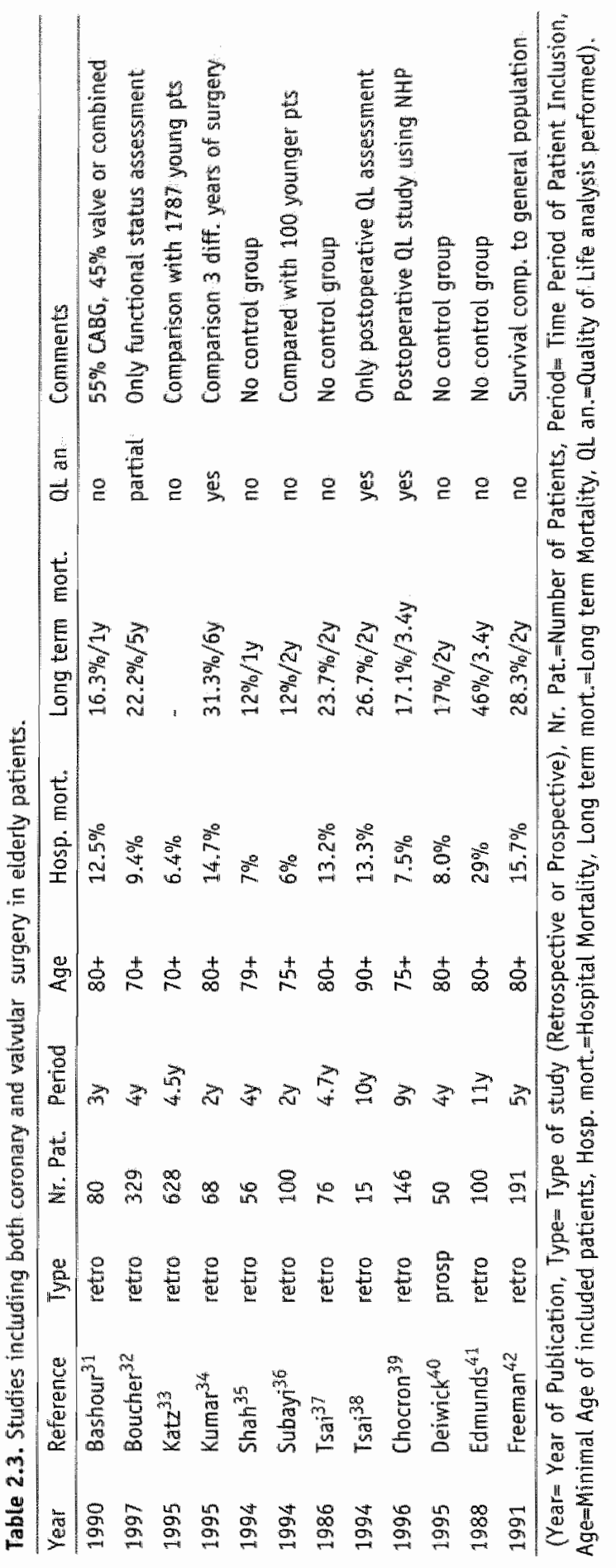


Table 2.4. Preoperative Risk factors for cardiac surgery in the elderly in different studies.

\begin{tabular}{|c|c|c|c|}
\hline Author/Near & Ref & Operation & Risk factors \\
\hline Logeais/"94 & 22 & AVR & Age, heart failure, no sinus rhythm, emergency surgery \\
\hline leiwick/ 95 & 40 & CABG+valve & Main stem disease, LVEF $<5 \%$, diabetes, combined surgery \\
\hline $0 / 92,91$ & 7,3 & CABG & LWEF $<30$, AP class 4, MV/AOV disease, re-operation \\
\hline Bashour/"90 & 31 & Alt, $>80 y$ & NYHA $=4$, MVR, pulmonary disease \\
\hline Tsail//91, & 12 & CABG & NYHA $=4$, LVEF $<40$, low cardiac output, IABP use \\
\hline Deleuze/ 90 & 26 & AVR & Energency 0.R., low LVEF, poor kidney function \\
\hline Freeman $/{ }^{\prime 2} 91$ & 42 & $\mathrm{All}_{x}>80 \mathrm{y}$ & Heart failure, MVR, pre-op. Bundle branch block on ECG \\
\hline Edmunds/88 & 41 & All, $>80 \mathrm{y}$ & Old Infarction, Cachexia, Emergency $0 . R$. \\
\hline Naunheim/ 87 & 9 & CABG & Low candiac output, Emergency O.R.. IABP use \\
\hline Adkins//95 & 18 & Valve+CABG & Aortic insufficiency \\
\hline Cammack/87 & 43 & MUR & Posterior mitral annulus calcification \\
\hline Elayda/"93. & 27 & AVR & $L V E F<45$, hypertension, heart failure, angina, combined $0 . R$. \\
\hline Aranki/" 93 & 20 & AVR & Male gender, mechanical prosthesis, combined $0 . R$., NYHA=4. \\
\hline
\end{tabular}

Most studies concerning Quality of Life after open heart surgery are focusing on young patients, and discuss items as return to work. In a recent meta-analysis by Duits/Erdman in which seventeen prospective Quality of life studies were reviewed in patients with coronary bypass surgery, only one study looked at patients older than 70 years. In that study by Chocron $^{2}$ it was found that an age above 70 years was associated with a lesser improvement of quality of life. These differences were present in the Energy, Sleep, and Social isolation section from the Nottingham Health Profile Questionnaire that was used for that study before and 3 months after surgery. In the other 16 studies from the meta-analysis no relation between age and Quality of Life is suggested. The major predicting factor in those studies associated with a worse Quality of Life after surgery is pre-operative anxiety and depression.

In a recent review article by Stemmer ${ }^{44}$ it was found that although the incidence of chronic diseases is higher in elderly patients, only $20 \%$ of patients aged 65 years and older have major limitations of activities. Heart disease appeared to be the most common disease that causes these limitations, followed by arthritis, visual impairment, and other less frequent disorders. Correcting heart disease by means ofopen heart surgery will result in improvement of quality of life in these patients. The incidence of anatomically significant coronary artery disease in patients over 70 years is $60-70 \%$, and the incidence of symptomatic coronary artery disease in that age group is $20 \%$. Also the incidence of sudden death is twice as high compared to that of 50 -year olds.

The postoperative morbidity is higher in elderly patients and can be $65^{\circ} \%$. The major age related complication was atrial arrhythmias (atrial fibrillation) which 
occurred in up to $40 \%$ of the elderly patients. Renal failure and pulmonary complications also had a higher incidence compared to younger patients. The admission duration is longer in elderly patients, resulting in higher costs.

\section{REFERENCES}

1. Duits AA, Bocke $S$, Taans MA, Passchier I, Erdman RA: Prediction of quality of life after coronary artery bypass graft surgery: a review and evaluation of multiple, recent studies. Psychosom. Med 1997. May. Jun. 59:257-268

2. Chocron S, Etievent JP, Viel JF, Dussaucy A, Clement F, Alwan K, Neidhardt M, Schipman N: Prospective study of quality of life before and after open heart operations. Ant. Thorac Surg. 1996;61:153-157

3. Ko W, GoldJP, Lazzaro R, Zelano JA, Lang S, Isom OW, Krieger KH: Survival analysis of octogenatian patients with coronary artery disease managed by elective coronary artery bypass surgery versus conventional medical treatment. Circulation 1992;86: II191-II197

4. Acinapura A.J, Rose DM, Cunninghann JN, Jr., Jacobowitz IJ, Kramer MD, Zisbrod Z: Coronary antery bypass in Septuagenarians. Analysis of mortality and morbidity. Circulat vion 1988;78:1-179-1-184

5. Antona CA, Pompilio G, Musumeci S, Arena V, Polvani G, Dainese L, Biglioli P: Matched comparison of patients older than 75 years versus a control group undergoing myocardial revascullarisation: an assessment of operative risk. Cardiology in the elderly $1994 ; 2: 395-400$

6. Khan SS, Kupfer JM, Matloff JM, Tsung Po Tsai, Nessim S: Interaction of age and preoperative risk factors in predicting operative mortality for coronary bypass surgery. Circulation 1992;86:186-190

7. Ro W, Krieger KH, Lazeriby WD. Shin YT, Goldstein M, Lazzaro R, Ison OW: lsolated coronary artery bypass grafting in one hundred consecutive octogenarian patients: A multivariate analysis. J. Thorac. Condiovast. Surg. 1991;102:532-538

8. Williams DB, Carrillo RG, Traad EA, Wyatt CH, Grahowksi R, Wittels SH, Ebra G: Determinants of operative mortality in octogenarians undergoing coronary bypass. Am. Thori. Surg. 1995;60:1038-104:3

9. Naunlieim KS, Kern MJ, McBride LR, et al: Coronary artery bypass surgery in patients aged 80 years or older. Am.J. Cardiol. 1987:59:804-807

10. Peterson ED, Cowper PA, Jollis JG, Bebchuk JD, DeLong ER, Muhlbaier LH, Mark $\mathrm{DB}$, Pryor:DB: Outcomes of coronary artery bypass graft surgery in 24,461 patients aged 80 years or older. Circulation 1995;92:1185-91

11. Tsai $\mathbb{T}^{\text {- }} \mathrm{P}$, Chaux A, Kass RM, Gray RJ, Matloff JM: Aortocoronary bypass surgery in septuagenarians and octogenarians. J. Cardiovase. Surg. 1989;30:364-368 
12. Tsai TP, Nessim S, Kass RM, Chaux A, Gray RJ, Khan SS, Blanche C, Utley C, Marloff JM: Morbidity and mortality after coronary artery bypass in octogenarans. Anw. Thorac. Swrg. 1991,51:983-986

13. Utley JR, Leyland SA: Coronary artery bypass grating in the octogenarian. J. Thorac.Cardionase.Surg. 1991;101:866-870

14. Cane ME, Chen C, Bailey BM, Fernandez], Laub GW, Anderson WA, McGrath LB: CABG in octogenarians: early and late events and actuarial survival in comparison with a matched population. Anm. Thorac Sug. 1995;60:1033-1037

15. Curtis JJ, Walls JT, Boley TM, Schmalz RA, Demny TL, Salam N: Coronary revascularization in the elderly: deteminants of operative mortality. Amm. Thora, Surg. 1994;58:1069-1072

16. Hannan EL, Burke I: Effect of age on mortality in coronary artery bypass surgery in New York, 1991-1992. Am. Heant J. 1994;128:1184-1191

17. HeGW, AcuffTE, Ryan WH, Bowman RT, Douthit MB, Mack MJ: Deteminants of operative mortality in elderly patients undergoing coronary artery bypass gafting. Emphasis on the influence of internal mammary artery grafting on mortality and morbidity. J. Therac. Cardiovasc. Surg. 1994:108:73-81.

18. Adkins MS, Amalfitano D, Hamum NA, Laub GW, McGrath LB: Efficacy of combined coronary revascularization and valve procedures in octogenarians. Chost $1995 ; 108: 927-931$

19. Antunes Mf: Valve replacement in the elderly. 1s the mechanical valve a good altemative? J. Thow Cardiovasc. Surg. 1989;98:485-491

20. Aranki SF, Rizzo RJ, Couper GS, Adams DH, Collins JJ, Jr., Gildea JS, Kinchla NM, Coln LH: Aortic valve replacenent in the elderly: Effect of gender and coronary artery disease on operative mortality. Circulation 1993;88:17-23

21. Levinson JR, Akins CW, Buckley MI, Newell JB, Palacios IF, Block PC, Fifer MA: Octogenarians with aortic stenosis: Outcome after artic valve replacement. Ciralotion $1989,80: 149-156$

22. Logeais $\mathrm{Y}$, Langanay $T$, Roussin R, Leguerrier A, Rionx $C$, Chaperon J, de Place $C$, Mabo P, Pony JC, Daubert JC, et al: Surgery for aortic stenosis in elderly pationts. A study of surgical risk and predictive factors. Circulation 1994:90:2891-2898

23. Tra TP, MatoffJ, Chau A, et al: Combined valve and cononary artery bypass procedures in septuagenarians and octogenarians: Results in 120 patients. Anm. Thord Surs. $1986 ; 42: 681-684$

24. Chocron S, Etievent JP, Clement F, Alwaw K, Neidhardt M, Taberlet C, Schipman N: Is surgery for aortic stenosis justified in pattents over 75 years of age? I Candiovas Swrs. Tonino. 1996;37:255-259

25. Craver JM, Goldstein J, Jones EI, et al: Clinical, hemodynamic, and operative descriptors affecting outcome of aortic walve replacement in elderly versus young patients. Am. Surg. 1984;199:733-741 
26. Deleuze $P$, Loisance DY, Bemmonow, Hillon ML, Aubry $P$, Bloch $G$, Cachera $\mathbb{P}$ : Severe aortic stenosis in octogenarians: Is operation an acceptable altermative? Anm. Thorac Sum. 1990;50:226-229

27. Elayda MA, Hall RJ, Reul RM, Alonzo DM, Gillette N, Reul GJ. Jr. Cooley DA: Aortic valve replacement in patients 80 years and older. Operative risks and long-trem results. Circulation 1993,88:11 11-6

28. Fiore $A C$, Namhem $K S$, Bamer HB, Pennington $D G$, McBride LR, Kaiser GC, Willman VL: Valve replacement in the octogenarian. Ann. Thorac Surg. 1989,48: $104-108$

29. Fremes $\mathrm{SE}$, Goldman BS, Ivanov J, Weisel RD, David TE, Salemo T: Valvular surgery in the elderly. Circulation $1989 ; 80: 177-190$

30. Gehlot A. Mullany CJ, Ilstrup D, SchaffHV, Orszulak TA, Morris J, Daly RC: Aortic valve replacement in patients aged eighty years and older: Early and long-term results. J. Thorac, Cardiovase.Surg. 1996;111:1026-1036

31. Bashour TT, Hanna ES, Myler RK, Mason DT, Ryan C, FeeneyJ, IskikianJ, Wald SH, Antonini C, Sr. Malabed LL: Cardiac surgery in patients over the age of 80 years. Clin. Cardial. 1990:13:267-270

32. Boucher JM, Dupras A, Jutras N, Page V, LeLonier J, Gagnon $\mathbb{R} M$ : Long-term survival and functionall status in the elderly after cardiac surgery. Cam.J.Cardiol. 1997.Jul. $13: 646-652$

33. Katz NM, Hannan RJ, Hopkins RA, Wallace RB: Cardiac operations in patients aged 70 years and over: mortality, length of stay, and hospital charge. Amm. Thorac. Surg. $1995 ; 60: 96-100$

34. Kumar P, Zehr K], Chang A, Cameron DE, Baumgartner WA: Quality of life in octogenarians after open heart surgery. Chest 1995;108:919-926

35. Shath VZ, Rosenfeldt FL, Parkin GW, Ugoni AM, Habersberger PG, Cooper E: Cardiac surgery in the very elderly. Med.J.Aust. 1994;160:332-334

36. Subayi JB, de Brux JL, Delhumeau A, Lotf N, Moreau X, Cottineau C, BukowskiJG, Corbeau IJ, Pillet J: [Cardiac surgery in aged patients; immediate and medium-term results in 100 patients over 75 years of age] Chirurgie cardiaque chez les patients ages; resultats immediats a moyen terme chez 100 patients ages de 75 ans et plus. Anh. Mal Coewr. Vaiss. 1994;87:1671-1677

37. Tsai TP. Matoff JM, Gray RJ, et al: Cardiac surgery in the octogenarian. J.Thorac Candiovas Smu. 1986;91:924-928

38. Tsai TP, Denton TA, Chaux A, MatloffJM, Kass RM, Blanche C, Khan SS: Results of coronary artery bypass grafting and/or aortic or mitral walve operation in parients $>$ or $=$ 90 yeats of age. Am.J.Cridiol. 1994,74960-962

39. Chocron S, Rude N, Dussalucy A, Leplege A, Clement F, Alwan K, VielJF, Etievent JP. Quality of life after open-heart surgery in patients over 75 years old. Alge. Agerng $1996 ; 25: 8-11$ 
40. Dewwick M, Mollhoff, Budde T, Scheld HH. Cardiac surgery in patients aged 80 years and above: does outcome justry significant perioperative norbidity? Cardology in the elderly $1995 ; 3: 381-386$

41. Edmunds LH, Jr. Stephenson LW, Edie RN, Ratchffe MB: Open-heart surgery in octogenarians. New Engl.J.Med. 1988;319:131-136

42. Freeman WK, SchafHV, O'Brien PC, Orsulak TA, Naessens JM, Tajik A]: Cardiac surgery in the octogenarian: perioperative outcome and clinical follow-up lsee comments]. J.Am. Coll. Caviol. 1991;18:29-35

43. Cammack PL, Edie RN, Ednunds LH, Jr. Bar calcification of the mitral anulus. A risk factor in mitral valve operations. J. Thorac. Cardiovase Surg. 1987;94:399-404

44. Stemmer EA, Aronow WS: Surgical management of coronary arterial disease in the elderly. Conon. Artery. Dis. 1998. 98 A.D ;9:279-290 



\section{CHAPTER 3}

\section{The Maastricht study: material and methods}

In order to investigate the outcome of cardiac surgery in elderly patients in comparison to younger patients we designed a prospective observational study. During a period of $3 \frac{1}{4}$ years, starting September $22^{\text {nd }} 1993$ until December $18^{\text {th }} 1996$ we included 200 patients who underwent open heart surgery, and were 75 years or older (Old group). Each of these patients were matched with two patients of less than 75 years (Young group), having the same operative procedure, and being of the same sex. During the inclusion period 290 patients older than 75 years have been operated, and 2499 patients younger than 75 years. Ninety elderly patients were not included because of logistic reasons, partially due to matching problems. The data analyzed include medical data, information about admission duration and costs, and assessment of the quality of life. The follow up duration of all surviving patients was minimally one year. All patients were operated upon in the Academic Hospital of Maastricht (Department of cardio thoracic surgery).

The Academic Hospital Mastricht is the only Hospital in the province of Limburg that offers cardiac surgery. Being located in the most southern part of the Netherlands explains that the majority of patients from hospitals in the southern part of Limburg are operated upon in Maastricht (Gigure 3.1). The majority of the Old patient group came from Maastricht (35.5\%), followed by Heerlen (33\%) and Sittard (15.5\%), which are the hospitals nearest to Maastricht. Only $2.5 \%$ of the patients were referred from hospitals above Weert. Most patients from the Young (control) group were selected from Maastricht (47.3\%) for logistic reasons (table 3.1).

\section{PATIENT POPULATION}

Main categories: According to the surgical procedure each patient was entered in one of the following major categories: 1) coronary artery disease, 2) valvular disease, 3) combined coronary and valvular disease. The majority $( \pm 2 / 3)$ of all patients had coronary surgery (table 3.2).

There were more female patients in the Old age group $(53.5 \%)$. For that reason a similar percentage of female patients was taken in the Young group. The mean age was higher in female patients, which was most pronounced in the Young group (table 3.3). A detailed age histogram is shown in figure 3.2. 


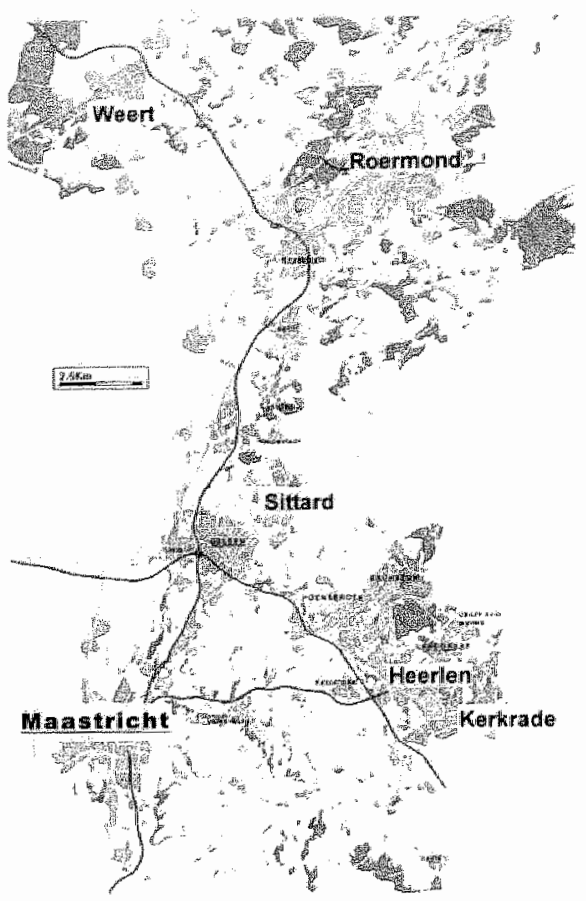

Figure 3.1. Maastricht and its geographic relation to the referring centre.

Tining of surgery: Operations were divided in three categories: 1) acute surgery (defined as surgery within 2 days after referral), 2) urgent surgery (defined as surgery within 2 weeks after referral, but during the same hospital admission), and 3) elective surgery (defined as surgery more than 2 weeks after referral, usually from a waiting list). No significant differences were seen in the incidence of acute surgery. However Old patients had a slightly higher incidence of urgent surgery $(53.0 \%$ versus $43.5 \%, P<0.05$, table 3.4$)$.

\section{DATA COLLECTION}

All patients were screened one day prior to surgery by the main investigator, who collected the results immediately in special data forms, to be used for computer analysis at a later stage.

Data recorded from the clinical history included: cardiac risk factors (smoking, hypercholesteremia, diabetes mellitus, hypertension), presence of an old or recent myocardial infarction ( $<2$ months old), history of congestive heart failure, 
Table 3.1. Referring hospitals.

\begin{tabular}{|c|c|c|c|c|}
\hline & \multicolumn{4}{|c|}{ Age group } \\
\hline & \multicolumn{2}{|l|}{ Young } & \multicolumn{2}{|c|}{ old } \\
\hline & Count & $\%$ & Count & $\%$ \\
\hline Maastricht & 189 & $47.3 \%$ & 71 & $35.5 \%$ \\
\hline Heerlen & 58 & $14.5 \%$ & 66 & $33.0 \%$ \\
\hline Sittard & 81 & $20.3 \%$ & 31 & $15.5 \%$ \\
\hline Kerkrade & 44 & $11.0 \%$ & 12 & $6.0 \%$ \\
\hline Roermond & 12 & $3.0 \%$ & 9 & $4.5 \%$ \\
\hline Weert & 5 & $1.3 \%$ & 6 & $3.0 \%$ \\
\hline Other & 11 & $2.8 \%$ & 5 & $2.5 \%$ \\
\hline Total & 400 & $100.0 \%$ & 200 & $100.0 \%$ \\
\hline
\end{tabular}

Table 3.2. Type of surgery.

\begin{tabular}{lcrrrr}
\hline & \multicolumn{3}{l}{ Age group } & & \\
\cline { 2 - 5 } & \multicolumn{1}{c}{ Young } & & \multicolumn{2}{c}{ Old } \\
\cline { 2 - 5 } & $\mathrm{Nb}$ & $\%$ & $\mathrm{Nb}$ & $\%$ \\
\hline CABG & 262 & $65.5 \%$ & 131 & $65.5 \%$ \\
klep & 72 & $18.0 \%$ & 36 & $18.0 \%$ \\
CABG+klep & 66 & $16.5 \%$ & 33 & $16.5 \%$ \\
Total & 400 & $100.0 \%$ & 200 & $100.0 \%$ \\
\hline
\end{tabular}

Table 3.3. Gender related differences in each age group.

\begin{tabular}{llrllll}
\hline Age group & Sex & $\mathrm{Nb}$ & Meain age & Std. Deviation & Std. Error Mean \\
\hline Young & male & 186 & 63.1 & 7.6675 & .5622 \\
& female & 214 & $67.0^{\mathrm{a}}$ & 6.3449 & .4337 \\
\multirow{2}{*}{ Old } & male & 93 & 77.6 & 2.2118 & .2293 \\
& female & 107 & $78.4^{\mathrm{b}}$ & 2.9363 & .2839 \\
\hline
\end{tabular}

a $P<.001, b<<.05$ 
Age Histogram

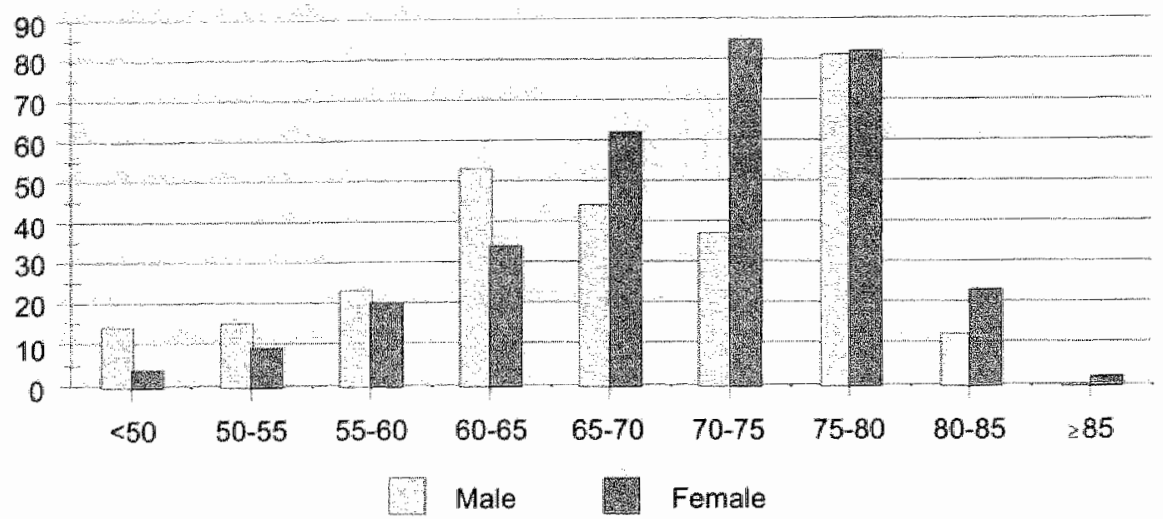

Figure 3.2. Distribution of age.

Table 3.4. Timing of surgery.

\begin{tabular}{|c|c|c|c|c|c|c|c|c|}
\hline \multirow[b]{2}{*}{ Agle group } & \multicolumn{2}{|c|}{$\begin{array}{l}\text { Acute } \\
\text { (within } 2 \text { days) }\end{array}$} & \multicolumn{2}{|c|}{$\begin{array}{l}\text { Urgent } \\
\text { (within 2weeks) }\end{array}$} & \multicolumn{2}{|c|}{$\begin{array}{l}\text { Elective } \\
\text { (after } 2 \text { weeks) }\end{array}$} & \multicolumn{2}{|c|}{ Total } \\
\hline & $\mathrm{Nb}$ & $\%$ & $\mathrm{Nb}$ & $\%$ & $\mathrm{Nb}$ & $\%$ & $\mathrm{Nb}$ & $\%$ \\
\hline Young & 17 & $4.3 \%$ & 174 & $43.5 \%$ & 209 & $52.3 \%$ & 400 & $100.0 \%$ \\
\hline old & 10 & $5.5 \%$ & 106 & $53.0 \%$ & 83 & $41.5 \%$ & 200 & $100.0 \%$ \\
\hline
\end{tabular}

previous cardiac operations, history of non-cardiac atherosclerotic vascular discase (cerebral, peripheral, kidney), history of arrhythmias, hypertension, and chronic obstructive pulmonary disease. If an aortic stenosis was present a history of syncope was also recorded.

The use of different types of medication was recorded, especially usage of nitrates, cliuretics, betablocking agents including sotalol, calcium antagonists, platelet inhibitors, anticoagulants, digoxine, ACE inhibitors, anti-arrhythmic drugs, sedative drugs, alpha blocking drugs and lipid lowering drugs. Data about medication use were also recorded at discharge, and at one year after surgery.

The severity of anginal and dyspnea complaints was graded in functional classes between I-IV, according to the New York Heart Association (NYHA) scale. Data recorded from physical examination included Body Mass index, Body Surface area, systolic blood pressure, carotid pulsations and murmurs, pulmonary rales and stage of congestive failure (Killip class. I-IV), and presence of leg varicosis. 
Data obtained from cardiac catheterisation included: Number of coronaries diseased (1-3), presence and severity of left main coronary disease, subjective description about the severity of calcification of the cononary arteries (graded as normal, moderately calcified, and severely calcified), value for left ventricular end diastolic pressure.

One day prior to surgery an echocardiogram was made, from which data were obtained concerning Left ventricular (LV) ejection fraction, LV end-diastolic diameter, wall thickness and $L V$-mass index, e/a-ratio, presence and severity of mitral incompetence and right ventricular systolic pressure.

From a 12-lead Electrocardiogram data were obtained concerning Rhythm, AV-conduction, bundle branch block, left ventricular hypertroplyy and presence of ischemia or infarction.

A blood sample was obtained to determine the Hemoglobin level, Creatinin, BUN, Sodium, Potassium, ALAT, ASAT, and Glucose level.

A chest $\mathrm{X}$-ray was performed to measure the Heart/Thorax-ratio, and the presence and severity of pulmonary congestion and/or pleural fluid.

Pulmonary function tests measuring the Vital Capacity and Forced expiratory one second Volume were additionally performed in 91 (45.5\%) Old patients and 203 (50.1\%) Young patients.

\section{QUALITY OF LIFE}

Many tests have been developed in the past to measure various aspects of quality of life. ${ }^{1-13}$ These aspects can be related to mood (anxiety, depression, sleep disorders), physical condition (immobility, exercise tolerance) and social functioning (restrictions in daily activities, work, contacts with people). Each of these tests measures a selected number of these aspects. Most of these tests are questionnaires that have to be filled out by the patients.

In order to cover both most of these aspects of quality of life, and to have a practical test with a limited number of questions, to be filled out in short time by each patient, we selected the following 2 questionnaires: 1) The Hospital Anxiety and Depression scale (H.A.D., after Zigmund and Snaith, 1983) ${ }^{14: 15}$ of which an official Dutch translation is available (oppendix 1 ). This questionnaire has 14 multiple choice questions dealing with anxiety and depressive complaints. 2) The Nottingham Health Profile (N.H.P., after Hunt, McKenna, 1981) 16:17, of which a Dutch translation exists since 1993 (appendix 2). This questionnaire has seven main items, consisting of: energy, pain, emotional reactions, sleep, social isolation, physical mobility and social functioning, with a total number of 45 questions, that can all be answered by filling out "yes" or "no".

Both questionnaires were filled out by the patient 1) one day before surgery, 2) two months after surgery, and 3) six months after surgery. The time that is needed to fill out these questionnaires varies between 5 and 15 minutes. 
Several studies have shown that these questionnaires are suitable for serial comparison, and have been useful in showing changes of quality of life after surgery. Validation studies have also been performed of the Dutch version of these questionnaires. $18: 19$

\section{ANESTHESIA AND MYOCARDIAL PERFUSION DURING SURGERY}

Standard anesthetic (lorazepam, fentanyl citrate, sufentanil citrate, alfentamil hydrochloride, midazolam hydrochloride, pancuronium bromide) and monitoring techniques (electrocardiogram, central venous/pulmonary and arterial pressure monitoring, urinary output, rectal and skin temperature monitoring) were used in both groups. Cefuroxim was used for antibiotic treatment, and the first dose was administered before sternotomy.

Before connecting the extra corporeal circuit for Cardio Pulmonary Bypass (CPB), heparin $(300 \mathrm{IU} / \mathrm{kg}$, Heparin Leo, Leo Pharmaceutical Products BV, Weesp. The Netherlands) was administered in order to achieve an activated coagulation time (ACT) $>480 \mathrm{~s}$ (Hemochron 400, International Technidyne Corp., New Jersey, USA).

The main components in the extra corporeal circuit consisted of a hollow fiber membrane oxygenator (Univox; Bentley/Baxter Inc., Irvine, CA, USA.), a venous reservoir (BMR-1900; Bentley/Baxter Inc.), a cardiotomy reservoir: William Harvey H4700; C.R.Bard Inc, Tewsbury, MA, USA.) and an arterial line filter: Sartorius; Sartorius AG, Göttingen, Germany.). The standard priming of the extra corporeal circuit was $1300 \mathrm{ml} \mathrm{Haemaccel} \mathrm{3.5 \%} \mathrm{(Behringwerke} \mathrm{AG,}$ Marburg, Germany), $200 \mathrm{ml}$ Mannitol 20\%, $100 \mathrm{ml}$ Human-Albumin 20\%, 50 $\mathrm{ml} \mathrm{NaHCO} 38.4 \%, 20 \mathrm{ml} \mathrm{KCl} 7.45 \%$ (B.Braun Medica BV, Uden, The Netherlands) and $6500 \mathrm{IU}$ Heparin Leo. After institution of cardiopulmonary bypass at a flow rate of $2.4 \mathrm{~L} / \mathrm{min} / \mathrm{m}^{2}$, and after reaching a blood temperature below $28^{\circ} \mathrm{C}$, the heart was topically cooled till fibrillation using cold saline $0.9 \%$ at $4^{\circ} \mathrm{C}$. The aorta was then cross clamped and a single dose of approximately $800 \mathrm{ml}$ of St. Thomas I cardioplegic solution at $4{ }^{\circ} \mathrm{C}$ was infused into the aortic root in a period of 4 minutes ( $3-5$ minutes) to provide myocardial preservation. Topic cooling was maintained during the infusion of the cardioplegic solution. Target flow rates of $2.4 \mathrm{~L} / \mathrm{min} / \mathrm{m}^{2}$ were maintained at normothermia and correspondingly lower rates of $2.0 \mathrm{~L} / \mathrm{min} / \mathrm{m}^{2}\left(1.8-2.2 \mathrm{~L} / \mathrm{min} / \mathrm{m}^{2}\right)$ were maintained at moderate hypothermia of $28^{\circ} \mathrm{C}$, depending on the venous oxygen saturation and the arterial pressurc. Pulsatile perfusion was used throughout the period of aorta cross clamping. In case the LAD was revascularized using the left internal mammary artery papaverine was locally applied to prevent spasm to the mammary artery following dissection. After completion of all the distal anastomoses, the aortic cross clamp was removed and the proximal anastomosis was performed with a partial occlusion clamp after spontaneous or electrical 
defibrillation, while rewarming of the patient to $37^{\circ} \mathrm{C}$ was continued. All pump blood was returned to the patient through the aortic cannula or intravenously via infusion bags without hemoconcentration.

Data was collected about bypass time, aortic cross clamping time, arterial blood pressure, central venous pressure, diastolic pulmonary artery pressure, circulatory arrest time, lowest temperature, lowest hematocrit during perfusion, cardioplegia, venous $\mathrm{O}^{2}$ saturation, and the need for inotropic support, temporary pacing or intra-aortic balloon pumping (IABP) at the end of the procedure.

\section{OPERATIVE PROCEDURE}

The operative technique consisted of a standard median sternotomy, routine aortic and right atrial canulation.

Data were collected on type of surgery, first or reoperation, use of intra-aortic balloon pump (IABP), quantity and type of grafts (arterial, venous), quality of vein grafts and native vessels, types of valve surgery (mechanical, biological, or reconstruction).

\section{POSTOPERATIVE COURSE}

Information was collected about mortality and morbidity. The last one included the need for inotropic support, use of IABP, duration of ventilatory support, occurrence of post operative arrhythmias especially atrial fibrillation or flutter. Data on complications were divided in cardiac complications (infarction, heart failure, conduction disturbances) and non-cardiac complications (e.g. bleeding, infections, renal failure, mental confusion, need for rethoracotony).

\section{FOLLOW-UP}

During follow up an echocardiogram, a chest X-ray, and physical examination were repeated after six months by the principal investigator. Data about functional class (NYHA classification) were collected six months and one year after operation. The Quality of life questionnaires were send by mail 2 and 6 month following surgery.

\section{ADMISSION DURATION AND COSTS}

Data are collected about the Pre-operative admission (Number of days in the coronary care unit and/or normal Department), the Post-operative admission (Number of days in the intensive care unit and the normal Department) and Readmissions (Number and days of readmissions because of cardiac causes, until one year after surgery). 


\section{STATISTICAL METHODS}

The Unpaired $t$-test was tused to demonstrate differences in Interval variables between both age groups. For Nominal variables Chi-square analysis of contingency was used. In case of Ordinal variables the Mann-Whitney rank-sum test was performed. To demonstrate changes in each treatment group after surgery the Paired $t$-test was used for Interval variables, McNemar's test for Nominal variables and Wilcoxon signed rank test for Ordinal variables. To analyze predictors of mortality Stepwise Logistic regression was performed. Survival analysis was done using the Kaplan-Meier method, with differences calculated using the Log rank test. Analyses were conducted using SPSS for Windows, release 8.0 (@PSS Inc, Chicago, Illinois.) 


\section{APPENDIX 1}

Duth wersion of the questions used in the Hospital Anxiety and Depression scale 14.15
Nam:
Datum:

Dokters zijn er zich van bewust dat de emoties wan angst en depressie bij de meeste ziektes een belangrijke tol spelen. Uw dokter zal beter in stat zijn om u te helpen indien hij weet hoe u zich voalt.

Deze wagenlijst dient als hulpniddel voor uw dokter on te weten te komen hoe u zicll woelt. Lees iedere wrags en onderstreep her antwoord dat het beste weergeeft hoe u zich igedurende de latste week gevoeld heeft.

Denk niet te lang na ower uw antwoord. Uw eerste reactie op elke vaag is warschijnlijk meen betrouwbarar dan een lang doordacht antwoord.

Ih mol me gespanen

Meestal

$\square$ Vak

- Ar en toe, soms

$\square$ Helemaal niet

Ik gemiet wiy steds wan de dingen waar ik wheger pan genow

Zeker zo veel

1 Niet zo veel als vroeger

1] Weinig

Haast helemaal niet

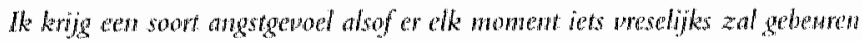

1 Heel zeker en wrij erg

Ja, maar niet zo erg

$\square$ Een beetje, maar ik maak me er geen zorgen over

D. Helemal niet

It kan haden an de dingen wan do wrolijke kann zien

0 Net zoveel als vroeger

- Niet zo goed als vroeger

$\square$ Beslist nier zoveel als wroeger

D. Helemaal niet

Ik matk whe valk angerwst

D Heel erg wak

V Vak

- Af en toe maar niet te valk

[] Alleen soms

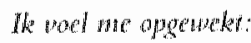

Helemaal nier

J Niat rak

D Soms

$\square$ Meestal 


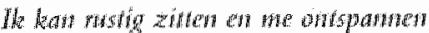

a Zeker

D) Medertil

a viet valak

D) Melleman niet

In wel alsof alles moeizanter gant

Bijna altijd

Q Heel walk

D Soms

9 Helemal niet

Th krijg eet soort bevatud, gespatwen gevol in mijn matg

D Hetemal niet

D Soms

$\square$ Vrij wakk

Deel valak

Ik foll geen interesse meer in nwing witerlijk:

Z Zeker

- Niet meer zoveel als ik zou moeten

Warschijnlijk niet zoveel

- Evenweel interesse als vroeger

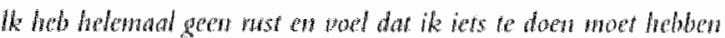

G Heel erg

D Tamelijk veel

a Niet erg veel

D Helemall niet

If wetheres we wan fevoren al op dingen

Net zoveel als vroeger

9 Een beetje minder dan vroeger

$D$ Zeker uninder dan wroeger

I Biyna nooit

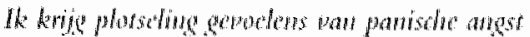

Uiler vaak

d Tamelijk vank

D Nier ergy viak

Jelemal niet

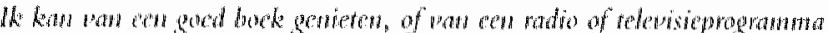

a Viak

$\square$ Soms

$\square$ Nise vak

D Hecl zelden 


\section{APPENDIX 2}

Dutch version of the Notringham Health Profle questionmaire 16,17

Ja/Nee

1. Ik ben aldoor moe

2. Ilk heb "s nachts pinn

3. Ik kan nergens meer tegen

4. Itk theb ondraglijke pijn

5. Ik gebruik pillen om in slap te komen

6. In ben vergeten hoe het is om ergens van te genieten

7. Ik voel me gespannen

8. Ik heb pijn wameer ik van houding verander

9. Ik voell me eenzaam

10. Alleen binnenshuis kan ik wat lopen

11. Ik vind het moeilijk on te bukken

12. Alles kost me moeite

13. Ik word's morgens erg wroeg wakker

14. Lopen is onmogelijk voor mij

15. Ik heb er moeite mee met mensen in contact te komen

16. De dagen slepen zich voort

17. Het kost me moeite om de trap op en af te gaan

18. Ik vind het moeilijk on iets te pakken

19. Lk heb pijn bij het lopen

20. Ik verlies tegenwoordig snel mijn geduld

21. Ik heb het gevoel dat niemand om me geeft

22. Ik lig het grootste deel van de nache wrakker

23. Ik heb het gewoel dat ik het miet meer in de hand heb

24. Stan doet mij pijn

25. Ik vind het moeilijk om mezelf ann te kleden

26. De fut is er snel uit

27. Ik vind het moeilijk on lang te staan (biju an het atmecht of bij de bushalte)

28. Ik heb altidd pijn

29. Ik kan moeiligk in slaap komen

30. Ik voel dat $i k$ anderen tot last ben

31. I $\mathrm{k}$ lig 's nachts te tobben

32. Het leven heeft weinig walde woor mij

33. Ik slaap 's nachts slectit

34. Ik kan slecht met mensen opshieten

35. Ik heb hulp nodig om buiten te kunnen lopen (bijv. een wandelstok of iemand die me ondersteund

36. Ik heb pijn wameer ik de trap op en af loop

37. Bij het opstaan ben ik al somber

38. Tk heb pijn bij het zitten 
Wake aktrititeiten in wo dagdijks leven worden beinvoed door ww gezondheid? Als een bepalde aktiviteit niet op u wat roepassing is, kruis dan het hokje onder nee an.

Ja/ Nate

1. Vuroorzatkt Uw huidige gezondheid moeilikheden met UW WERK (d.w.z. betaald werkj?

2. Veroorzakt Uw huidige gezondheid modilikheden met UW HUISHOUDELIJKE WERKZAAMHEDEN (bijy, schoonmaken en koken,klusjes in en om het huis, enz.)?

3. Vercorzakt Uw hudige gezondheid moeilijh heden met UW SOCIALE LEVEN (bijv uitgan, vrienden bezoeken, bezoek aan de sportclub)?

4. Veroonzakt Uw huidige gezondheid moeilijkeden met UW HUISELIJK LEVEN (d.w.z. relatie met andere mensen in huis)?

5. Veroorzakt ww hudige gezondheid moeilijkheden not UW SEXLEVEN?

6. Veroorzakat Uw huidige gezondheid moeiligkheden met UW INTERESSES EN HOBBIES (bijw. sporten, knutselen en handenarbeid, cursussen wolgen, doe-het-zelf akriviteinen, enz.)?

7. Veroorzakt Uw huidige gezondheid moeilijkheden met UW VAKANTIES bijw zomerof wintervakantie, weekends weg, enz.)?

\section{REFERENCES}

1. Mayou R, Bryant B: Quality of life in cardiovascular disease. Br. Heart J. 1993;69: $460-466$

2. Kumar P, Zehr KJ, Chang A, Cameron DE, Baumgartner WA: Quality of life in octogenarians after open theart surgery. Chesi 1995;108:919-926

3. Spiegellatter DJ, Gore SM, Fitzpatrick R, Fletcher AE, Jones DR, Cox DR: Quality of life mensures in health care. HI: Resource allocation. BMJ. 1992;305:1205-1209

4. Fitzpatrick R, Fletcher A, Gore S. Jones D, Spiegelhalter D, Cox D: Quality of life measures in heaith care. 1: Applications and isstes in assessment. BMI. 1992;305: $1074 \ldots 1077$

5. Flether A, Gore $S_{n}$ Jones D, Fitzpatrick R, Spiegelhalter D, Cox D: Quality of dife measures in thealth care. II: Design, analysis, and interpretation. BMJ. 1992,305: $1145-1148$

6. Loma Cay $\mathbb{E}$, Rourke $\mathrm{O}^{\prime} \mathrm{A}$ : The emotional stace of patients after coronary bypass surgery, in Walter PJ (ed): Qualigy of Life affer Open Heat Surgery. Kluwer Academic Publishers, 1992, pp 177-183

7. Hlatky MA, Boineau RE, Higginbotham MB, Lee KL, Mark DB, Califf RM, Cobb FR, Pryor DB: A briefself-administered questionnaire to determine functional capacity (the Duke Acrivicy Starus Index). Am. J Cardiol 1989:64:651-654

8. Duits AA, Boeke S, Tamm MA, Passchier J, Erdman RA: Prediction of quality of life after cononary artery bypass graft surgery: a review and evaluation of multiple, recent studies. Psylwow. Mad. 1997.May.-Jun. 59:257-268 
9. Chocron S, Rude N, Dussaucy A, Leplege A, Clement F, Alwan K, VielJF, EtiewentJP: Quality of life after open-heart surgery in patients over 75 years old. Age. Agethe $1996 ; 25: 8-11$

10. Caine N, Harrison SC, Sharples LD, Wallwork J: Prospective study of quality of life before and after coronary artery bypass grafring. BMI. 1991:302:511-516

11. Cay EL, O'Rourke $A$ : The emorional state of patients after coronary bypass surgery , in Walter PJ (ed): Quality of life after apen hear sungery, the Netherlands, Kluwer Academic Publishers, 1992, pp 177-183

12. Visser MC, Koudstaal PJ, Erdman RA, Deckers JW, Passchier ], van Gijn J, Grobbee $\mathrm{DE}$ : Measuring quality of life in patients with myocardial infarction or stroke: a fensibility study of four questionatires in The Netherlands. J. Epidemiol. Communty. Hown $1995 ; 49.513-517$

13. Wenger $N K$, Mattson ME, Furberg $\mathrm{CD}$, Elinson J: Assessment of quality of life in clinical trials of cardiovascular therapies. Am.J. Camdiol. 1984;54:908-913

14. Snaith P: Measuring anxiety and depression. Pratitioner. 1993;237:554-559

15. Zigmund AS, Snaith RP: The hospital anxiety and depression scale. Acta psydriatr. seand. $1983 ; 67: 361-370$

16. Hunt SM, Mc Kenna SP, Mc Ewen J, Williams J, Papp E: The Nottingham health profile: Subjective health status and medical consultations. Soc Sa.Med. 1981;15A: 221-229

17. Jenkinson C, Fitzpatrick R, Argyle M: The Nottingham halth profile: an analysis ofits sensitivity in differentiating illness groups. Soc.Sci.Med. 1988;27:1411-1414

18. Spimhoven P, Omel I, Sloekers PP, Kempen GI, Speckens AE, Van Hemert AM: A validation study of the Hospital Anxiety and Depression Scale (H.ADS) in different groups of Dutch subjects. Psydtol. Med. 1997;27:363m370

19. Erdman RA, Passchier J, Kooijman M, Stronks DL: The Dutch version of the Nottingham Health Profile: investigations of psychometric aspects. Psychol.Rep. $1993 ; 72: 1027-1035$ 



\section{Coronary artery bypass surgery}

\section{INTRODUCTION}

The benefits of coronary revascularisation for ischemic heart disease are well documented for the patient with coronary artery disease in general. With the improvement of surgical and anesthesiological techniques and myocardial protection, the outcome has improved over the last two decades with perioperative mortality now being below $5 \%$. Because of these results, an increasing number of elderly patients are being operated upon. However, the effect of age on morbidity, operative mortality and quality of life after coronary bypass surgery remains controversial, and probably institution related ${ }^{1-3}$. Knowledge of results is of importance because the elderly population is continuously increasing in Western societies, leading to an increasing demand for coronary revascularisation procedures.

To assess the differences in outcome of coronary bypass surgery we performed a prospective study, with two gender matched groups of 131 patients 75 years or older, and 262 patients younger than 75 years. None of these patients had concomitant valve surgery. The follow-up duration after surgery was minimally twelve months. All patients were operated over a 3-year period in the University Hospital of Maastricht, the Netherlands. Results were analyzed to determine risk factors for morbidity and mortality.

\section{METHODS}

From September 23, 1993 through November 21, 1996, 131 consecurive patients aged 75 years or older were included in our prospective study (Old group). During the same time 262 gender matched patients (50.4\% male in both groups) younger than 75 years were included for comparison (Young group). In the Old group the mean age was 77.8 years with a range from 75 to 86 years. In the Young group the mean age was 65.0 years, with a range from 35 to 74 years. Women were relatively older then men, which was most pronounced in the Young group (mean age women 66.7 years, men 63.2 years, $P<0.001$ ). In the Old group the mean age of women was 78.1 years, men 77.4 years, $P=$ n.s. (Figure 4.1) 


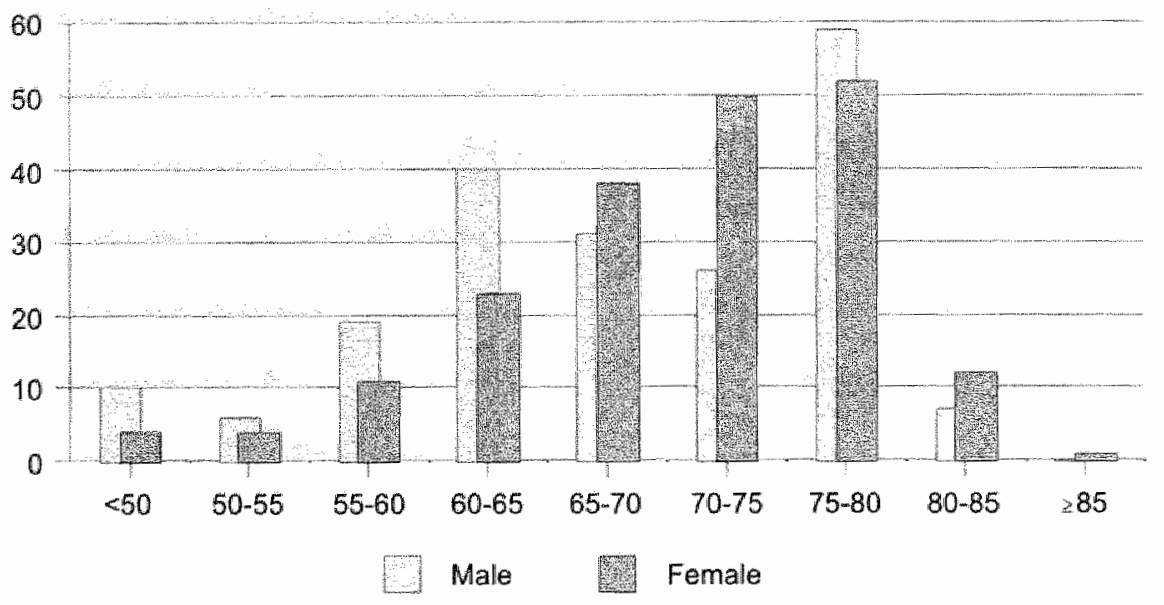

Figure 4.1. Age and gender distribution of the patients studied.

Table 4.1. Timing of operation in different age groups.

\begin{tabular}{|c|c|c|c|c|c|}
\hline \multirow[b]{2}{*}{ Age group } & \multicolumn{5}{|c|}{ Time of operation $(P<.05)$} \\
\hline & acute & $\begin{array}{l}\leq 2 \text { days } \\
\text { after } \\
\text { acceptation }\end{array}$ & $\begin{array}{l}\leq 2 \text { weeks } \\
\text { during } \\
\text { admission }\end{array}$ & elective & Total \\
\hline Young & & $\begin{array}{l}16 \\
6.1 \%\end{array}$ & $\begin{array}{l}127 \\
48.5 \%\end{array}$ & $\begin{array}{l}119 \\
45.4 \%\end{array}$ & $\begin{array}{l}262 \\
100.0 \%\end{array}$ \\
\hline Old & 1 & $8.1 \%$ & $\begin{array}{l}81 \\
61.8 \%\end{array}$ & $\begin{array}{l}41 \\
31.3 \%\end{array}$ & $\begin{array}{l}131 \\
100.0 \%\end{array}$ \\
\hline
\end{tabular}

All patients were screened one day prior to surgery by the same investigator. Details about the variables that were recorded are described in chapter 3 . In the Old group more patients were operated while being admitted to hospital for unstable angina $(61.2 \%$ vs $48.5 \%, P<0.05$, table 4.1$)$. Except for differences in body mass index and area, no differences in physical examination were found.

\section{ANESTHESIA AND MYOCARDIAL PERFUSION DURING SURGERY}

A detailed description for the standard procedures of the anesthesia and myocardial perfusion is given in chapter 3 . In table 4.3 the differences are described between both groups. Old patients had a significant lower hematocrit during surgery, and required more often temporary pacing at the end of surgery. No difterences were found in cross clamp time, perfusion time, and hemodynamic measurements. 
Table 4.2. Baseline characteristics of the patients studied

\begin{tabular}{|c|c|c|}
\hline & Young $(n=262)$ & old $(n=131)$ \\
\hline Age (yrs) & $65.0 \pm 7.2$ & $77.8 \pm 2.3$ \\
\hline Male & $132(50.4 \%)$ & $66(50.4 \%)$ \\
\hline \multicolumn{3}{|l|}{ Clinical History \& Physical examination } \\
\hline Mean NYHA class (angina) & $3.45 \pm .7$ & $3.67 \pm .5 * *$ \\
\hline Angina in rest, $N Y H A=4(n)$ & $146(56 \%)$ & $90(69 \%)^{*}$ \\
\hline NYHA class 3-4 for dyspnea (n) & $127(48.4 \%)$ & $66(50.4 \%)$ \\
\hline Previous Myocardial Infarction ( $n$ ) & $135(51.5 \%)$ & $77(58.8 \%)$ \\
\hline Recent Myocardial Infarction ( $<2$ months) & $43(16.4 \%)$ & $24(18.3 \%)$ \\
\hline History of Congestive Heart Failure & $27(10.3 \%)$ & $13(9.9 \%)$ \\
\hline Diabetes Mellitus (type 1 or 2 ) & $52(19.9 \%)$ & $26(19.9 \%)$ \\
\hline Claudication ( $<500 \mathrm{~m}$ walking distance) & $25(9.5 \%)$ & $10(7.6 \%)$ \\
\hline Systemic Hypertension (treated with drugs) & $88(34 \%)$ & $41(31 \%)$ \\
\hline Cerebrovascular Disease (TIA/CVA) & $20(7.6 \%)$ & $14(10.6 \%)$ \\
\hline History of renal faiture $($ Creat. $>140 \mu \mathrm{Mol} / \mathrm{L})$ & $23(8.8 \%)$ & $14(10.7 \%)$ \\
\hline Hypercholesterolemia $(\geq 6.5 \mathrm{mMol} / \mathrm{l})$ & $99(37.9 \%)$ & $32(24.7 \%)^{* *}$ \\
\hline Smoking & $63(24 \%)$ & $18(13.8 \%)^{\star \star}$ \\
\hline Body mass index $\left(\mathrm{g} / \mathrm{m}^{2}\right)$ & $27.4 \pm 4.2$ & $25.7 \pm 3.4^{* * *}$ \\
\hline Body surface area $\left(\mathrm{m}^{2}\right)$ & $1.86 \pm .18$ & $1.79 \pm .16^{\star \star \star}$ \\
\hline Systolic blood pressure & $136 \pm 22.6$ & $138 \pm 21.4$ \\
\hline Killip class $2(n)$ & $10(3.8 \%)$ & $7(5.3 \%)$ \\
\hline Re-operation & $40(15.2 \%)$ & $15(11.5 \%)$ \\
\hline Anti-anginal triple medication & $134(51.1 \%)$ & $71(54.2 \%)$ \\
\hline Intra-aortic Balloon pump pre-op & $21(8.0 \%)$ & $8(6.1 \%)$ \\
\hline Preoperative stay on CCU (days) & $1.07(0-10)$ & $1.73(0-13)$ \\
\hline \multicolumn{3}{|l|}{ Cardiac measurements. } \\
\hline LV Ejection Fraction pre-op (\%) & $54.9 \pm 10.6$ & $53.0 \pm 9.9$ \\
\hline LV Ejection Fraction $<40 \%$ ( $n)$ & $24(9.2 \%)$ & $12(9.4 \%)$ \\
\hline LV End-diastolic Diameter pre-op (mm) & $49.2 \pm 5.4$ & $48.3 \pm 5.6$ \\
\hline Posterior wall enddiast wall thickness (mm) & $9.5 \pm 1.1$ & $9.6 \pm 1.0$ \\
\hline LV-mass index pre-op $\left(\mathrm{g} / \mathrm{m}^{2}\right)$ & $112.3 \pm 24.9$ & $114.6 \pm 20.9$ \\
\hline e/a-ratio pre-op & $.92 \pm .34$ & $.81 \pm .35^{* *}$ \\
\hline Mitrall Insufficiency grade 3 (m) & $12(4.6 \%)$ & $9(7.1 \%)$ \\
\hline 5yst RV-press. pre-op $(\mathrm{mmHg})$ & $24.8 \pm 5.8$ & $26.2 \pm 5.8^{*}$ \\
\hline Number of diseased coronaries (1-3) & $2.62 \pm .57$ & $2.78 \pm .5^{* *}$ \\
\hline 3 Vessel disease $(n)$ & $173(66.3 \%)$ & $107(81.7 \%)^{* *}$ \\
\hline Left Main stenosis $>70 \%$ (n) & $20(7.7 \%)$ & $18(13.7 \%)^{*}$ \\
\hline Calcified coronary arteries ( $n$ ) & $65(24.9 \%)$ & $40(30.5 \%)$ \\
\hline LVEDP pre-cine $(\mathrm{m} / \mathrm{m} H \mathrm{~g})$ & $12.7 \pm 7.4$ & $15.7 \pm 7.3^{*}$ \\
\hline
\end{tabular}


Table 4.2. Continued.

\begin{tabular}{|c|c|c|}
\hline & Young $(n=262)$ & Old $(n=131)$ \\
\hline Chest X-ray (Redistribution/congestion) & $9(3.5 \%)$ & $8(6.1 \%)$ \\
\hline Chest $X$-ray (Heart/Thorax ratio) & $51.3 \pm 4.9$ & $51.8 \pm 5.2$ \\
\hline \multicolumn{3}{|l|}{ Laboratory data } \\
\hline Sodium (mMol/l) & $139.7 \pm 2.4$ & $139.9 \pm 2.7$ \\
\hline Potassium (mol/l) & $4.42 \pm .41$ & $4.38 \pm .42$ \\
\hline Creatinin pre-op ( $(\mu$ Molll) & $98.7 \pm 48$ & $102.3 \pm 40$ \\
\hline Creatinin $>200 \mu \mathrm{mol} / \mathrm{L}(\mathrm{n})$ & $6 .(2.3 \%)$ & $3(2.3 \%)$ \\
\hline BUN pre-op (mMol/l) & $6.8 \pm 3.0$ & $7.7 \pm 3.1^{* *}$ \\
\hline Hemoglobin pre-op $(\mathrm{m}$ Mol/l) & $8.6 \pm .9$ & $8.1 \pm .8^{* *}$ \\
\hline \multicolumn{3}{|l|}{ Pulmonary function } \\
\hline Vital capacity (l) & $3.57 \pm .98$ & $2.90 \pm .89^{* * *}$ \\
\hline Vital capacity \% / norm & $101.1 \pm 15.6$ & $99.5 \pm 19.7$ \\
\hline FEV1 (1) & $2.6 \pm .79$ & $1.96 \pm .56^{* * *}$ \\
\hline FEV1 \% / Vital capacity & $73.3 \pm 10.2$ & $69.9 \pm 13.1$ \\
\hline
\end{tabular}

* $P<0.05, * * P<0.01, * * * 0<0.001$

\section{SURGICAL PROCEDURE}

The operative technique consisted of a standard median stemotomy, routine aortic and right atrial canulation. In $77 \%$ of all cases one venous graft was used for making the anastomosis (table 4.4). In the Young group in 13.3\% no venous grafts were used (4.7\% in Old group) because of complete arterial revascularisation $(P=0,006)$. The use of two or three different venous grafts was more frequent in the Old group. Also the number of anastomoses was higher in the Old group with a mean total number of $3.95 \pm 1.2$ compared to $3.6 \pm 1.3$ in the Young group ( $P=0.01$ ). In 97\% of all cases in both groups with venous grafts the Saphena Magna vein was used, and in the remaining 3\% the Saphena Parva vein. The quality of the vein grafts was subjectively judged by the surgeon and divided in thee groups (good, moderate, poor). Although there was a tendency for more moderate and poor quality grafts in the Old group (22.4\% vs $18.6 \%$, this difference was statistically not significant (table 4.5). The quality of the native coronary vessels was also judged subjectively, showing again no statistical difference between both groups (table 4.6). Moderate and Poor quality coronaries were present in $47.9 \%$ of the Young group and $52.3 \%$ of the Old group.

The Left intemal mammary artery was used in 233 (89\%) Young patients and 100 (76\%) Old patients ( $P=0.001)$. The Right intemal mammary artery only was used in $16(6.1 \%)$ Young patients and $3(2.3 \%)$ Old patients $(P=$ n.s.). The Gastro-epiploic artery was exclusively used in Young patients in $12(4.6 \%)$ cases $(P=0.013)$. No prosthetic vein grafts were used in this study. 
Table 4.3. Perioperative data of the patients studied

\begin{tabular}{|c|c|c|}
\hline & Young $(n=262)$ & $\operatorname{ald}(n=131)$ \\
\hline Lowest Temperature $\left({ }^{\circ} \mathrm{C}\right)$ & $23.9 \pm 4.6$ & $23.4 \pm 4.5$ \\
\hline Cardioplegic solution (m) & $789 \pm 358$ & $828 \pm 299$ \\
\hline Bypass time (minutes) & $86 \pm 36$ & $93 \pm 34$ \\
\hline Aortic Crossclanp time (minutes) & $53.5 \pm 23.7$ & $56.1 \pm 21.1$ \\
\hline Total duration of surgery (minutes) & $188 \pm 59$ & $189 \pm 58$ \\
\hline Mean arterial bloodpressure $(\mathrm{mmHg})$ & $73.5 \pm 6.6$ & $72.8 \pm 5.1$ \\
\hline Lowest bloodpressure during surgery $(\mathrm{mmH}$ ) & $45.6 \pm 10.0$ & $44.0 \pm 9.3$ \\
\hline Lowest hematocritt during surgery (\%) & $22.1 \pm 3.4$ & $20.9 \pm 2.9^{* *}$ \\
\hline Venous $0^{2}$ saturation at end of perfusion (\%) & $76.6 \pm 7.8$ & $78.6 \pm 7.8^{*}$ \\
\hline Central venous pressure at end of surgery $(\mathrm{mmHg})$ & $9.0 \pm 3.3$ & $8.7 \pm 3.5$ \\
\hline Diastolic AP-pressure at end of surgeny $(\mathrm{mmHg})$ & $15.2 \pm 4.3$ & $15.2 \pm 4.5$ \\
\hline Inotropic support needed at end of surgery (n) & $60(23.0 \%)$ & $39(29.8 \%)$ \\
\hline Pacing required at end of surgery $(n)$ & $74(28 \%)$ & $60(46 \%)^{* *}$ \\
\hline IABP required at end of surgery $(n)$ & $24(9.2 \%)$ & $10(7.6 \%)$ \\
\hline Surgery without extracorporal circulation (m) & $2(0.76 \%)$ & $1(0.76 \%)$ \\
\hline
\end{tabular}

$* P<0,05, * * P<0,01$

Table 4.4. Number of venous grafts used.

\begin{tabular}{llllll}
\hline Age group & 0 & 1 & 2 & 3 & Total \\
\hline Young & 36 & 201 & 24 & $\mathbb{1}$ & 262 \\
& $13.7 \%$ & $76.7 \%$ & $9.2 \%$ & $.4 \%$ & $100.0 \%$ \\
Old & 6 & 102 & 20 & 3 & 131 \\
& $4.6 \%$ & $77.9 \%$ & $15.3 \%$ & $2.3 \%$ & $100.0 \%$ \\
\hline
\end{tabular}

Table 4.5. Quality of venous grafts used.

\begin{tabular}{lllll}
\hline Age group & good & moderate & poor & Total \\
\hline Young & 184 & 37 & 5 & 226 \\
& $81.4 \%$ & $16.4 \%$ & $2.2 \%$ & $100.0 \%$ \\
\multirow{2}{*}{ lld } & 97 & 24 & 4 & 125 \\
& $77.6 \%$ & $19.2 \%$ & $3.2 \%$ & $100.0 \%$ \\
\hline
\end{tabular}

Table 4.6. Quality of mative coronary arteries.

\begin{tabular}{lllll}
\hline Age group & good & moderate & poor & Total \\
\hline Young & 136 & 99 & 26 & 261 \\
& $52.1 \%$ & $37.9 \%$ & $10.0 \%$ & $100.0 \%$ \\
\multirow{2}{*}{ old } & 62 & 49 & 19 & 130 \\
& $47.7 \%$ & $37.7 \%$ & $14.6 \%$ & $100.0 \%$ \\
\hline
\end{tabular}




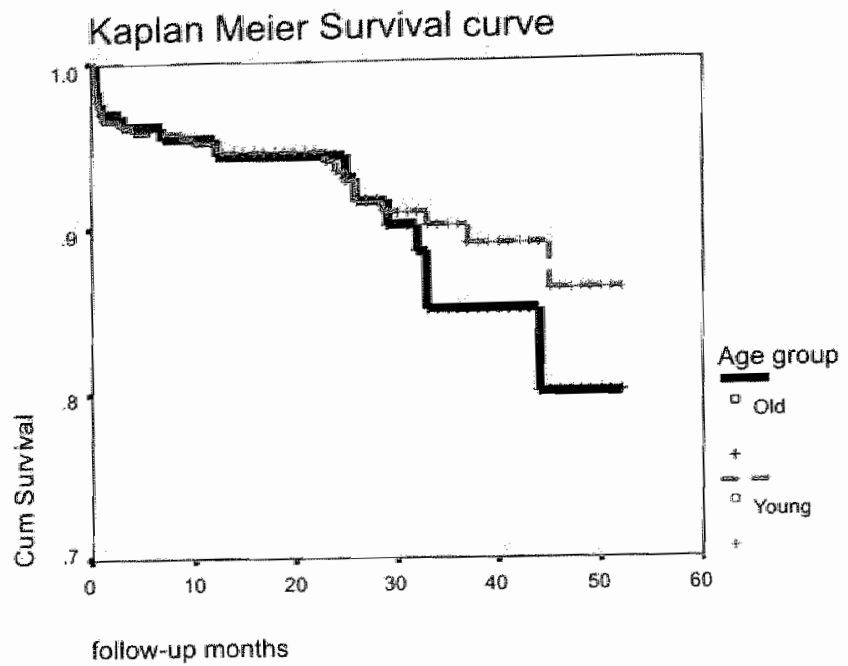

Figure 4.2. Surviwal after bypass surgery in bath age groups.

\section{RESULTS}

The overall operative mortality (defined as mortality within 30 days following surgery or during the same hospital admission) was $3.1 \%$. There were 8 (3.1\%) death in the Young group and $4(3.1 \%)$ in the Old group. The late mortality (defined as mortality after discharge from hospitall) was $5.9 \%$ being $15 \mathrm{in}$ the Young group and $7.9 \%$ being 10 in the Old group ( $P=$ n.s.). The mean follow up duration of the hospital survivors was $28 \pm 12.9$ months. The calculated actuarial survival rate with the life table method, including hospital mortality, for 1 and 4 years is $95 \% / 86 \%$ in the Young and $95 \% / 81 \%$ in the Old group. Causes of death in the Young group were myocardial infarction, sudden death, heart failure, bleeding, septic shock, pulmonary embolism, malignancy and cerebrovascular accident, in the Old group myocardial infarction, sudden death. respiratory failure, septic shock and cerebrovascular accident. Sudden death was the most common cause of cardiac mortality after discharge, both in the Old and Young group.

Survival analysis showed no difference in survival between both groups within three years. After three years a somewhat higher mortality was seen in the Old age group, which was statistically not significant. This can be due to the lower normal life expectancy of elderly people.

To analyze predictors for one year mortality 15 pre-operative variables, that could be possible predictors, as suggested by other studies ${ }^{4-6}$, were entered into a 
Table 4.7. Causes of early and late mortality.

\begin{tabular}{|c|c|c|c|c|c|c|c|}
\hline \multirow[b]{2}{*}{ Cause of death } & & \multicolumn{5}{|c|}{ Jime of death: } & \multirow[b]{2}{*}{ Total } \\
\hline & & $\begin{array}{l}\text { during } \\
\text { surgery }\end{array}$ & $\begin{array}{l}\text { within } \\
1 \text { week }\end{array}$ & $\begin{array}{l}\text { whthin } \\
2 \text { weeks }\end{array}$ & $\begin{array}{l}\text { within } \\
1 \text { month }\end{array}$ & $\begin{array}{l}\text { late } \\
\text { mortality }\end{array}$ & \\
\hline \multicolumn{2}{|c|}{ Myocardial Infarction Young } & & 1 & & & & 1 \\
\hline & Otd & & & 1 & & & 1 \\
\hline \multirow[t]{2}{*}{ Sudden death } & Young & & & & & 6 & 6 \\
\hline & Old & & & & & 4 & 4 \\
\hline \multirow[t]{2}{*}{ Heart failure } & Young & & 1 & $\mathbb{1}$ & & 3 & 5 \\
\hline & old & & & & & 1 & 1 \\
\hline Bleeding & $\begin{array}{l}\text { Young } \\
\text { old }\end{array}$ & 1 & & & & & 1 \\
\hline \multirow[t]{2}{*}{ Respiratory } & Young & & & & & & \\
\hline & old & & & & 2 & 1 & 3 \\
\hline \multirow[t]{2}{*}{ Septic Shock } & Young & & & & 3 & & 3 \\
\hline & Old & & & & 1 & & 1 \\
\hline \multirow[t]{2}{*}{ Pulm. embolism } & Young & & & & & 1 & 1 \\
\hline & old & & & & & & \\
\hline \multirow[t]{2}{*}{ Malignancy } & Young & & & & & 4 & 4 \\
\hline & old & & & & & 2 & 2 \\
\hline Cerebrovascular & Young & & & & 1 & 1 & 2 \\
\hline Accident & old & & & & & 2 & 2 \\
\hline
\end{tabular}

stepwise logistic regression model. Of these variables 4 remained in the final model, being of predictive value. The age of the patient was of no predictive value for outcome. Cardiac predictors of mortality (table 4.8) were a history of severe heart-failure requiring preoperative hospital admission, and persistent ischemia (ST-depression or elevation) on a pre-operative ECG. Non-cardiac preclictors were the presence of a carotid murmur, a pre-operative Creatinin value of more than $200 \mu \mathrm{Mol} / \mathrm{l}$, and severe COPD with a forced expiratory one-second volume of less than one liter. Factors that did not influence operative and 1 year mortality in the logistic regression model include: moderate COPD, diabetes, smoking, re-operation, emergency surgery, obesity, gender, LIMA use, intra-aortic balloonpump use, peripheral vascular disease and hypertension.

The only age specific predictor for mortality in elderly patients we found was a history of a myocardial infarction (table 4.9).

\section{MORBIDITY}

The mean admission duration on the intensive care unit was $2.95 \pm 7.4$ days in the Old group and $2.32 \pm 4.2$ days in the Young group $(P=12 . s$.$) . The to-$ tal postoperative admission duration however was three days (median) longer in the Old group, being $15.1 \pm 10$ (medlian 12) days versus $11.8 \pm 9$ (median 9) days $(P=0.001)$. Except for a higher incidence in the Old group of atrial fibrilla- 
Table 4.8. Results of logistic regression in all age groups for predicting one year martality.

\begin{tabular}{|c|c|c|c|c|c|c|}
\hline Wariable & $\begin{array}{l}\text { Parameter } \\
\text { estumate }(B)\end{array}$ & $\begin{array}{l}\text { Standard } \\
\text { error }\end{array}$ & Wald $x^{2}$ & Pvalue & R & Odds ratio \\
\hline Severe COPD $($ FEV $<1)$ & 3.3812 & 1.7269 & 3.8336 & .0502 & .1411 & 29.4048 \\
\hline Creatimin $>200$ Mol/1 & 2.3739 & 1.1842 & 4.0188 & .0450 & .1480 & 10.7391 \\
\hline Ischemia on ECG & 2.3126 & 1.1430 & 4.0933 & .0431 & .1507 & 10.1007 \\
\hline Carotid murmur & 1.8780 & 1.0086 & 3.4671 & .0626 & .1262 & 6.5403 \\
\hline History pumpfatilure & 1.5840 & .9846 & 2.5883 & .1077 & .0799 & 4.8745 \\
\hline
\end{tabular}

Table 4.9. Univariate Pre-operative Predictors of 1-year mortality.

\begin{tabular}{lll} 
& Young $(\mathrm{n}=262)$ & old $(\mathrm{n}=131)$ \\
\hline Pre-operative Creatinin >140uMol/l & $4 / 22(18.2 \%)^{*}$ & $2 / 13(15.4 \%)$ \\
Previous Myocardial infarction & $9 / 135(6.7 \%)$ & $7 / 77(9.1 \%)^{* *}$ \\
Diabetes Mellitus & $4 / 52(7.7 \%)$ & $2 / 26(7.7 \%)$ \\
LVEF $<53 \%$ & $8 / 103(7.8 \%)$ & $6 / 71(8.5 \%)$ \\
Re-operation & $3 / 40(7.5 \%)$ & $1 / 15(6.7 \%)$ \\
Pre-operative Heart-failure & $6 / 27(22.2 \%)^{* * *}$ & $1 / 13(7.7 \%)$ \\
Congestion on chest X-ray & $2 / 9(22.2 \%)^{*}$ & $1 / 8(12.5 \%)$ \\
One-sided caratid murmur & $4 / 13(30.8 \%)^{* * *}$ & $1 / 7(14.3 \%)$ \\
Ischemia on pre-operative ECG & $11 / 95(11.6 \%)^{* *}$ & $5 / 73(6.8 \%)$ \\
Emergency surgery & $1 / 16(6.3 \%)$ & $0 / 9(0 \%)$ \\
\hline
\end{tabular}

* $P<0.05$, ** $P<0.01$, *** $P<0.001$

tion and congestive heartailure (especially moderate heartailure, Killip 2), and a higher need for temporary pacing, there were no differences in the occurrence of postoperative complications (table 4.10).

\section{FOLLOW-UP AFTER DISCHARGE FROM HOSPITAL}

The follow-up duration of the surviving patients in this study varied from 1-4 years. After six and twelve months patients were asked about anginal and dyspnea complaints (graded in NYHA class I-IV) and quality of life using questionnaires. These questionnaires were filled out by $236 / 253(93.2 \%)$ of the Young patients and $117 / 128(91.4 \%)$ of the Old surviving patients.

155 out of $214(72.4 \%)$ Young patients and 88 out of $114(77.2 \%)$ Old patients being in preoperative NYHA class III or IV for anginal complaints improved to NYHA class 1 after six months ( $P<0.001$, figure 3 ). However in the time period between six and twelve months following surgery there was a slight increase of complaints in both groups $(P<0.01)$. The same pattern was seen for clyspnea complaints, where the mean NYHA class decreased from 2.32 to 1.94 in the 
Table 4.10. Incidence of postoperative complications.

\begin{tabular}{lcc}
\hline Postoperative complications & Young $(n=262)$ & Old $(n=131)$ \\
\hline Inotropic support $>1$ day & $22(8.4 \%)$ & $15(11.4 \%)$ \\
Intra aortic ballon pump $>1$ day & $15(5.7 \%)$ & $4(3.1 \%)$ \\
Mechanical ventilation $>1$ day & $42(16.0 \%)$ & $28(21.4 \%)$ \\
Atrial fibrillation & $92(35.1 \%)$ & $83(6.3 \%)$ \\
Ventricular tachycardia/fibrillation & $6(2.3 \%)$ & $5(3.8 \%)$ \\
Myocardial infarction & $33(12.6 \%)$ & $22(16.8 \%)$ \\
Congestive heart failure (Killip 2-4) & $81(30.9 \%)$ & $56(42.7 \%)^{*}$ \\
Ay-conduction disturbances requiring pacing & $20(7.6 \%)$ & $19(14.5 \%)^{*}$ \\
Excessive blood loss (transfusion/rethoracotomy) & $40(15.2 \%)$ & $20(15.3 \%)$ \\
Respiratory infection & $16(6.1 \%)$ & $13(9.9 \%)$ \\
Mediastinitis & $6(2.3 \%)$ & $6(4.6 \%)$ \\
Acute Tubular Necrosis & $13(5.0 \%)$ & $7(5.3 \%)$ \\
Cerebrovascular accidents & $6(2.3 \%)$ & $5(3.8 \%)$ \\
Mental confusion & $29(11.1 \%)$ & $22(16.9 \%)$ \\
Rethoracotomy performed & $24(9.2 \%)$ & $11(8.4 \%)$ \\
\hline
\end{tabular}

$* P \leq 0.05, * * P<0.001$

Young group and from 2.45 to 1.97 in the Old group $(P=0.001)$, again followed by a small increase after 12 months $(P<0,01)$.

The mean number of anti-anginal drugs used (max. 3 , being betablocker, nitrate and calcium-antagonist), decreased from 2.40 pre-operatively to 0.38 one year after surgery in the Young group and from 2.48 to 0.36 in the Old group $(P<0.001) .185(70.9 \%)$ Young and 93 (71.0\%) Old patients did not use any anti-anginal medication six months following surgery. Platelet inhibiting drugs were used in $77.2 \%$ of the Young and $75 \%$ of the Old patients $(P=n . s$.$) . The use of$ diuretics was more frequent in the Old group $(44.2 \%$ versus $27.8 \%, p=0.002)$. and the use of lipid lowering drugs was more frequent in the Young group (29\% versus $15 \%, P=0.003)$.

44 (17.3\%) Young and 11. (8.7\%) Old patients had a readmission to hospital within one year for cardiac reasons or surgery related reasons $(P<0,05)$. The nean duration of these readmissions was longer in the Young group being $18.6 \pm 18.7$ days, versus $9.6 \pm 7.0$ days $(P=0.014)$.

6-7 Months following surgery a routine echocardiogram was performed in 229 (91\%) Young and 111 (88\%) Old surviving patients. In contrast to the preoperatively performed echocardiogram a significantly higher Left ventricular mass index was found in the Old group $\left(116.2 \pm 19.6 \mathrm{~g} / \mathrm{m}^{2}\right.$ versus $110.3 \pm 25.1 \mathrm{~g} / \mathrm{m}^{2}$, $P<0.016)$, due to an increase of $L V$-mass in the Old group and a decrease in the Young group. The ascending aorta diameter increased in both groups signif- 


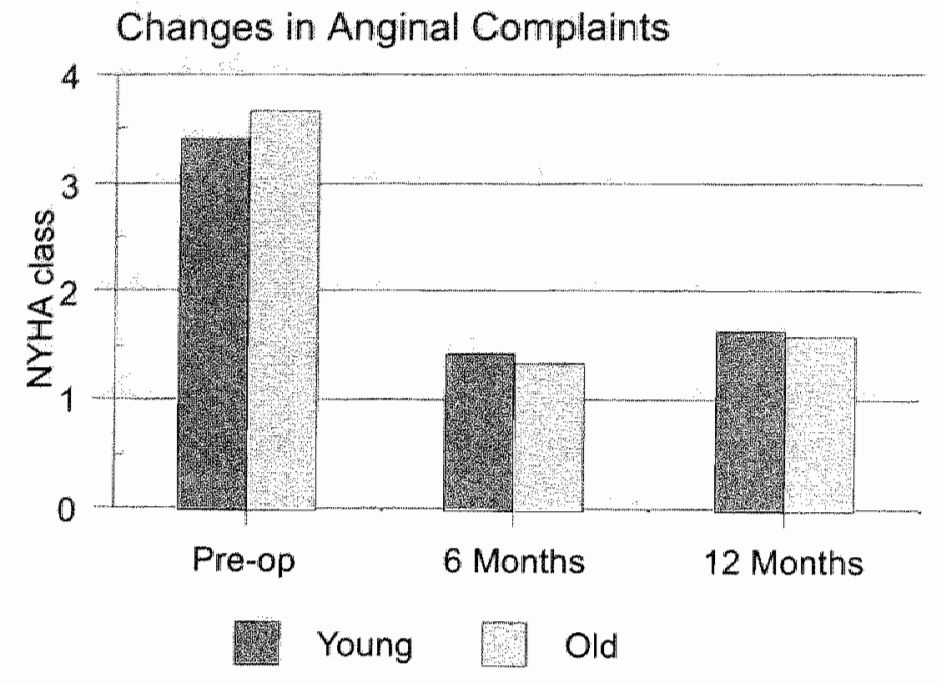

Figure 4.3. Incidence of anginal complaints before and 6 and 12 months after coronary bypass surgery.

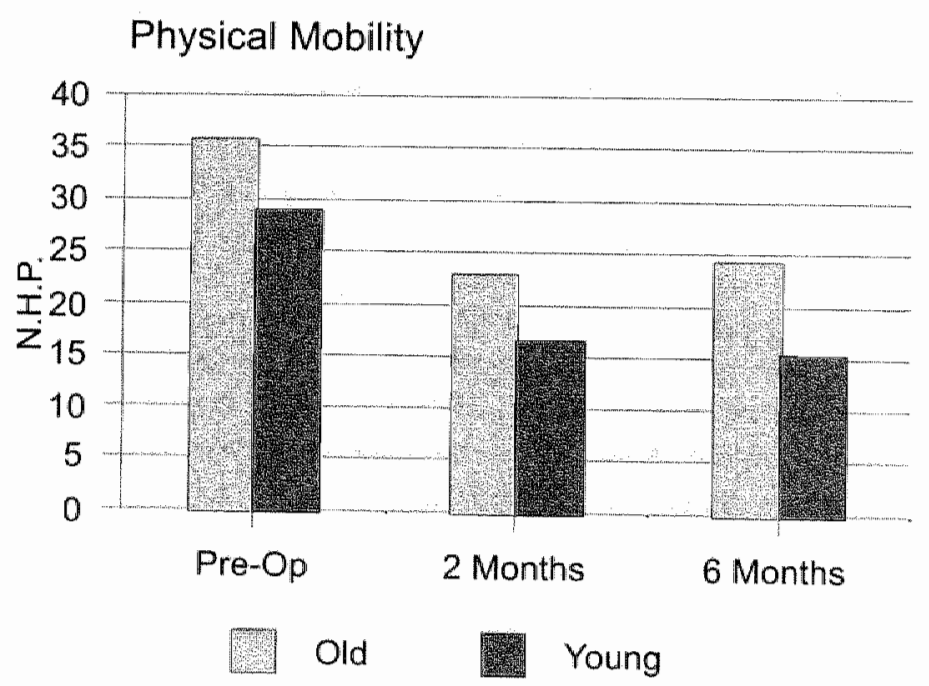

Figure 4.4. Changes in physical mobility before and after surgery. 
cantly, from 35.1 to $35.5 \pm 3.3 \mathrm{~mm}$ in the $Y$ oung $(P<0.05)$, and from 34.9 to 35.9 $\pm 3.2 \mathrm{~mm}$ in the Old group $(P<0.001)$. Also a significant increase in e/a-ratio (0.93 to 1.01, $P<0.001$, Young group, and 0.81 to $0.93, P<0.001$, Old group), and left atrial size $(45.6$ to $46.5 \mathrm{~mm}, P<0.001)$ was found. A Chest $\mathrm{X}$-raly that was repeated the same day as the echocardiogram, showed a significant decrease of the heart/thorax ratio compared to the pre-operative Chest X-ray (51.3 to $48.9 \pm 5 \%$ in the Young, and 51.9 to $50.8 \pm 5 \%$ in the Old, $P<0.001$ ).

\section{QUALITY OF LIFE}

Both questionnaires were returned by $236(94 \%)$ Young and $116(92 \%)$ Old surviving patients. Items of the Nottingham Health Profile (NHP) were expressed in a $0-100$ scale, in which 100 means that all items were present for that variable. The maximal range in the Hospital Anxiety and Depression scale was 0-21. Old patients had a significantly worse score for Physical Mobility (NHP) pre-operatively $(35.8 \pm 27$, Old, versus $29.0 \pm 27$, Young, $P=0.01$ ). Despite the improvement in mobility following surgery, the difference between the groups was still present after two $(P=0.019)$ and six $(P=0.001)$ months. All other variables showed no differences between the two groups (table 11). Two months following surgery a significant improvement was measured in all items from both scales. The amount of improvement was similar in both groups. No further improvement in quality of life was seen in the time period between two and six months following surgery.

Table 4.11. Results of Hospital Anxiety and Depressions scale and Nottingham Health Profile.

\begin{tabular}{|c|c|c|c|c|c|c|}
\hline & \multicolumn{2}{|l|}{ Pre-op } & \multicolumn{2}{|c|}{2 months } & \multicolumn{2}{|c|}{6 months } \\
\hline & Young & old & Young & old & Young & Old \\
\hline Anxiety & 8.6 & 8.3 & 5.2 & 5.1 & 6 & 5.3 \\
\hline Depression & 6.5 & 6.8 & 5 & 5.5 & 5.3 & 4.9 \\
\hline Energy & 46.3 & 44 & 24.4 & 29 & 24 & 26 \\
\hline Pain & 25.9 & 26 & 15.1 & 14 & 13 & 17 \\
\hline Emotional Reactions & 30.7 & 26.5 & 14.2 & 15.6 & 16.8 & 16.3 \\
\hline Sleep & 43.2 & 44 & 34.9 & 31.6 & 32.6 & 32.7 \\
\hline Social Isolation & 9.5 & 10.5 & 5.9 & 7.7 & 8.8 & 6.4 \\
\hline Physical Mobility & 29 & 35.8 & 16.7 & 23.1 & 15.5 & 24.4 \\
\hline
\end{tabular}




\section{DrSCUSSION}

During the last 3 decades a dramatic decrease in operative mortality for CABG has been reported in patients older than 70 years, going down from $28 \%$ in 1970 to $5 \%$ in $1990^{7}$. In our study we found in our institution an even lower mortality of $3.1 \%$ in patients 75 years and older. Despite the fact that Old patients had significantly more often angina in rest, used more anti-anginal medication before surgery, had more severe coronary artery disease and left main disease, and were pre-operatively hemodynamically more compromised with higher right ventricular pressures and more often mitral incompetence, the mortality rate was not different compared to the younger group $(3.0 \%)$. This is in contrast to several other studies that reported a higher mortality rate in the elderly $2 ; 8-1$. The strongest pre-operative cardiac predictors for mortality were persistent ischemia on the last pre-operative ECG, and a history of severe cardiac dyspnea. A strong non-cardiac predictor was severe COPD with a forced expiratory one second volume of less than one liter. Also a serum creatinin of more than $200 \mu \mathrm{Mol} / 1^{4: 12}$ and the presence of an one sided carotid murmur had an important predictive value. Several authors suggest that patients with a carotid murmur should have preoperative carotid screening and carotid endarterectomy in selected cases ${ }^{13-17}$ We could not confirm that emergency surgery was a predictor for mortality ${ }^{5}$, but only $6.4 \%$ of our population had emergency surgery. ${ }^{12}$ Equivalent to the study of Jacob et al ${ }^{18}$ we also did not see that a moderate diminished lungfunction was a predictor for mortality. However in severe COPD we also found a longer mean admission duration, irrespective of age (25 \pm 26 days versus $12.6 \pm 7$ days, $P<0.001)$.

The median postoperative admission duration was four days longer in the Old group. This was mainly due to a $35 \%$ higher incidence of postoperative heart failure, a $78 \%$ higher incidence of postoperative atrial fibrillation and a $93 \%$ higher incidence of temporary AV-conduction disturbances requiring temporary pacing. This longer admission duration is consistent with other studies, that also not surprisingly demonstrated that this was accompanied with higher costs 19 : 20. Despite the fact that the intitial admission duration was longer, the number and duration of readmissions was lower in the Old group in the first year following surgery. The number of patients that were in NYHA class I after 1 year was similar in both groups (68\% Old, $66 \%$ Young).

By using the Dutch version of the Nottingham Health Profile $21 ; 22$ and the Hospital Anxiety and Depression scale $23 ; 24$ repeatedly we could demonstrate a significant improvement of Quality of life in the first two months following surgery, which was equal in both groups. This improvement also remained present after six months. 
In conclusion we can state, that coronary bypass surgery in patients older than 75 years has the same prognosis, and gives the same improvement of quality of life as in younger patients. Only the direct postoperative morbidity was greater in the older age group, leading to a longer admission duration. We can conclude that advanced age on its self should not be a contrandication for coronary bypass surgery.

Following discharge sudden death was the most important cause for cardiovascular mortality, both in the Young and Old group. As shown very few patients received $\beta$-blocking and lipid lowering agents following surgery. Since coronary artery disease is a progressive disease those drugs should probably be continued after cononary bypass surgery to slow progression of the disease and to protect the patient against sudden death from a new ischemic episode.

\section{REFERENCES}

1. Cane ME, Chen C, Bailey BM, Fernandez J, Laub GW. Anderson WA, McGrath LB: CABG in octogenarians: exly and late events and actuarial survival in comparison with matched population. Ann. Thorti Surg. 1995;60:1033-1037

2. Khan SS, Kupfer JM, Matloff JM, Tsung Po Tsai, Nessim S: Interaction of age and preoperative risk factors in predicting operative mortality for coronary bypass surgery. Cinalation 1992;86:186-190

3. Utley JR, Leyland SA: Coronary artery bypass grafting in the octogenarian. I. Thorac. Cardiovasc. Swag. 1991;101:866-870

4. Ko W, Krieger KH, Lazenby WD, Shin YT, Goldstein M, Lazzaro R, Isom OW: Isolated coronary artery bypass grafting in one hundred consecutive octogenarian patients: A multivariate analysis J. Thow Cardiowas. Surg. 1991;102:532-538

5. Naunheim KS, Kern My, McBride LR, et al: Coronary antery bypass surgery in patients aged 80 years or older. Am. I.Cardiol. 1987:59:804-807

6. Tsai TP, Nessim S, Kass RM, Chaux A, Gray RJ, Kuan SS, BIanche C, Uttey C, Matloff JM: Morbidity and mortality after cononary artery bypass in octogenarians. Am. Thorar. Sarg. 1991:51:983-986

7. Keon WJ: Operative results and risk factors over the past three decades, in Walter $\mathbb{P I}$ (ed): Coronary bypass sugery in the dderly. Kluwer Academic Publishers, 1995, pp 27-40

8. Canver CC, Nichols RD, Cooler SD, Heisey DN, Muray EL, Kroncke GM: Influence of increasing age on long-term survival after coronary artery bypass grafting. Ann. Thora. Surg. 1996;62:1123-1127

9. Hannan EL, Burke J: Eftect of age on mortality in coronary artery bypass surgery in New York, 1991-1992. Am. Heant J. 1994; 128:1184-1191

10. He GW, AcuffTE, Ryan WH, Bowman RT, Douthit MB, Mack MI: Determinants of operative mortality in elderly patients undergoing coronary artery bypass grafing. 
Empliasis on the infuence of internal mammary artery grafting on mortality and morbidity I. Thorac Cardiondse.Surg. 1994:108:73-81

11. Katz NM, Hantian RL, Hopkins RA, Wallace RB: Cardiac operations in patients aged 70 years and over: mortality, length of stay, and hospital charge. Anw. Thorac.Sug. $1995: 60: 96-100$

12. Whliams DB, Carrillo RG, Trad EA, Wyate CH, Grahowksi R, Whittels SH, Ebra $G$ : Determinants of operative mortality in octogenarians undergoing coronary bypass. 4no Thorac Surg. 1995;60:1038-1043

13. Berens ES, Kouchoukos NT, Murphy SF, Wareing TH: Preoperative carotid artery screning in elderly patients undergoing cardiac surgery f. Vasc Surg. 1992;15.313-323

14. Faggioli GL, Cur GR, Ricotta J]: The rolle of carotid screening before coronary artery bypass. I.VASC.SURG. 1990;12:724-731

15. Johnsson P, Norrving B, Nilsson B, Srahh $\mathbb{E}$ : Risk of cerebral complications during coronary artery bypass graft surgery in patients with previous cearebrovascular symproms or carotid disease. Cardiology in the elderly 1993;1:15-21

16. Wareing TH, Daily BB, Murphy SF: Spectrum and management of coexistent carotid arterial disease in elderly cardiac surgical patients. Cardiology in the dderly $1994 ; 2: 462-467$

17. Wareing TH, Davila Roman VG, Dally BB, Murphy SF, Schechtman KB, Barzilai B, Kouchoukos NT: Strategy for the reduction of stroke incidence in cardiac surgical patients. Am Throrat Surg. 1993;55:1400-1408

18. Jacob B, Amoateng-Adjepong Y, Rasakulastriar S, Manthous CA, Haddad R: Preoperative pulmonary function tests do not predice outcome after coronary artery bypass. Conn.Med. 1997;61:327-332

19. Peigh PS, Swartz MT, Vaca KJ, Lohmann DP, Nanheim KS: Effect of advancing age on cost and outcone of coronary artery bypass grafting. Ann. Thorac Surg. $1994 ; 58: 1362-1366$

20. Peterson ED, Cowper PA, Jollis JG, Bebchuk JD, DeLong ER, Muhlbaier LH, Mark DB, Piyon DB. Outcomes of coronary artery bypass graft surgery in 24,461 patients aged 80 years or older. Cimalation 1995;92;1185-91

21. Hunt SM, Mc Kenna SP, Mc Ewen J, Williams ], Papp E: The Nottingham health profile: Subjective health status and medical consultations. Soc Sa.Med. 1981;15A: $221-229$

22. Erdnaw RA. Passchier J, Kooijman M, Stronks DL: The Dutch version of the Nottinghan Health Profile: investigations of psychometric aspects. Psyhol.Rep. 1993,72:1027-1035

23. Zignund AS, Snairh RP: The hospital anxiety and depression scale. Acta psychiatr.scand. $1983 ; 67: 361-370$

24. Spinhoven P, Omel J, Sloekers PP, Kempen GI, Speckens AE, Van Hemert AM: A validation study of the Hospital Anxiety and Depression Scale (HADS) in different groups of Dutch subjects. Pipdol. Med. 1997;27:363-370 
CHAPTER 5

\section{Valvular surgery}

\section{INTRODUCTION}

The upper age limit for cardiac surgery has constantly been extended since the 1980's, with the most pronounced extension observed in surgery of the aortic valve, especially in calcified aortic stenosis. Only limited data exists on the effect of different types of valve surgery on the final outcome in elderly patients, regarding morbidity, mortality and quality of life.

To assess differences in outcome of valvular surgery we performed a prospective study with 69 patients of 75 years and older in comparison to 138 younger patients. These patients underwent valve surgery with or without concomitant coronary artery bypass surgery.

\section{METHODS AND PATIENTS}

From October 1, 1993 through November 11, 1996, 69 consecutive patients aged 75 years and older were included in our prospective study (Old group). In the same time period 138 gender and procedure matched patients younger than 75 years were included for comparison (Young group). Since there were more women operated in the Old group ( $\mathrm{n}=42,61 \%)$, an equal proportion of women were included in the control group. Male patients were relatively younger than female patients, especially in the Young group (median age $63.5 \pm 8.0$ vs $69.0 \pm 6.3, P<0.001$ [Young], and $77.6 \pm 2.4$ vs $78.1 \pm 3.5$ [Old], P=n.s., figure 5.1).

One day before surgery data from each patient were recorded concerning clinical history (cardiac and non-cardiac), risk factors and physical examination. Additional data were collected from an 12 lead electrocardiogram, a chest X-ray, laboratory findings, cardiac catheterisation, an echocardiogram, and pulnonary function testing.

Quality of life assessment was also done one clay before surgery, and repeated 2 and 6 months later. This was done by using the Dutch version of the hospital anxiety and depression scale (HAD) ${ }^{1-5}$ and the Nottingham Health profile $(\mathrm{NHP})^{6-8}$. 
Age Histogram

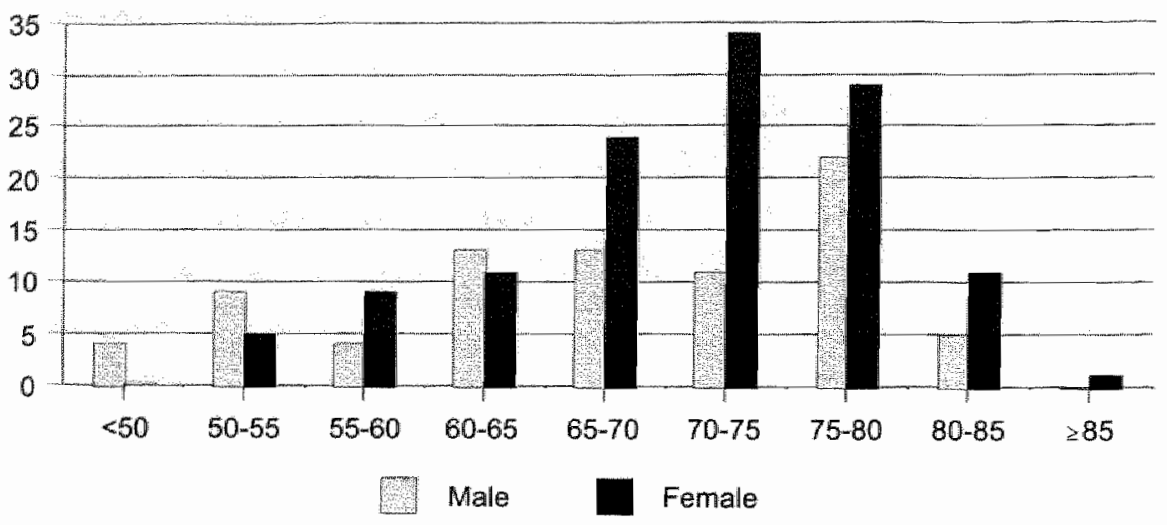

Figure 5.1. Age distribution in valvular surgery.

Table 5.1. Time of operation.

\begin{tabular}{|c|c|c|c|c|}
\hline Age group & $\begin{array}{l}\leq 2 \text { days } \\
\text { after } \\
\text { acceptation }\end{array}$ & $\begin{array}{l}\leq 2 \text { weeks } \\
\text { during } \\
\text { admission }\end{array}$ & elective & Total \\
\hline Young & $\begin{array}{l}1 \\
.7 \%\end{array}$ & $\begin{array}{l}47 \\
34.1 \%\end{array}$ & $\begin{array}{l}90 \\
65.2 \%\end{array}$ & $\begin{array}{l}138 \\
100,0 \%\end{array}$ \\
\hline old & $\begin{array}{l}2 \\
2.9 \% \\
\end{array}$ & $\begin{array}{l}25 \\
36.2 \% \\
\end{array}$ & $\begin{array}{l}42 \\
60.9 \% \\
\end{array}$ & $\begin{array}{l}69 \\
100.0 \%\end{array}$ \\
\hline
\end{tabular}

Most patients in both groups had elective surgery (table 5.1), with no significant differences between both groups.

Old patients had a higher incidence of diabetes mellitus (type 2), a lower incidence of treated systemic hypertension, a lower smoking incidence, a smaller body surface area, and a larger wall thickness on echocardiography (table 5.2). No differences were present in severity of complaints, severity of valvular or coronary disease, and stage of heart failure.

\section{ANESTHESIA AND MYOCARDIAL PERFUSION DURING SURGERY}

Standard anesthetic and monitoring techniques were used in both groups (see chapter 3). Old patients had a significant shorter duration of the surgical procedure. This was accompanied with a tendency to a shorter (but not statistically significant) perfusion and crossclamp time (table 5.3). 
Table 5.2. Baseline characteristics of the patients studied.

\begin{tabular}{|c|c|c|}
\hline & Young $(n=138)$ & Old $(n=b 9)$ \\
\hline Age (yrs) & $64.8 \pm 7.5$ & $78.2 \pm 3.1$ \\
\hline Malle & $54(39 \%)$ & $27(39 \%)$ \\
\hline \multicolumn{3}{|l|}{ Cinical Histony \& Physical examination } \\
\hline Angina Pectoris NYHA $=3$ or $4(n)$ & $48(34.8 \%)$ & $28(40.6 \%)$ \\
\hline Dyspmea in rest, $\mathrm{NYHA}=4(\mathrm{n})$ & $36(26.1 \%)$ & $15(21.7 \%)$ \\
\hline Previous Myocardial Infarction & $24(17.4 \%)$ & $11(15.9 \%)$ \\
\hline History of collapse (in aortic stenosis) & $14(16.7 \%)$ & $14(25.9 \%)$ \\
\hline History of congestive Heart Failure & $74(53.6 \%)$ & $40(57.9 \%)$ \\
\hline Diabetes Mellitus (type 1 or 2 ) & $17(12.3 \%)$ & $11(15.9 \%) * *$ \\
\hline Systemic Hypertension (treated with drugs) & $46(33.3 \%)$ & $14(20.3 \%)^{* * *}$ \\
\hline Cerebrovascular Disease (TIA/CVA) & $14(10.2 \%)$ & $3(4.3 \%)$ \\
\hline History of renal failure $($ Creat $>140 \mu \mathrm{Mol} / \mathrm{L})$ & $15(10.9 \%)$ & $5(7.2 \%)$ \\
\hline Smaking & $43 .(31.1 \%)$ & $11(15.9 \%)^{*}$ \\
\hline Body mass index $\left(\mathrm{g} / \mathrm{m}^{2}\right)$ & $26.3 \pm 4.5$ & $25.7 \pm 3.3$ \\
\hline Body surface area $\left(m^{2}\right)$ & $1.79 \pm .17$ & $1.74 \pm .13^{*}$ \\
\hline Systolic blood pressure & $137 \pm 25$ & $138 \pm 28$ \\
\hline Killip class $2-4(n)$ & $14(10.1 \%)$ & $7(10.1 \%)$ \\
\hline Re-operation & $26(1.8 .8 \%)$ & $7(10.1 \%)$ \\
\hline AV-conduction disturbances & $14(10.3 \%)$ & $9(13 \%)$ \\
\hline Atrial fibrillation & $31(22.5 \%)$ & $20(29 \%)$ \\
\hline \multicolumn{3}{|l|}{ Cardiac measurements } \\
\hline LV Ejection Fraction pre-op (\%) & $55.6 \pm 13.1$ & $55.5 \pm 12.0$ \\
\hline LW Ejection Fraction $<40 \%(n)$ & $22(1.5 .9 \%)$ & $10(14.5 \%)$ \\
\hline LW End-diastalic Diameter pre-op (mm) & $52.1 \pm 7.5$ & $50.2 \pm 6.4$ \\
\hline Posterior wall enddiast wall thickness (mm) & $10.4 \pm 1.4$ & $11.2 \pm 1.5 * * *$ \\
\hline W-mass index pre-op $\left(g / \mathrm{m}^{2}\right)$ & $143.6 \pm 35.1$ & $153.4 \pm 33.9$ \\
\hline Left atrial size $(\mathrm{mm})$ & $51.8 \pm 8.7$ & $53.0 \pm 7.2$ \\
\hline e/a-ratio pre-op & $1.1 \pm .65$ & $1.1 \pm .93$ \\
\hline Mitral Insufficiency grade $3-4(\mathrm{n})$ & $48(34.8 \%)$ & $16(23.2 \%)^{*}$ \\
\hline Syst RV-press. pre-op ( $\mathrm{mmH}$ ) & $36.6 \pm 14.7$ & $37.0 \pm 13.8$ \\
\hline 3 Vessel disiease $(n)$ & $3.4(24.6 \%)$ & $14(20.3 \%)$ \\
\hline Chest $X$-ray (Redistribution/congestion) & $23(16.6 \%)$ & $13(18.8 \%)$ \\
\hline Chest $X$-ray (Heart/Thorax ratio) & $54.0 \pm 5.58$ & $55.7 \pm 6.69$ \\
\hline \multicolumn{3}{|l|}{ Laboratory data } \\
\hline Sodium $(\mathrm{m} M \mathrm{Ml} / \mathrm{l})$ & $139.9 \pm 2.6$ & $139.9 \pm 3.0$ \\
\hline Potassium (mMol/l) & $4.37 \pm .46$ & $4.36 \pm .56$ \\
\hline Creatinin pre-op $(\mu \mathrm{Mol} / \mathrm{l})$ & $92.3 \pm 21.9$ & $97.0 \pm 25.7$ \\
\hline BUN pre-op (mMol/l) & $7.14 \pm 3.0$ & $7.75 \pm 3.7$ \\
\hline
\end{tabular}


Table 5.2. Continued.

\begin{tabular}{|c|c|c|}
\hline & Young $(n=138)$ & Old $(n=69)$ \\
\hline Hemoglobin pre-op (molli) & $8.37 \pm 1.0$ & $8.13 \pm .9$ \\
\hline \multicolumn{3}{|l|}{ Pulmonary function } \\
\hline Vital capacity (1) & $3.06 \pm 1.12$ & $2.65 \pm .73 i$ \\
\hline Vital capacity / nom & $95.2 \pm 19.9$ & $101.6 \pm 19.9$ \\
\hline FEV1 $(0)$ & $2.10 \pm .85$ & $1.95 \pm .60$ \\
\hline FEV of / Vital capacity & $69.5 \pm 14.6$ & $74.1 \pm 10.9$ \\
\hline
\end{tabular}

$* p_{<0} 0.05 * * 0 \times 0.001$

Table 5.3. Perfusion data.

\begin{tabular}{|c|c|c|}
\hline & Young $(n=138)$ & old $(n=69)$ \\
\hline Lowest Temperature $\left({ }^{\circ} \mathrm{C}\right)$ & $22.6 \pm 3.6$ & $22.5 \pm 3.6$ \\
\hline Cardioplegic solution (ml) & $1263 \pm 526$ & $1255 \pm 541$ \\
\hline Bypass time (minutes) & $136 \pm 50$ & $124 \pm 49$ \\
\hline Aortic Crossclamp time (minutes) & $97.7 \pm 37$ & $87.9 \pm 37$ \\
\hline Total duration of surgery (minutes) & $234 \pm 84$ & $197 \pm 66^{* * *}$ \\
\hline Mean arterial bloodpressure $(\mathrm{mmHg})$ & $73.4 \pm 5.3$ & $73.6 \pm 4.5$ \\
\hline Lowest bloodpressure during surgery $(\mathrm{mmHg})$ & $41.8 \pm 9.1$ & $40.8 \pm 9$ \\
\hline Lowest hematocrit during surgery $(\%)$ & $22.1 \pm 3.0$ & $21.7 \pm 2.8$ \\
\hline Venous $0^{2}$ saturation at end of perfusion $(\%)$ & $78.3 \pm 7.3$ & $77.4 \pm 8.4$ \\
\hline Central wenous pressure at end of surgery $(\mathrm{mmHg})$ & $10.1 \pm 3.4$ & $10.5 \pm 4.2$ \\
\hline Diastolic AP-pressure at end of surgery $(\mathrm{mmHg})$ & $17.0 \pm 4.6$ & $17.7 \pm 4.6$ \\
\hline Inotropic support needed at end of surgery ( $n$ ) & $62(45 \%)$ & $25(36.2 \%)$ \\
\hline Pacing required at end of surgery $(n)$ & $79(57 \%)$ & $38(55 \%)$ \\
\hline IABP required at end of surgery (in) & $8(5.8 \%)$ & $1(1.4 \%)$ \\
\hline
\end{tabular}
$* * * 0 \times 0.001$

\section{SURGICAL PROCEDURE}

The operative technique consisted of a standard median sternotomy, routime artic and right atrial canulation. Male patients more often had concomitant coronary bypass surgery (55.6\%) than female patients (42.9\%, table 5.4 ). Aortic valve surgery was performed in 93 Young patients and 56 Old patients. In Old patients more bioprostheses were implanted compared to Young patients (27 $[48 \%]$ versus $10[11 \%], P<0.001]$. Aortic incompetence without the presence of aortic stenosis as a reason for aortic valve surgery was present in only one Old patient and 5 Young patients. Combined aortic incompetence (grade 2-4) and stenosis (moderate or severe) was present in 33 Old and 50 Young patients. Pure artic stenosis without hemodynamic important incompetence (Sgrade 1) was 
Table 5.4. Gender related differences in procedure.

\begin{tabular}{llllll}
\hline & \multicolumn{2}{l}{ Male } & & & Female \\
\cline { 2 - 6 } type of surgery & valwe & valve + CABG & & valwe & valwe + CABG \\
\hline Young & $24(44 \%)$ & $30(56 \%)$ & $48(57 \%)$ & $36(43 \%)$ \\
old & $12(44 \%)$ & $15(56 \%)$ & $24(57 \%)$ & $18(43 \%)$ \\
\hline
\end{tabular}

present in 23 Old and 38 Young patients. A Bentall procedure was done in only 5 Young patients and not done in Old patients. The mean size of the aortic valve that was implanted was $23.3 \pm 2.58$ in the Young group and $22.6 \pm 1.71$ in the Old group ( $P=$ n.s. $)$. A small sized (19) mechanic valve was used in 8 Young and 2 Old patients.

Mitral valve surgery was performed in 59 Young patients and 17 Old patients. A mitral valve reconstruction with a Carpentier ring was performed more often in the Old group ( $35 \%$ versus $20 \%, P<0.05$ ). In only 3 cases a bioprosthesis was used ( 1 Old, 2 Young patients). All other patients received a mechanical prosthesis. Severe mitral incompetence, without the presence of significant mitral stenosis was the major indication for mitral valve surgery (12 Old and 37 Young patients). Moderate or severe mitral stenosis was present in 3 Old and 18 Young patients. Valve abnormalities due to endocarditis or a local tumor were present in one Old and 3 young patients. The mean size of the mitral valve that was implanted was $30.3 \pm 2.43$ in the Young group and $31.1 \pm 2.21$ in the Old group $(P=n$.s. $)$. Calcification of the mitral annulus was present in $20(33.9 \%)$ Young and $9(56.3 \%)$ Old patients undergoing mitral valve replacement $(P<0.05)$.

Combined Aortic and Mitral valve surgery was done in 15 Young and 5 Old patients.

Additional reconstructive surgery for correction of tricuspid incompetence was done in 15 Young and 5 Old patients.

The St Jude, Carbomedics and ATS valve were the mechanical valves that were used. Only bileaflet mechanical valves were implanted. The Carpentier Edwards valve was the most used biological valve (Table 5). No homografts were implanted

\section{RESULTS}

The Operative mortality (defined as mortality within 30 days following surgery or during the same hospital admission) was $5.8 \%(n=4)$ in the Old group and $7.2 \%(\mathrm{n}=10)$ in the Young group $(P=n .5$.). The Late mortality (defined as mortality after discharge from the initial admission from hospital and after 1 month following surgery) was $12.3 \%(\mathrm{n}=8)$ in the Old group and $6.3 \%(\mathrm{n}=8)$ in 
Table 5.5. Type of valve prosthesis used in the patients studied

\begin{tabular}{lllllll}
\hline & \multicolumn{2}{c}{ Young } & & \multicolumn{1}{c}{ old } & \\
\cline { 3 - 6 } Type valwe & & Aorta & Mitral & & Aorta & Mitral \\
Mechanical & St. Jude & $29(35 \%)$ & $14(31 \%)$ & $16(55 \%)$ & $2(20 \%)$ \\
& Carbonedics & $44(54 \%)$ & $18(40 \%)$ & $10(35 \%)$ & $6(60 \%)$ \\
& A.TS & $9(11 \%)$ & $13(29 \%)$ & $3(10 \%)$ & $2(20 \%)$ \\
Biological & Carpentier Edwards & $7(70 \%)$ & $1(50 \%)$ & $25(93 \%)$ & $1(100 \%)$ \\
& Sorin & $3(30 \%)$ & $1(50 \%)$ & $2(7 \%)$ & $0(0 \%)$ \\
\hline
\end{tabular}

the Young group ( $P=$ n.s.). This is calculated with a median follow-up duration of 29 months (range 1.3-51 months). The actuarial Total survival rate (including hospital mortality) after 1 and 4 years, calculated with the Life table method is $94 \% / 83 \%$ in the Old group and $95 \% / 89 \%$ in the Young group. Despite a lower life expectancy in elderly people, no significant statistical differences in mortality could be demonstrated within 4 years following surgery.

The most frequent cause for early mortality in the Old group was Bleeding (table 5.6), and in the Young group Heart failure. The major cause for late mortality was a Cerebrovascular accident in the Old group and Sudden death in the Young group. $50 \%$ of the patients with sudden death had coronary artery disease and a previous myocardial infarction. Four of six Old patients that died because of a cerebrovascular accident were on coumarin treatment at that time.

Survival analysis with the Kaplan Meier method showed no difference in survival between both groups (figure 5.2).

Significant predictors of 1 year mortality in the Old age group were: a preoperative Creatinine value $>140 \mathrm{\mu Mol} / \mathrm{l}$, a systolic $\mathrm{RV}$ pressure preoperative of more than $45 \mathrm{mmH}$, postoperative bleeding requiring a rethoracotomy, and postoperative need for inotropic support longer than 4 days. All other riskfactors that were significant in the Young group appeared not to be significant in the Old group (table 5.7). Concomitant coronary surgery appeared not to be an extra risk factor for mortality in both groups. Also emergency surgery, the presence of severe lungfunction disturbances, a diminished Left ventricular ejection fraction, and carotid murmurs, which were all of predictive value in coronary bypass surgery, appeared not to be predictive in the elderly patient with valvular surgery. This may be the result of the low incidence of some of these variables in our study population. 
Table 5.6. Time of dying and cause of death in both age groups.

\begin{tabular}{|c|c|c|c|c|c|c|}
\hline \multirow[b]{3}{*}{ Cause of death } & & \multicolumn{4}{|c|}{ Time of death } & \multirow[b]{3}{*}{ Total } \\
\hline & & within & within & within & Late & \\
\hline & & 1 week & 2 weeks & 1 month & mortality & \\
\hline Myocardial infarction & $\begin{array}{l}\text { Young } \\
\text { old }\end{array}$ & 1 & & & 1 & 2 \\
\hline Sudden death & $\begin{array}{l}\text { Young } \\
\text { Old }\end{array}$ & & & 1 & 3 & 4 \\
\hline Heart failure & $\begin{array}{l}\text { Young } \\
\text { old }\end{array}$ & $\begin{array}{l}1 \\
1\end{array}$ & 2 & 1 & $\begin{array}{l}1 \\
1\end{array}$ & $\begin{array}{l}6 \\
2\end{array}$ \\
\hline Bleeding & $\begin{array}{l}\text { Young } \\
\text { old }\end{array}$ & 2 & & 2 & 1 & $\begin{array}{l}4 \\
2\end{array}$ \\
\hline Septic shock & $\begin{array}{l}\text { Young } \\
\text { old }\end{array}$ & & & 2 & 2 & $\begin{array}{l}2 \\
2\end{array}$ \\
\hline Cerebrovascular Accident & $\begin{array}{l}\text { Young } \\
\text { old }\end{array}$ & & & 1 & $\begin{array}{l}2 \\
5\end{array}$ & $\begin{array}{l}2 \\
6\end{array}$ \\
\hline
\end{tabular}

Table 5.7. Univariate Predictors of 1-year mortality.

Young $(n=138) \quad$ old $(n=69)$

\section{Pre-operative variables}

Pre-operative Creatinin $>140 \mu \mathrm{Mol} / \mathrm{L}$

FEV $1<1$ liter

$2 / 15(13.3 \%)$

$11 / 36(30.6 \%)^{*}$

Previous Myocardial infarction

Diabetes Mellitus

LVEF $<53 \%$

\section{Re-operation}

RV Syst. pressure $>45 \mathrm{mmHg}$ Pre-operative

Additional coromary surgery

Mitral valve surgery

Emergency surgery

Peri/Postoperative variables

Mechanical ventilation $>24$ hours

Acute tubular necrosis

Postoperative AV-conduction disturbanices

Bleeding requiring rethoracotomy

Sternal dehiscence

Inotropics required at end of perfusion

Inotropic support for $\geq 4$ days

Postoperative infarction

Bypass time $>165$ minutes

Aortic cross clamp time $>110$ minutes.

Lowest mean $A B P$. during perfusion $<40 \mathrm{mmHg}$

Postoperative intensive care stay $>6$ days

Postoperative admission duration $>20$ days
$7 / 24(29 \%)^{* *}$

$2 / 17(11.8 \%)$

$10 / 44(22.7 \%)^{*}$

$5 / 26(19.2 \%)$

$5 / 30(16.7 \%)$

$12 / 66(18.2 \%)$

$11 / 59(18.6 \%)$

$0 / 1(0 \%)$

$12 / 33(36 \%) * * *$

$9 / 18(50 \%)^{* * *}$

$10 / 44(22.7 \%)^{*}$

$6 / 20(30 \%)^{* * *}$

$3 / 6(50 \%)^{\text {* }}$

$15 / 62(24 \%) * *$

$6 / 9(66.7 \%)^{* * *}$

$6 / 16(37.5 \%)^{* *}$

$14 / 27(5.2 \%)^{\text {*** * }}$

$12 / 45(27 \%)^{\text {* * }}$

$15 / 77(19.5 \%)^{\star}$

$7 / 13(5.4 \%)^{* * *}$

$8 / 27(30 \%)^{* * *}$
$4 / 5(80 \%) * *$

$2 / 19(10.5 \%)$

$1 / 11(9.1 \%)$

$2 / 11(18.2 \%)$

$5 / 25(20 \%)$

$1 / 7(14.3 \%)$

$6 / 11(55 \%) *$ *

$6 / 33(18.2 \%)$

$4 / 17(23.5 \%)$

$0 / 2(0 \%)$

$4 / 20(20 \%)$

$2 / 11(18.2 \%)$

$4 / 23(17.4 \%)$

$2 / 5(40 \%)^{*}$

$0 / 0$

$5 / 25(20 \%)$

$1 / 4(25 \%)^{*}$

$1 / 8(12.5 \%)$

$3 / 12(25.0 \%)$

$3 / 14(21.4 \%)$

$5 / 40(12.5 \%)$

$1 / 9(11.1 \%)$

$3 / 16(18.8 \%)$

* P<0.05, * P<0.01, ** P $<0.001$ 


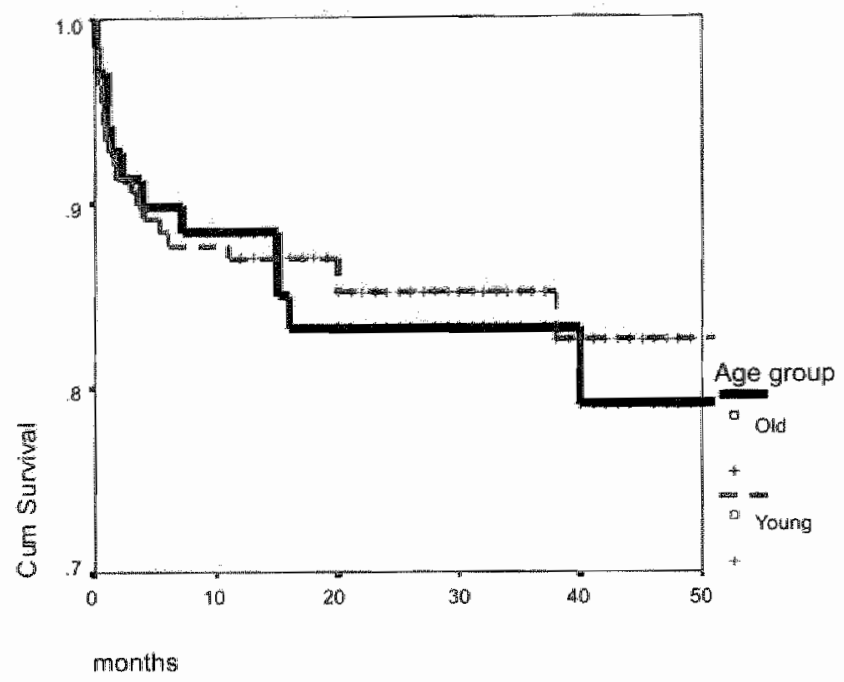

Figure 5.2. Survival analysis using Kaplan-Meier curves.

\section{MORBIDITY}

The median postoperative stay in the intensive care unit was two days in both groups. The median postoperative admission duration was 13 days (mean $17 \pm 16$ days) in the Young group and 14 days (mean $17 \pm 12$ days) in the Old group. Old patients had a higher incidence of postoperative atrial fibrillation and mental confusion (table 5.8).

Mental confusion occurred more frequently in elderly patients. The severity of symptoms varied from slight desorientation in time, place and person to symptoms of psychosis. From the group with mental confusion $8(44.4 \%)$ Young and $11(47.8 \%)$ Old patients had such severe symptoms that treatment with neuroleptic drugs was required. Symptoms of mental confusion were in all cases transient and had disappeared at the time of discharge. The incidence of Mental confusion was clearly lower in patients with mitral valve reconstruction (table 5.9). No statistical differences were seen between mechanical or biological valves, aortic or mitral valve position and additional coronary surgery. Risk factors for mental confusion in elderly people were: prolonged bypass time, aortic crossclamp time, together with increased use of cardioplegic solution and prolonged duration of surgery (table 5.10). These risk factors could not be demonstrated in the Young group. 
Table 5.8. Postoperative Complications.

\begin{tabular}{lcc}
\hline Complications & Young (n=138) & Old (n=69) \\
\hline Inotropic support >1 day & $21(15.3 \%)$ & $10(14.5 \%)$ \\
Intra aortic balloon pump $>1$ day & $7(5.1 \%)$ & $1(1.4 \%)$ \\
Mechanical ventilation $>1$ day & $33(23.9 \%)$ & $20(29.0 \%)$ \\
Atrial fibrillation & $89(64.5 \%)$ & $54(78.3 \%)$ \\
Ventricular tachycardia/fibrillation & $6(4.3 \%)$ & $1(1.4 \%)$ \\
Myocardial infarction & $16(11.6 \%)$ & $8(11.6 \%)$ \\
Congestive heart failure (Killip 2-4) & $61(44.5 \%)$ & $3.4(49.3 \%)$ \\
Cardiogenic shock (Killip 4) & $11(8.0 \%)$ & $2(2.9 \%)$ \\
Pacing required & $44(32.1 \%)$ & $23(33.3 \%)$ \\
Permanent pacemaker implanted & $6(4.4 \%)$ & $7(10.1 \%)$ \\
Excessive bloon loss (transfusion/rethoracotomy) & $47(34.3 \%)$ & $17(24.6 \%)$ \\
Rethoracotomy performed & $22(16.1 \%)$ & $7(10.1 \%)$ \\
Respiratory infection & $25(18.2 \%)$ & $13(18.8 \%)$ \\
Mediastinitis & $5(3.7 \%)$ & $1(1.4 \%)$ \\
Acute Tubular Necrosis & $18(13.2 \%)$ & $11(15.9 \%)$ \\
Cerebrovascular Accidents & $5(3.7 \%)$ & $4(5.8 \%)$ \\
Mental confusion & $18(13.1 \%)$ & $23(33.3 \%) *$ \\
\hline
\end{tabular}

$* P<0.05, * * P<0.01$

Table 5.9. Incidence of Mental Confusion following surgery. ${ }^{\star}$ a bioprosthesis in mitral position was implanted in only 2 Young and 1 old patient.

\begin{tabular}{lcc} 
& Young (n=138) & $0.10(n=69)$ \\
\hline Pure valve surgery & $12(16.7 \%)$ & $11(30.6 \%)$ \\
Combined valve + cononary surgery & $6(9.2 \%)$ & $12(36.4 \%)^{\text {** }}$ \\
Aortic valve (mechanical) & $11(13.3 \%)$ & $10(34.5 \%)^{*}$ \\
Aortic valve (biological) & $2(20.0 \%)$ & $10(37.0 \%)$ \\
Mitral valve (mechanical) & $7(15.9 \%)$ & $5(50 \%)^{*}$ \\
Mitral valve (reconstruction) & $1(8.3 \%)$ & $1(16.7 \%)$ \\
\hline
\end{tabular}

$* P<0.05$ ** $P<0.01$

\section{FOLLOW-UP AFTER DISCHARGE FROM HOSPITAL}

The follow-up duration of the surviving patients in this study was at least 12 months with a maximum of 51 months. The median follow-up duration was 28 months. After six and twelve months patients were asked about anginal and dyspnea complaints (graded in NYHA class I-IV). 67 out of 91 (73.6\%) Young patients and 29 out of $41(70.7 \%)$ Old patients who were in preoperative NYHA class III or IV improved to NYHA class I or II after six months $(P<0.001)$. No changes were seen between 6 and 12 months following surgery 
Table 5.10. Riskfactors for mental confusion in both age groups.

Std.

\begin{tabular}{|c|c|c|c|c|c|c|c|}
\hline \multicolumn{4}{|c|}{ Age group } & \multirow{2}{*}{$\frac{N}{119}$} & \multirow{2}{*}{$\frac{\text { Mean }}{132.92}$} & \multirow{2}{*}{$\frac{\text { Deviation }}{50.08}$} & \multirow{2}{*}{$\frac{\text { Std. Error }}{4.59}$} \\
\hline Young & Bypass time & confusion & ne & & & & \\
\hline & & present. & yes. & 18 & 147.56 & 36.49 & 8.60 \\
\hline & Crossclamp & confusion & no & 119 & 96.62 & 37.14 & 3.40 \\
\hline & time & present & yes & 18 & 105.11 & 37.26 & 8.78 \\
\hline & Duration of & confusion & no & 119 & 230.48 & 85.56 & 7.84 \\
\hline & surgery & present. & yes & 18 & 250.83 & 63.46 & 14.96 \\
\hline & LVEF pre-op & confusion & no & 119 & 55.92 & 12.95 & 1.19 \\
\hline & & present & yes & 18 & 53.00 & 14.32 & 3.38 \\
\hline & Creatinin & confusion & no & 119 & 91.78 & 22.65 & 2.08 \\
\hline & prewop & present & yes & 18 & 96.00 & 16.60 & 3.91 \\
\hline & Syst. & confusion & no & 119 & 35.79 & 13.46 & 1.23 \\
\hline & RV-pressure & present & yes & 18 & 39.83 & 19.80 & 4.67 \\
\hline & Cardioplegic & confusion & no & 119 & 1247.31 & 508.92 & 46.65 \\
\hline & solution (mL) & present & yes: & 18 & 1350.00 & 647.39 & 152.59 \\
\hline \multirow[t]{14}{*}{ Old } & Bypass time & confusion & no & 46 & 114.65 & 37.00 & $5.44^{*}$ \\
\hline & & present & yes & 23 & 142.13 & 62.76 & 13.09 \\
\hline & Crossclamp & confusion & no & 46 & 79.89 & 24.59 & $3.62^{* * \pi}$ \\
\hline & time & present & yes & 23 & 103.83 & 49.93 & 10.41 \\
\hline & Duration of & confusian & no & 46 & 182.11 & 50.07 & $7.38^{* *}$ \\
\hline & surgery & present & yes & 23 & 225.52 & 82.82 & 17.27 \\
\hline & LVEF pre-op & confustion & no & 46 & 55.33 & 11.34 & 1.67 \\
\hline & & present & yes & 23 & 55.78 & 13.45 & 2.80 \\
\hline & Creatinin & confusion & no & 46 & 95.95 & 28.43 & 4.19 \\
\hline & pre-op & present & yes & 23 & 99.00 & 19.39 & 4.04 \\
\hline & Syst. & confusian & no & 46 & 36.35 & 11.42 & 1.68 \\
\hline & RV-pressitue & present & yes & 23 & 38.39 & 13.49 & 2.81 \\
\hline & Cardioplegic & confusion & no & 46 & 1143.48 & 411.58 & $60.68^{*}$ \\
\hline & solution (ml) & present & yes & 23 & 1478.26 & 693.94 & 144.70 \\
\hline
\end{tabular}

$* p_{<00} 05, * p_{<0} 0.01$

(figure 5.3). 46 out of $72(63.9 \%)$ Young patients and 25 out of 39 (64.1\%) Old patients that were on treatment with diuretics before surgery, continued using diuretics One year following surgery.

There were more Young patients (87.4\%) than Old surviving patients (72.1\%) on coumarin treatment one year after surgery $(P<0.05)$.

Readmissions because of cardiac or procedure related problems up to one year after surgery were significantly more common in the Old group $(19 / 64,29.7 \%)$ 


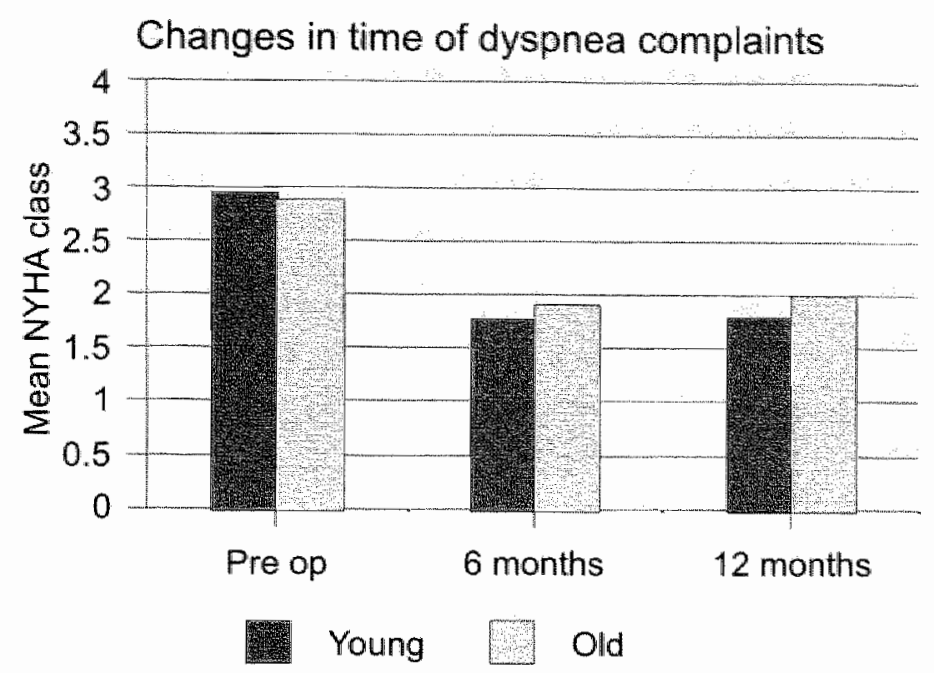

Figure 5.3. Changes in NYHA dyspnea class after surgery.

than in the Young group $(13 / 125,10.4 \%, P<0.01)$. The median admission duration of these readmissions was however not statistically different (Young $=10$ days, Old $=8$ days). The highest incidence of readmissions in the Old group was in patients that receiving a mechanical mitral valve $(5 / 9,55.6 \%)$ or undergoing mitral valve reconstruction $(3 / 5,60 \%)$.

6-7 months following surgery a routine echocardiogram and chest $\mathrm{X}$-ray were performed in 118/120 (98\%) Young and 52/61 (85\%) Old surviving patients. Both groups showed a decrease in left ventricular mass index, systolic right ventricular pressures and the heart/chest ratio on the chest X-ray. The Young group also showed a significant decrease in Left ventricular end diastolic diameter and Left atrial dimension. No changes were seen regarding Left ventricular ejection fraction and e/a-ratio (table 5.11).

The results of valve surgery were echocardiographically graded in three categories: 1) good result of surgery (normal functioning valve), 2) moderate result of surgery (small paravalvular leakage or slightly increased gradient over valve), 3) poor result of surgery (important paravalvular leakage and/or high gradient over valve with hemodynamic impairment).

In case of aortic valve surgery moderate / poor results were found in $5(6.0 \%) / 3$ (3.6\%) Young patients and $5(11.4 \%) / 1(2.3 \%)$ Old patients $(P=n . s$.$) .$

In case of mitral valve surgery moderate / poor results were found in $4(8.2 \%) / 4$ $(8.2 \%)$ Young patients and $3(21.4 \% / 1(7.1 \%)$ Old patients $(P=$ n.s.). Mitral valve reconstruction was disappointing in the Old age group. Only $25 \%$ of the Old group had good results, compared to $54.5 \%$ in the Young group $(P<0.01)$. 
Table 5.11. Echocardiographic and chest $X$-ray changes before and six months following surgery.

\begin{tabular}{|c|c|c|c|c|}
\hline & \multicolumn{2}{|l|}{ Young } & \multicolumn{2}{|l|}{ Old } \\
\hline & Before & After & Before & After \\
\hline LW ejection fraction & $56.1 \pm 12.9$ & $57.3 \pm 11.3$ & $56.4 \pm 11.4$ & $59.0 \pm 10.2$ \\
\hline LV enddiast. diam. & $52.2 \pm 7.2$ & $49.6 \pm 6.4^{* * *}$ & $49.9 \pm 5.9$ & $48.7 \pm 6.2$ \\
\hline Ly mass index & $144.4 \pm 33.9$ & $128.4 \pm 29.9^{* * k}$ & $148.9 \pm 32.6$ & $133.7 \pm 22.2^{*}$ \\
\hline e/a-ratio & $1.08 \pm 0.68$ & $0.94 \pm 0.41$ & $1.0 \pm 0.60$ & $0.89 \pm 0.35$ \\
\hline Syst. RV pressure & $36.0 \pm 14.6$ & $28.3 \pm 9.0^{* \times *}$ & $36.2 \pm 10.3$ & $30.5 \pm 7.7^{* * *}$ \\
\hline Left atrium size & $52.3 \pm 8.9$ & $50.8 \pm 8.1^{* *}$ & $53.4 \pm 7.3$ & $52.7 \pm 7.8$ \\
\hline Heart/Chest ratio & $53.8 \pm 5.5$ & $50.7 \pm 5.8^{*}$ & $54.7 \pm 7.5$ & $52.4 \pm 5.6^{*}$ \\
\hline
\end{tabular}

* $P<0.05$, * $P<0.01$ * * * $P<0.001$

Table 5.12. Nottingham Health Profile data. All data are mean \pm standard deviation.

\begin{tabular}{|c|c|c|c|c|c|c|}
\hline & \multicolumn{3}{|l|}{ roung } & \multicolumn{3}{|l|}{ Old } \\
\hline & Pre-ops & 2 months & 6 months & Pre-op & 2 months & 6 months \\
\hline Energy & $48.4 \pm 40.9$ & $24.6 \pm 32.8^{* * *}$ & $24.1 \pm 36.2^{* * *}$ & $40.2 \pm 36.0$ & $27.2 \pm 35.1$ & $25.2 \pm 34.4^{*}$ \\
\hline Enot. reactions & $26.8 \pm 24.8$ & $16.5 \pm 23.1^{* * * *}$ & $16.8 \pm 23.7^{* * *}$ & $27.2 \pm 25.9$ & $15.9 \pm 19.8^{*}$ & $17.5 \pm 21.2^{1 *}$ \\
\hline $\operatorname{Patin}^{*}$ & $17,8 \pm 22.4$ & $14.1 \pm 22.8$ & $10.9 \pm 18.5$ & $17.2 \pm 20.5$ & $9.8 \pm 17.4^{*}$ & $13.8 \pm 19.8$ \\
\hline Sleep & $46.2 \pm 35.3$ & $35.5 \pm 35.6^{* * *}$ & $31.2 .234 .5^{* * x}$ & $45.3 \pm 34,0$ & $38.4 \pm 36.5$ & $34.7 \pm 38.5^{*}$ \\
\hline Social isolation & $11.5 \pm 21.8$ & $7.7 \pm 17.1$ & $8.8 \pm 19.5$ & $11.3 \pm 18.6$ & $11.0 \pm 19.6$ & $7.3+15.1$ \\
\hline Plays. mobility & $31.8 \pm 27.0$ & $18.0 \pm 25.0^{* * k}$ & $18.8 \pm 25.4^{* * *}$ & $33.0 \pm 26.2$ & $25.5 \pm 23.2^{\text {ix }}$ & $26.3 \pm 22.3$ \\
\hline Social functions & $2.6 \pm 1.9$ & $1.8 \pm 1.9^{*+*}$ & $1.6 \pm 1.9^{* * *}$ & $1.9 \pm 1.9$ & $1.5 \pm 1.5$ & $1.3 \pm 1.7$ \\
\hline
\end{tabular}

* $P<0.05$, ** $P<0.01$, **** $P_{<} 0.001$

\section{QUALITY OF LIFE}

The two questionnaires (Nottingham Health Profile and Hospital Anxiety and Depression scale) that were send two month following surgery were returnod by $113 / 126$ (89.7\%) Young and 55/64 (85.9\%) Old surviving patients. After six month following surgery these questionnaires were returned by $116 / 122(95.1 \%)$ Young and $54.62(87.1 \%$ Old surviving patients.

The Hospital Anxiety and Depression scale (HAD) showed a significant decrease of anxiety symptoms after surgery in both age groups $(P<0.001)$. The Young group also showed a significant reduction of depression symptoms following surgery ( $P<0.01)$, which could not be demonstrated in the Old group (figure 5.4).

The Nottingham Health Profile (NHP) showed a significant improvement two months following surgery in the Old group in Emotional reactions, Pain and Physical mobility. After six months also a significant improvement of Energy and sleep disturbances was found. However at that time a significant increase of pain symptoms was observed. which was not present in the Young group (table 5.12). The amount of improvement in Plysical mobility, Energy and sleep distur- 


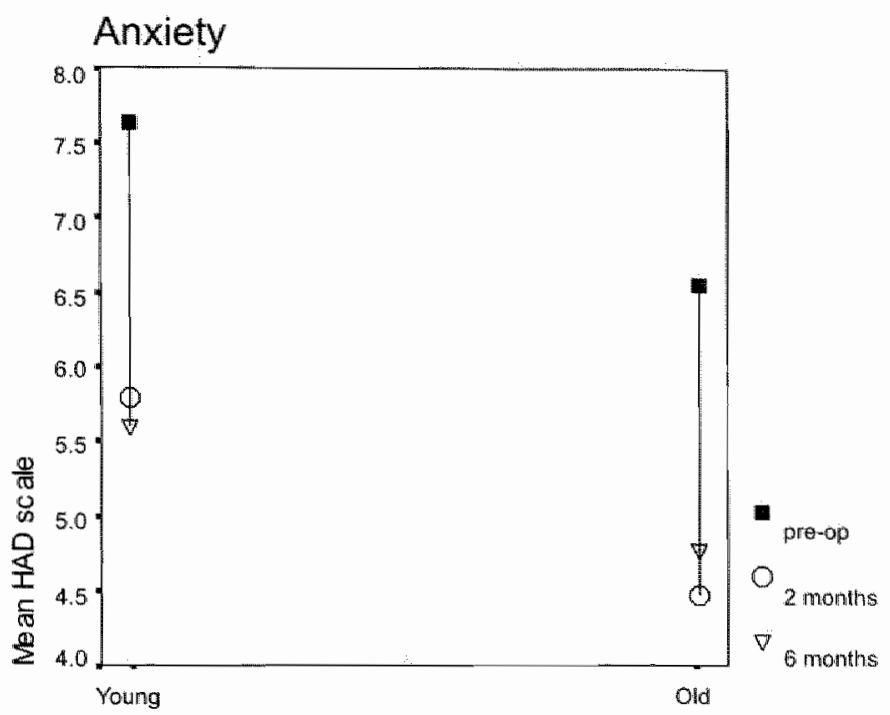

\section{Depression}

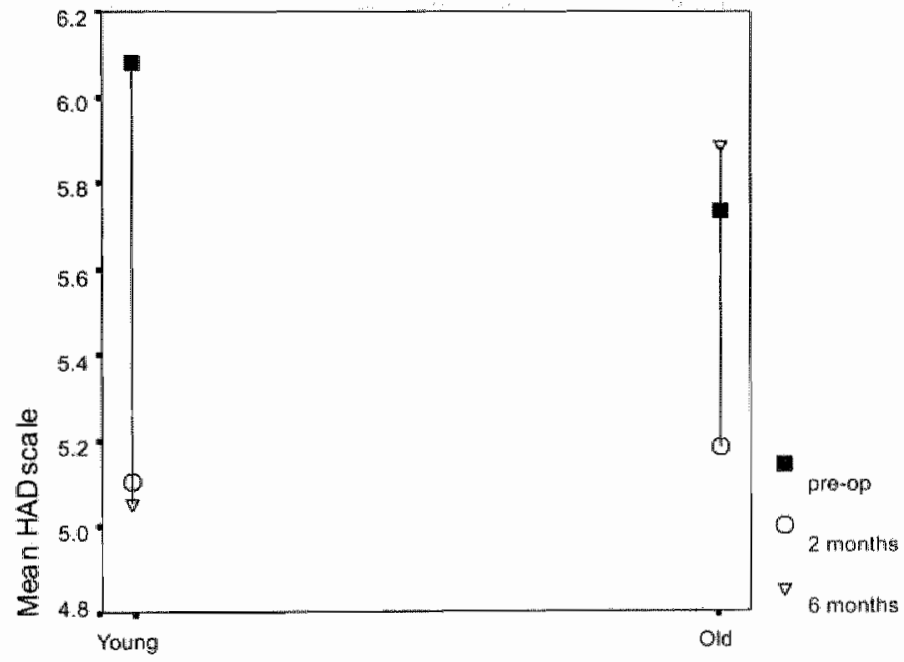

Figure 5.4. Score for anxiety and depression, before, 2 and 6 months after surgery. 
bances was less in the Old age group. Since patients in the Old age group were usually not working, and less socially active, no improvement was seen in social functioning.

At the end of the follow-up period (median $=29$ months) the surviving patients were asked by telephone about their subjective well being. $80.6 \%$ Young and $75 \%$ Old patients experienced an improvement of well being compared to before the operation. No changes were reported by $9.7 \%$ Young and $12.5 \%$ Old patients, and worsening was present in $9.7 \%$ Young and $12.5 \%$ Old patients ( $P=$ n.s. $)$.

\section{DISCUSSION}

During the last decades degenerative calcified valvular disease has become a major indication for valvular surgery in the western society. The reason being the declining incidence of rheumatic valvular disease and increasing age limits for cardiac surgery.

The surgical mortality reported in several studies varies between $5.3 \%$ and $28 \% \%$; ${ }^{10}$, depending on the type of operation, riskfactors, lowest age limit and the surgical center ${ }^{11-13}$. In our study we had a surgical mortality of $5.8 \%$ which was statistically not different from the Young group.

Late mortality varies between $8.1 \%$ and $39.8 \% \%^{14 ;} 15$ in several studies ${ }^{16-21}$, depending on the follow-up duration ( $1-5$ years) and the lowest age limit for inclusion which varied from $65-80$ years. We found a late mortality of $12.3 \%$ with a lower age limit of 75 years at a median follow-up duration of 29 months. The minimal follow-up duration of the surviving patients was 12 months, with a maximum of 51 months. With this follow-tup duration the re was again no statistical difference in tiontality compared to Younger patients.

The best pre-operative predictors for mortality in the elderly were a premoperative serum Creatinin value of more than $140 \mu \mathrm{Mol} / \mathrm{l}$ and the presence of high right sided pressures $(>45 \mathrm{mmHg}$ systolic) measured with an echocardiogram one day before surgery. We could not confirm the findings of severall other studies $10 ; 18 ; 16 ; 18-20 ; 22$ that: combined coronary and valve surgery, multiple valve surgery, emergency surgery, low LV-ejection fraction, aortic insufficiency, posterior mitral annulus calcification, hypertension and male gender were independent risk factors for mortality. However the incidence of some of these variables was low in our study population, which could explain these differences.

The postoperative admission duration was similar in both groups. A striking difference in morbidity was a $2 \frac{1}{2}$ times higher incidence of postoperative mental confusion in the Old age group. One third of these patients had symptoms of 
mental confusion. Neary $/ 2$ of those patients needed temponat treatment with neuroleptic drugs (haloperidol). The incidence of mental confusion was clearly related to the length of the surgical procedure. Only a few studies looked at the incidence of postoperative confusion. Christenson ${ }^{23}$ found a higher incidence of mental confusion in elderly patients after a reoperation for coronary bypass grafting. Craver ${ }^{9}$ found a significantly higher incidence of postoperative psychosis in elderly patients ( $>70$ years) with aortic valve surgery, as compared to younger patients. Hofsté24 found a high incidence of delirium and cognitive disorders in elderly patients over 70 years, especially after a prolonged cross-clamping time and an intra operative hemoglobin level of less than 5 $\mathrm{mMol} / 1$. This last riskfactor however was not of importance in our study.

The late results were nearly similar in both age groups, with a comparable improvement of symptoms, and a similar mortality rate. Only readmissions were 2.9 times higher in the Old group, especially in case of mitral surgery. In a retrospective study by Arcidi 25 in which mitral valve surgery was compared to conservative treatment in patients with moderate mitral incompetence undergoing $C A B G$, conservative treatment of mitral valve disease had good hospital survival and long-term functional stability compared to those who underwent additional mitral valve surgery. This could justify a more conservative approach for moderate mitral valve disease in the elderly undergoing CABG.

Old patients showed a clear improvement of Quality of life after valvular surgery. The amount of improvement however is somewhat less than in Young patients. In conclusion valvular surgery in patients older than 75 years can be performed with a low operative mortality and has a good prognosis also as to quality of life. However a higher morbidity rate (mental confusion) and a higher number of readmissions within one year following surgery was found in elderly patients who underwent mitral valve surgery.

\section{REFERENCES}

1. Hermann $\mathrm{C}$, Scholz $\mathrm{KH}$, Kreuzer $\mathrm{H}$ : Psychologic screening of patients of a cardiologic acute care clinic with the German version of the Hospial Anxiery and Depression Scale] Psychologisches Screening von Patienten einer kardiologischen Akutklinik mit einer deutschen Fassung der "Hospital. Anxiety and Depression"

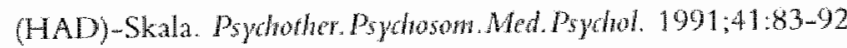

2. Snaith P: Measuring anxiety and depression. Pratitioncr. 1993;237:554-559

3. Visser MC, Koudstal PJ, Erdman RA, Deckers JW. PasschicerJ, van Gijn J, Grobbee $D E$ : Measuring quality of life in patients with myocandial infarction or stroke: a feasibility study of four questionmaires in The Netherlands. J. Epidemiol. Community. Healh $1995 ; 49: 513-517$ 
4. Wenger NK, Mattson ME, Furberg CD. Elinson J: Assessment of quality of life in clintcall trials of cardiovascular therapies. An.J.Cardiol. 1984;54:908-913

5. Ziqnund AS, Snaith RP. The hospital anxiety and depression scale. Acta psydniatr. scand. $1983,67,361-370$

6. Erdman RA, Passchier J, Koojiman M, Stronks DL. The Dutch version of the Notinghan Health Profile: investigations of psychometric aspects. Psychol.Rep. $1993 ; 72: 1027-1035$

7. Hunt SM, Mc Kenna SP, Mc Ewen J, Williams J, Papp E: The Nottingham health profile: Subjective health status and medical consultations. Sor Sri.Med. 1981:15A: 221-229

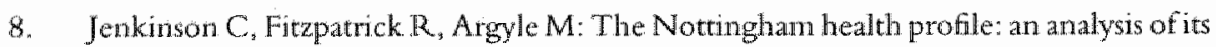
sensitivity in differentiating illness groups. Soc.Sci.Med. 1988;27.1411-1414

9. Craver JM, Goldstein J, Jones EL, et al: Clinical, hemodynamic, and operative descriptors affecting outcome of aortic valve replacement in elderly versus young patients. ANN.SURG. 1984;199:733-741

10. Deleuze P, Loisance DY, Besnainou F, Hillion ML, Aubry P, Bloch G, Cachera JP: Severe aortic stenosis in octogenarians: Is operation an acceptable alternative? Amw. Thorac Sury. 1990;50:226-229

11. Aranki SF, Rizzo RJ, Couper GS, Adans DH, Collins JJ, Jr., Gildea JS, Kinchla NM, Colm IH: Aortic valve replacement in the elderly: Effect of gender and coronary artery disease on operative mortality. Ciralation 1993;38:17-23

12. Fremes SE, Goldman BS, Ivanov], Weisel RD, David TE, Salemo T: Valvular surgery in the elderly. Circulation 1989;80:177 190

13. Logeais $\mathrm{Y}$, Langanay T, Roussin R, Leguerrier A, Rioux C, Chaperon J, de Place C, Mabo P, Pony JC, Daubert JC, et al: Surgery for aortic stenosis in clderly patients. A study of surgical risk and predictive factors. Circulation $1994: 90: 2891-2898$

14. Antunes MI: Valve replacement in the elderly. Is the mechanical valve a good alternative? J Thorac Cardiomasc. Surfy. 1989;98:485-491

15. Gchlot A, Mullany CJ, Ilstrup D, SchaffHV, Orszulak TA, Morris J, Daly RC: Aortic valve replacement in patients aged eighty years and older: Early and long-term results. J.Thom Cartionase. Surg. 1996:111:1026-1036

16. Adkins MS, Amalfitano D. Harnum NA, Lawb GW. McGrath LB: Efticacy of conbined coronary revascularization and valve procedures in octogenarians. Chest $1995 ; 108: 927-931$

17. Chocron S, Etievent JP. Clement F. Alwan K, Neidhardt M, Taberlet C, Schipman N: Is surgery for aortic stenosis justified in patients over 75 years of age? $\mathrm{J}$ Cardiondsc. Sur. Torino. 1996:37:255-259

18. Elayda MA, Hall RJ, Reul RM, Alonzo DM, Gillette N, Reul GJ, Jr., Cooley DA: Aortic valve replacement in patients 80 years and older. Operative risks and long-term results. Cimwlation 1993,88:1111-6 
19. Fiore AC, Naunheim KS, Barner HB, Pennington DG, MCBride LR, Kaiser GC, Willman VL: Valve replacement in the octogenarian. Anm. Thord. Song. 1989;48: $104-108$

20. Levinson JR, Akins CW, Buckley MJ, Newell JB, Palacios VF, Block PC, Fifer MA: Octogenarians with aortic stenosis: Outcome after aortic valve replacement. Cirulation $1989 ; 80: 149-156$

21. Tsai TP, MatloffJM, Chaux $A$, et al: Combined valve and coronary artery by pass procedures in septuagenarians and octogenarians: Results in 120 patients. An Thoroc Surg. $1986 ; 42: 681-684$

22. Cammack PL, Edie RN, Edmunds LH, Jr: Bar calcification of the mitral anulus A risk factor in mitrall valwe operations. J. Thorac Cardiovase Surg. 1987;94:399-404

23. Christenson JT, Sinonet F, Schmuziger M: The intluence of age on the results of reoperative coronary artery bypass grafting. Copon. Aktery. Dis 1997;8:91-96

24. Hofsté WJ, Linssen CA, Boezeman EH, Hengeveld JS, Leusink JA, de-Boer A: Delirium and cognitive disorders after cardiac operations: relationship to pre- and intraoperative quantitative electroencephalogram. Int.J. Clin. Monit. Comput 1997. Fol. 97 A.D.; $14: 29-36$

25. Arcidi JM, Jr., Hebeler RF, Craver JM, Jones EL, Hatcher CR, Jr., Guyton RA: Treatment of moderate nitral regurgitation and cotonary diseas by coronary bypass allone. J. Thorac Candiovasc. Surg. 1988:95:951-959 


\section{Prophylactic $\beta$-blocking therapy for atrial fibrillation post cardiac surgery}

Incidence and impact of contraindications for $\beta$-blockade, and the efficacy of low dose Sotalol in different age groups

Charles J.H.J. Kirchhof, MD,PhD, Jan A. Heijmeriks, MD, Willem R.M.Dassen, PhD, Kees Prenger, MD* and Hein J.J. Wellens, MD, PhD, FACC

Department of Cardiology, Department of Cardiothoracic Surgery*, University Hospital Maastricht, Maastricht, The Netherlands 


\section{ABSTRACT}

Background: The incidence of atrial fibrillation (AF) after cardiac surgery can be markedly reduced by $\beta$-blocking drugs.

Dbjectives: We compared the incidence of contraindications for $\beta$-blocking agents in elderly and younger subjects and evaluated the impact on routine use of low dose sotalol post cardiac surgery. We furthermore studied the prophylactic efficacy of sotalol for postoperative atrial fibrillation (POAF), and the effects on postoperative hospital stay.

Methods: 200 patients of 75 years and older (0ld) admitted for cardiac surgery (CABG, valvular surgery or both) were compared with 400 gender- and procedure-matched subjects younger than 75 years of age (roung). The incidence of each of the following relative contraindications for $\beta$-blockers was determined: chronic obstructive pulmonary disease, pre- or postoperative heartfailure, impaired left ventricular function, prolonged postoperative ventilation and pre-or postoperative sinus node dysfunction or AV conduction disturbances. POAF was detected by telemetric ECG monitoring and by daily ECG'5. The effects of low dose sotalol ( $40 \mathrm{mgr}$. b.i.d.) on incidence of POAF and length of postoperative hospital stay were determined.

Results: The incidence of contraindications for $\beta$-blockade was $57.5 \%$ in the Young versus $67 \%$ in the old population $(p<0.05)$. Preoperative heartfailure and postoperative sinus node dysfunction or AV conduction disturbances occurred more often in Young or Old patients subjected to valwular surgery. Prophylactic sotalol reduced the overall incidence of POAF in Young patients from $69 \%$ to $27.6 \%(p<0.001)$, and in old subjects from $91.9 \%$ to $32.6 \%(p<0.001)$. Irrespective of age, POAF occurred significantly more often after valwular surgery than after CABG, but was prevented to a similar extent by sotalol. In Young patients prevention of POAF was associated with a 5 -days shorter postoperative hospital admission, whereas this was only 2 days among old patients.

Conclusions: Cardiac surgery patients show a high $(>50 \%)$ incidence of contraindications for $\beta$-blocking agents which further increases with age. The incidence of postoperative atrial fibrillation is significantly higher in elderly patients, but can be markedly reduced by low dose sotalol at all ages. Postoperative atrial fibrillation is associated with a prolonged postoperative hospital stay. 


\section{CONDENSED ABSTRACT}

We compared the incidence of contraindications to $\beta$-blockers in 200 elderly $(\geq 75$ yrs) and 400 younger cardiac surgery patients, and studied the efficacy of prophylactic low dose sotalol ( $40 \mathrm{mgr}$ b.i.d.) in preventing postoperative atrial fibrillation (POAF). The incidence of contraindications in the elderly was $17 \%$ higher than in younger patients. In daily practice these contraindications did not preclude sotalol use in 20\% of the cases. POAF occurred significantly more often with a preoperative history of AF, after valvular surgery, and in the elderly. Low dose satalol caused a marked reduction in POAF. We conclude that effective prophylaxis of POAF by low dose sotalol is stitl markedly hampered by contraindications to problockade in all age groups.

\section{INTRODUCTION}

Atrial fibrillation (AF) is the most common cardiac tachyarrhythmia with an estimated incidence of $1.7 \%$ in the general population ${ }^{1}$. Patients recovering from cardiothoracic surgery represent an independent risk group for developing atrial fibrillation on the second or third day postoperatively. Incidences between $11 \%$ and $100 \%$ have been reported depending on patients' age, previous history of atrial fibrillation, type of cardiac disease and means of postoperative AF detection ${ }^{2-7}$. A meta-analysis by Andrews et al. revealed a $27 \%$ incidence of atrial hbrillation after $\mathrm{CABG}^{8}$. Increased postoperative morbidicy due to atrial fibrillation may have therapeutic consequences, may lengthen hospital stay and postoperative rehabilitation, and therefore must have an important impact on hospital resources $2 ; 5 ; 9$.

The pathophysiologic mechanism underlying post cardiac surgery atrial fibrillation remains unclear. Sterile pericarditis, proarrhythmic autononic or hemody namic disturbances, atrial ischemia or fibrotic tissue changes all may play a role ${ }^{10}$. With respect to clinical management, several studies have shown that postoperative atrial fibrillation may be prevented by $\beta$-adrenergic blocking drugs $8 ; 11-14$. Therefore routine administraton of prophylactic $\beta$-blocking drugs post cardiac surgery has been advocated by several authors $9 ; 15$.

The use of $\beta$-blocking agents to prevent postoperative atrial fibrillation is basically limited to patients free of contraindications for these drugs. Therefore, most clinical trials on this subject have excluded patients with contraindications to $\beta$-blockers. However, to the best of our knowledge no data exist on the incidence of (relative) contraindications for $\beta$-blocking drugs in cardiac surgery patients. Neither do we know whether these contraindications are related to the patients" age or cardiac disease, and to what extent these contraindications preclude the use 
of $\beta$-blockers in daily practice. Finally, sotalol in moderate dosages appeared to be at least as effective as regular $\beta$-blocking drugs in preventing postoperative atrial fibrillation 11: 16 . No data are available on the prophylactic efficacy of a minimal dose of sotalol in the elderly, whereas patients in their eighth or ninth decade represent a growing subpopulation of cardiac surgery patients.

In the present cohort study we determined the incidence of relative contra-indications for $\beta$-adrenergic blocking drugs in cardiac surgery patients. We furthermore studied the impact of these contraindications on the routine use of low dose sotalol ( $40 \mathrm{mgr}$. b.i.d.) in daily practice, and investigated the effectiveness of this prophylactic regimen against postoperative atrial fibrillation in different age groups and in relation to different types of surgery.

\section{METHODS}

\section{PATIENT POPULATION}

Between September 1993 and December 1996 six hundred patients were included in the study. During this period all patients $(n=215)$ of 75 years or older and who were admitted for elective or emergency $(<48$ hours after admission) coronary artery bypass grafting $(\mathrm{CABG})$, aortic or mitral valve repair or replacement, or a combined valvular/coronary bypass procedure were considered for study inclusion. Two hundred of these patients were enrolled in the primary study (Old). Fifteen patients were not included for logistic reasons. For comparison, 400 sex-and procedure-matched patients younger than 75 years of age (on admission) were randomly included in the Young age group. The histogram in figure 1 illustrates age and gender distribution of both study groups. The median age in the Young group was 66.6 years, in the Old group 77.3 years. In both groups $46.5 \%$ of the patients were male, $65.5 \%$ had coronary artery bypass surgery, $18 \%$ valvular surgery (mitral, aortic or both) and $16.5 \%$ a combined valvular/coronary bypass procedure.

\section{PRE-OPERATIVE SCREENING}

After informed consent was obtained all patients were preoperatively evaluated by the same cardiologist (J.H.). Past and current medical history, functional class (NYHA), current medication, and risk factors for cardiovascular diseases were documented. Routine physical examination, blood and urine tests, a standard chest $\mathrm{X}$-ray, a standard 12-lead electrocardiogram, a pulmonary plethysmogram, a transthoracic echocardiogram and a selective coronary angiogram were otained. All data were stored in a patient database. This database was not accessible for clinical decision making by the attending physicians responsible for the management of the patient. 


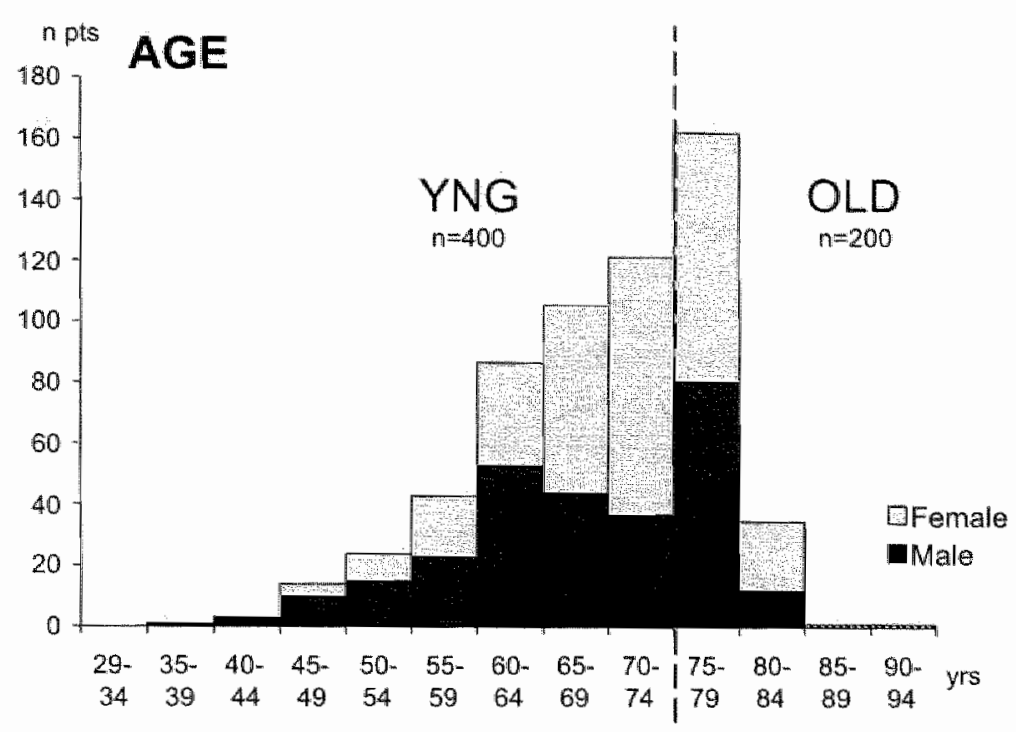

Figure 6.1. Age and gender distribution of both patients groups. The OLD patient group ( 75 years and older) contained all subjects admitted for cardiac surgery. The YNG group was selected to match the QLD population with respect to gender distribution and type of surgical procedure.

\section{SURGICAL TECHNIQUES AND POSTOPERATIVE MANAGEMENT}

All patients in both age groups were operated upon using the same standard anesthetic, surgical and hemodynamic monitoring techniques. Cardiopulmonary bypass was instituted with a flow rate of $2.4 \mathrm{~L} / \mathrm{min} / \mathrm{m}^{2}$. After cross-clamping the aorta, antegrade infusion of St. Thomas cristalloid cardioplegic solution was combined with topical cooling of the heart using cold saline. The average bypass time was $104 \pm 46$ minutes (Young: $104 \pm 48$; Old: $104 \pm$ 42; n.s.). The average aortic crossclamp-time was $68 \pm 34$ minutes (Young: 69 \pm 36 ; Old: $67 \pm 31$ ). Moderate systemic hypothermia $\left(28-32^{\circ}\right.$ Celsius in both groups) was used. Patients who were in atrial fibrillation before surgery and who were not converted into sinus rhythm during cardioplegia were cardioverted intrathoracically by DC shock $(8 \mathrm{~J} / \mathrm{s})$.

\section{PREVENTION OF POST-OPERATIVE ATRIAL FIBRILLATION}

Prophylactic treatment for postoperative atrial fibrillation was standardized to sotalol $40 \mathrm{mgr}$ b.i.d orally and was statted during the first 24 hours post-operatively or as soon as possible. Basically, if no general contraindications for $\beta$-adrenergic blocking agents or sotalol in particular (QT-prolongation or Torsade de Pointes ventricular arrhythmias) were considered to be present, oral sotalol $40 \mathrm{mgr}$ b.i.d. was given as soon as the patient was extubated (median in- 
tubation time in both patient groups: $<24$ hours). Sotalol was continued during post-operative hospital stay unless adverse effects required withdrawal of the drug. In dally practice prophylactic low dose sotalol was prescribed by the attending physician based upon clinical state and severity of contraindications for p-blocking drugs. Consequently, patients without contraindications could still be withheld from low dose sotalol for other reasons (gastrointestinal problems, infections, neurologic complications), whereas patients with mild contraindications could still receive low dose sotalol if the attending physician anticipated a prophylactic effect. If sotalol was contrainclicated, no other prophylactic $\beta$-blocking or anti-arrhythmic agents were given.

\section{CONTRAINDICATION FOR $\beta$-BLOCKERS}

Relative contraindications for $\beta$-adrenergic blocking agents were defined as:

1. Chronic obstructive pulmonary disease requiring bronchodilating drugs on a dialy basis. (COPD)

2. A documented history of congestive heartfailure (NYHA 3-4). (Preop. HeartFailure)

3. An echocardiographically determined pre-operative left ventricular ejection fraction of less than $40 \%$. (LVEF $<40 \%$ )

4. Post-operative heart failure requiring positive inotropic agents. (Postop. HeartFailure)

5. Post-operative respiratory insufficiency requiring prolonged ( $>24$ hours) ventilation. (Postop. Vent. $>24 \mathrm{~h}$ )

6. Preoperative history of documented sinus bradycardia $(<50 \mathrm{bpm})$, sinus node dysfunction, significant atrioventricular conduction delay (PR > 0.26 sec) or high degree AV-block. (Preop. SND/AV\#)

7. Peri- or postoperative (temporary) sinus node dysfunction or atrioventricular conduction disturbances (see 6). (Postop: SND/AV\#)

\section{POST-OPERATIVE DETECTION OF ATRIAL FIBRILLATION}

Detection of atrial fibrillation was started immediately post surgery and continued until 1) in-hospital discontinuation of sotalol because of adverse drug effects; 2) hospital discharge or 3) in-hospital death. During the first 4 to 5 postoperative days atrial fibrillation was detected by continuous telemetric ECG monitoring (lead I, II or III; Hewlett Packard 78510B) visually interpreted by a trained intensive care nurse. An algoritm detecting ventricular arrhythmias and ventricular rates above $120 \mathrm{bpm}$ was used for general arrhythmia scanning. Atrial tachyarrhythmias were discriminated from other rhythm disturbances and documented on paper for review and authorization by a cardiologist (J.H.). Electrocardiographically, atrial fibrillation was defined as an absence of regular P- or F-waves, and the presence of rapid irregular atrial activity with a continuous va- 
riation in complex morphology. The moment of onset of the first detected episode of postoperative atrial fibrillation was documented. There was no minimal time duration for a tachyarrhythmia to be considered as atrial fibrillation. As a result, also short asymptomatic and clinically irrelevant episodes of atrial fibrillation were taken into account. In case of poor quality recordings or diagnostic difficulties, a standard 12-lead electrocardiogram was obtaned. After 3-4 days of continuous telemetric ECG monitoring, detection of atrial fibrillation was based upon daily ECG's and on ECG's recorded for clinical indications.

\section{STATISTICAL ANALYSIS}

All data are expressed as mean \pm standard deviation unless stated otherwise. Differences between two groups were evaluated using the unpaired Student's t-test if the groups were normally distributed. Otherwise the Mann-Withney rank sum test for unpaired samples was applied. Frequencies were compared by using the Pearson $\mathrm{chi}^{2}$-test for equalty of proporties with Yates correction for small numbers, or by using the Fisher exact test whenever appropriate $(2 \times 2$, expected value less than 5 in one cell). All data were analyzed using the SPSS 8.0 statistical package.

\section{RESULTS}

\section{PATIENTS BASELINE CHARACTERISTICS}

In table 1 the characteristics of all study patients are summarized. The quetelet index and body surface area (BSA) were significantly lower in the Old group. Preoperative left ventricular function and left atrial dimension were similar. Only the left ventricular enddiastolic diameter showed a slight but significant difference. Preoperative laboratory tests revealed a significantly higher BUN level and a slightly lower hemoglobin concentration in the elderly patients. Preoperative creatinine levels were similar. Regarding pulmonic function the Old patients showed a significantly lower mean vital capacity and $\mathrm{FEV}^{-1}$ value. However, this difference appeared to be age- and BSA-related. In both age groups more than $50 \%$ of the patients suffered a recent ( $\leq 2 \mathrm{mnths}$ ) or previous (>2 mnths) myocardial infarction. A similar number of patients suffered from diabetes mellitus, peripheral arterial sclerosis or a previous cerebrovascular event. A positive smoking history and hypercholesterolemia (upper limit: 6.4 $\mathrm{mmol} / \mathrm{l}$ ) occurred more frequently in Young patients.

The majority $(94.5 \%)$ of patients in both groups were subjected to elective surgery. The in-hospital-mortality was $5 \%$ in the Young population, $4 \%$ in the Old group (n.s.), and was never related the use of low dose sotalol. 
Table 6.1. Baseline characteristics of the patients studied.

\begin{tabular}{|c|c|c|}
\hline & Young $(n=400)$ & ald $(n=200)$ \\
\hline Male/Female & $186 / 214$ & $93 / 107$ \\
\hline Age [range] (yrs) & $65 \pm 7[35.2-74.9]$ & $78 \pm 3[75.0-91.3]$ \\
\hline Body mass index $\left(\mathrm{g} / \mathrm{m}^{2}\right)$ & $27.0 \pm 4.3$ & $25.7 \pm 3.3^{*}$ \\
\hline Body surface area $\left(\mathrm{m}^{2}\right)$ & $1.84 \pm .18$ & $1.77 \pm .15^{* *}$ \\
\hline \multicolumn{3}{|l|}{ Cardiac measurements } \\
\hline LVEF pre-Op $(\%)$ & $55 \pm 12$ & $54 \pm 11$ \\
\hline LVEDD pre-op (mm) & $50 \pm 6$ & $49 \pm 6^{*}$ \\
\hline $\mathrm{LV}$-mass index pre-op $\left(\mathrm{g} / \mathrm{m}^{2}\right)$ & $123.7 \pm 32.4$ & $128.2 \pm 32.0$ \\
\hline Left atrium pre-op $(\mathrm{mm})$ & $48 \pm 7$ & $49 \pm 6$ \\
\hline E/A-ratio pre-op & $0.97 \pm 0.44(n=346)$ & $0.89 \pm 0.58$ \\
\hline Syst RV-press. pre-op (minHg) & $29 \pm 11$ & $30 \pm 10$ \\
\hline LVEDP pré-cine ( $\mathrm{mmHg}$ ) & $14 \pm 8$ & $15 \pm 8$ \\
\hline \multicolumn{3}{|l|}{ Laboratory data } \\
\hline Creatinin pre-cp $(\mu \mathrm{Mol} / \mathrm{l})$ & $97 \pm 41$ & $105 \pm 73$ \\
\hline BUN pre-op $(\mathrm{mMol} / \mathrm{l})$ & $6.9 \pm 3.0$ & $7.7 \pm 3.3^{* *}$ \\
\hline 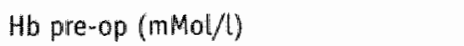 & $8.5 \pm .9$ & $8.1 \pm .9^{* *}$ \\
\hline \multicolumn{3}{|l|}{ Pulmonary function } \\
\hline $\mathrm{VC} \% / \mathrm{nolm}$ & $99 \pm 18$ & $101+20$ \\
\hline FEV1 (l) & $2.41 \pm 0.85$ & $1.97 \pm 0.57^{\star \star \star}$ \\
\hline FEV1 \% / VC & $72 \pm 12$ & $71 \pm 12$ \\
\hline \multicolumn{3}{|l|}{ Cardiovascular riskfactors } \\
\hline Previous Myocardial Infarction" & $28 \%$ & $31 \%$ \\
\hline Recent Myocardial Infarction $\$$ & $12 \%$ & $14 \%$ \\
\hline History of Heart Failure (NYHA 3-4) & $25 \%$ & $26.5 \%$ \\
\hline Diabetes Mellitus (type 1 or 2) & $17 \%$ & $19 \%$ \\
\hline Peripherat Vascular Disease & $17 \%$ & $16 \%$ \\
\hline History of Systemic Hypertension & $45 \%$ & $45 \%$ \\
\hline Cerebrovascullar Disease & $9 \%$ & $9 \%$ \\
\hline Hypercholesterolemia $(26.5 \mathrm{mmol} / \mathrm{l})$ & $33 \%$ & $20 \% * *$ \\
\hline Smoking & $27 \%$ & $15 \% * *$ \\
\hline
\end{tabular}

* Pe0.05,* P<0.01, * $P<0.001, \&$ : previous MI: $>2$ months, recent MI: $\leq 2$ months. 


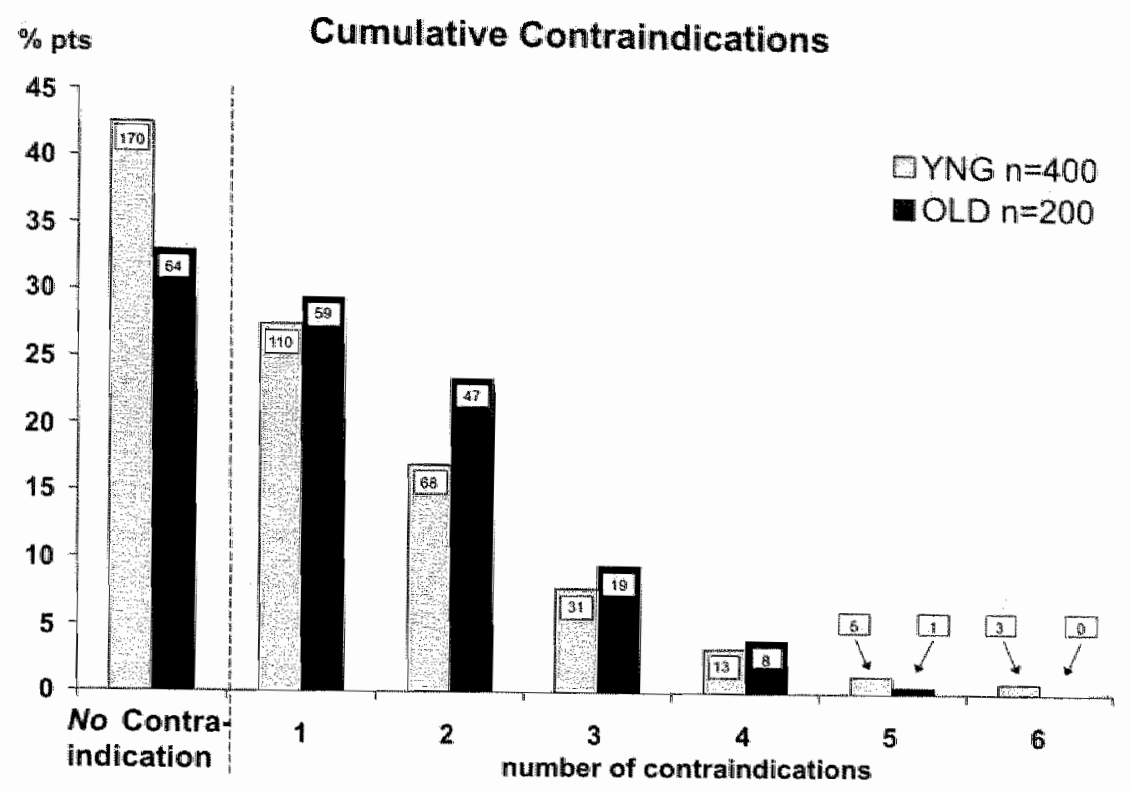

Figure 6.2. Bar diagram illustrating the frequency distribution of relative contraindications for $\beta$-blockers in both age groups. The absolute number of patients in each subgroup is given in the box in top of each bar. As can be seen, less than $50 \%$ of the patients were free of contraindications. This means that more than half of all patients was no candidate for prophylactic treatment with $\beta$-blockers for postoperative atrial fibrillation. The elderly patient group showed a trend towards more than one contraindication. ${ }^{*} p<0.05$.

\section{CONTRA-INDICATIONS FOR B-ADRENERGIC BLOCKING DRUGS}

None of the patients in either age group had a previous history of idiosyncratic reactions to $\beta$ blocking agents or sotalol, neither did anyone suffer from Torsade des Pointes arthythmias ventricular arrhythmias. Figure 2 illustrates the incidence of contraindications for $\beta$-blockade in both age groups. $57.5 \%$ of the Young patients and $67 \%$ of the Old ones $(p<0.05)$ had one or more contraindications for $\beta$-blocker use. Of these patients $52.2 \%$ in the Young and $56 \%$ in the Old category (n.s.) had two or more contraindications. If these contraindications were strictly applied more than half of the cardiac surgery patients would not be a candidate for postoperative $\beta$-blocker use.

The incidence of each individual contraindication screened for is given in figure 3 for both age groups and for the different types of cardiac surgery. Overall, chronic obstructive pulmonary disease was present in $16.3 \%$ of the Young and $20 \%$ of the Old subjects. In CABG patients COPD occurred almost wice as often in the Old group $(p<0.01)$. However, in case of valvular surgery this age-related difference was reversed. Postoperative respiratory insufficiency requiring prolonged venti- 


\section{Incidence of contraindications}
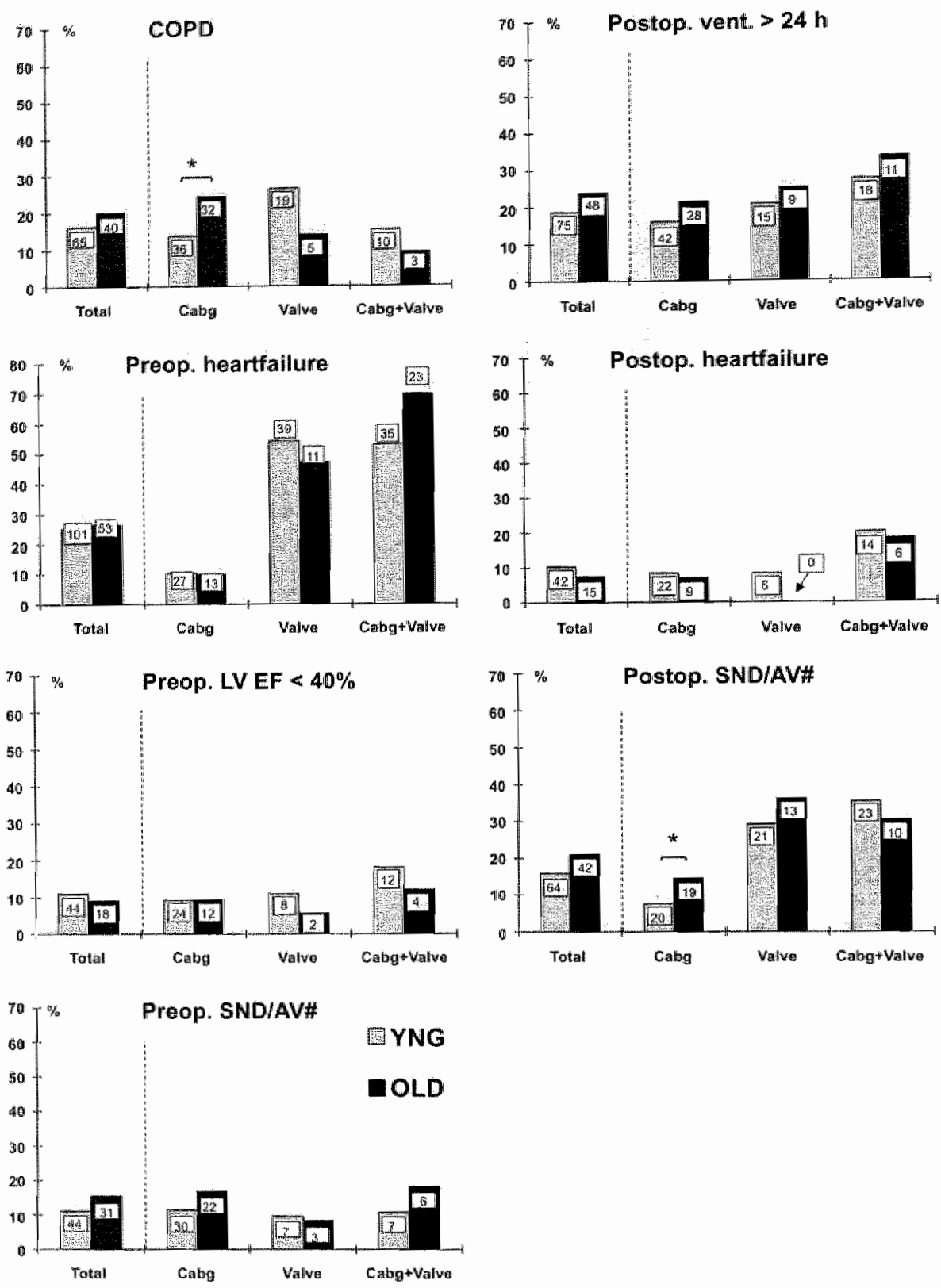

Figure 6.3. Incidence of the seven individual (relative) contraindications related to different types of cardiac surgery. Each bar diagram gives the incidence of the indicated contraindication for bypass grafting (CABG), mitral or aortic valve repair or replacement, or a combination of both. The numbers in top of each bar give the absolute number of patients in the respective subgroups. As can be seen, only preoperative heartfailure and postoperative sinus node dysfunction or AV conduction disturbances showed a clear positive relationship with the type of procedure. 
lation occurred in $19 \%$ of the Young and $24 \%$ of the Old patients with a trend towards a higher incidence in valvular and combined procedures. The most frequent contraindication for $\beta$-blockade was a previous history of moderate or severe congestive heartfailure, occurring in about a quarter of patients in both age groups and showing an evident positive relationship with valvular surgery. A preoperative LVEF $<40 \%$ and postoperative heart failure both showed the lowest incidence, about $10 \%$, in both age groups with a slight trend towards a higher incidence in case of combined surgery. Preoperative sinus node dysfunction or atrioventricular conduction disturbances were present in about $11 \%$ of the Young and almost in $16 \%$ of the Old patients with a somewhat lower incidence in case of valvular surgery. Finally, postoperative atrioventricular conduction disturbances or sinus node dysfunction occurred about $30 \%$ more often than preoperatively, with an overall incidence of $16 \%$ in the Young and $21 \%$ in the Old patients. In this case there was a clear positive relationship with valvular and valvular/coronary surgery.

A preoperative history of paroxysmal or chronic atrial fibrillation was associated with higher incidences of contraindications for $\beta$-blockade. Young patients with preoperative AF $(19.8 \%)$ had significantly more often preoperative heartfailure $(63 \%$ versus $16 \% ; p<0.001)$, postoperative heart failure $(20 \%$ versus $8 \% ; p<$ $0.01)$, prolonged postoperative ventilation $(27 \%$ versus $17 \% ; \mathrm{p}<0.05)$ or peri- or postoperative sinus node dysfunction or atrioventricular conduction disturbances $(38 \%$ versus $11 \%)$. In the Old group a history of preoperative atrial fibrillation $(28.5 \%)$ was only associated with a higher incidence of preoperative heart failure (49\% versus $17 \% ; \mathrm{p}<0.001)$.

In summary, preoperative heart failure, prolonged postoperative ventilation and postoperative sinus dysfunction or AV conduction disturbances were the most frequent contraindications for $\beta$-blockers, irrespective of age but with a clear positive relation to valvular or combined valvular/coronary surgery.

\section{THE IMPACT OF CONTRAINDICATIONS ON POSTOPERATIVE LOW DOSE SOTALOL USE}

After cardiac surgery the attending physicians decided upon the prophylactic use of low dose sotalol ( $40 \mathrm{mgr}$. b.i.d. orally) taking the patient's clinical situation and presence of contraindications into account. As a result, patients with relative contraindications for $\beta$-blockade could still receive low dose sotalol, whereas patients without contraindications could not receive the drug for other clinical reasons. Only in this way the impact of contraindications on the use of low dose sotalol in daily practice could be studied. In $57.0 \%$ of the Young patients and in $44.5 \%$ of the Old population sotalol was given (table 2). Of all Young patients with one or more contraindications $34.5 \%$ still received low dose sotalol because of a low risk profile for adverse drug effects according to the 
Table 6.2. Presence of contraindications to beta-blocking drugs and incidence of prophylactic pastoperative sotalol administration.

\begin{tabular}{lllll}
\hline & Young & & Old \\
Contraindication: & Sotalol given & $n(\%)$ & Sotalal given & $n(\%)$ \\
\hline None & $149 / 170$ & $(87.6 \%)$ & $44 / 66$ & $(67 \%)$ \\
One or more & $79 / 229^{5}$ & $(34.5 \%)$ & $45 / 134$ & $(33.6 \%)$ \\
\hline COPD & $16 / 64$ & $(25 \%)$ & $12 / 40$ & $(30 \%)$ \\
PreOp Heartfailure & $20 / 100$ & $(20 \%)$ & $16 / 53$ & $(30.2 \%)$ \\
Preop LVEF \& 40\% & $6 / 44$ & $(13.6 \%)$ & $7 / 18$ & $(38.9 \%)$ \\
Postop HeartFailure & $4 / 41$ & $(9.8 \%)$ & $1 / 15$ & $(6.7 \%)$ \\
Postop Vent. $>24 h$ & $18 / 75$ & $(24 \%)$ & $10 / 48$ & $(20.8 \%)$ \\
Pre0p SND/AVH & $25 / 44$ & $(56.8 \%)$ & $13 / 31$ & $(41.9 \%)$ \\
Post0p SND/AVH & $11 / 64$ & $(17.2 \%)$ & $10 / 42$ & $(23.8 \%)$ \\
\hline
\end{tabular}

$\$$ : one missing value, Data represent number of patients $(n), * P<0.05, * P<0.01, * * *<0.001$.

attending physician. On the other hand, $12.4 \%$ of the group of Young patients without any contraindication did ot receive sotalol for other reasons like gastro-intestinal problems, infectious or neurologic complications. Similarly, also Old patients with relative contraindications still received low dose sotalol in $33.6 \%$ of the cases. However, it was also withheld in $33 \%$ of the elderly for other reasons than contraindications to $\beta$-blockade. In none of the Young or Old patients with contraindications who still received low dose sotalol the drug had to be withdrawn because of hemodynamic or pulmonic side effects. These findings indicate that general contraindications to $\beta$-blockade do not preclude the use of low dose sotalol in patients post cardiac surgery.

Postoperative use of low dose sotalol, despite of documented contraindications to B-blockers, was not specifically related to one of the defined contraindications screened for (table 2). Young patients receiving low dose sotalol could have each of the seven contraindications, although preoperative sinus dysfunction or AV conduction disturbances had by far the lowest impact on postoperative low dose sotalol use in daily practice. In the Old population only prolonged postoperative ventilation, postoperative AV block or sinus node dysfunction, and postoperative heartfilure were associated with a less than $25 \%$ prescription rate of prophylactic sotalol. Other contraindications had even less impact on prescription habits with a more than $30 \%$ use of sotalol. These findings indicate that general contraindications for $\beta$-blockers have only a moderate impact on low dose sotalol use in daily cardiosurgical practice. None of the clefined contraindications turned out to be an absolute one. 


\section{THE EFFECTS OF LOW DOSE SOTALOL ON POSTOPERATIVE ATRIAL FIBRILLATION}

In the Young group $19.8 \%$ of the patients had a doctmented history of chronic $(8 \%)$ or paroxysmal $(11.9 \%)$ atrial fibrillation. In the Old group this was the case in $28.5 \%(P<0.05)$, due to a higher incidence $(19.5 \%)$ of paroxysmal atrial fibrillation. Since a preoperative history of atrial fibrillation has been identified as an independent risk factor for the development of postoperative atrial fibrillation, this subpopulation was considered separately ${ }^{3}$. Overall, postoperative atrial fibrillation occurred in $83.8 \%$ of cases. Interestingly, there was no difference between the Young and Old patients, but the incidence increased with valvular surgery. In Young patients undergoing a combined valvular/coronary procedure the incidence was even $100 \%$. Without sotalol the incidence of postoperative atrial fibrillation was almost $90 \%$ in the Young and even 100\% in the elderly. This was reduced by almost $30 \%$ in the Young and by almost $50 \%$ in the elderly patients using prophylactic low dose sotalol. This antifibrillatory effect was greatest in $\mathrm{CABG}$ patients.

Among all 463 patients who were free of a previous history of atrial fibrillation the incidence of post-operative atrial fibrillation was 44.1\% (table 4), being almost $50 \%$ lower than in patients with a preoperative history of atrial fibrillation. The incidence of postoperative AF was lowest after CABG (33.9\%) but increased to more than $50 \%$ if valvular surgery was involved. In the elderly postoperative atrial fibrillation occurred significantly more often (61.5 versus $36.3 \%$ in the Young group). This was in contrast to the subpopulation of patients with a preoperative history of atrial fibrillation in which no such age-related difference was found (table 3). The highest incidence (70\%) of new onset postoperative AF was found in elderly patients subjected to valvular surgery.

Overall, low dose sotalol reduced the incidence of new onset postoperative AF by more than $50 \%$ in both age groups. In case of valvular surgery a reduction of 60 to $85 \%$ was found. This was opposite to the patients with a positive history of atrial fibrillation where low dose sotalol was most effective in patients recovering from coronary bypass surgery. These results demonstrate sotalol's efficacy in reducing the incidence of postoperative atrial fibrillation, both in young and elderly patients with and without a preoperative history of atrial fibrillation.

\section{DURATION OF HOSPITAL ADMISSION POST CARDIAC SURGERY}

We determined the length of postoperative hospital admission in both age groups in relation to the occurrence of postoperative atrial fibrillation (table 5). The median length of postoperative admission was 13 days in Young patients with postoperative atrial fibrillation. This was 5 days longer than in Young patients in whom no atrial fibrillation was detected $(p<0.001)$. In the elderly, postoperative atrial fibrillation was associated with a median hospital admission 
Table 6.3. Incidence of postoperative atrial fibrillation in patients with a preoperative history of atrial fibrillation.

\begin{tabular}{|c|c|c|c|c|}
\hline & Young & & old & \\
\hline & $19.8 \%(79 / 400)$ & & $28.5 \%(57 / 200)$ & \\
\hline $\mathrm{CABG}$ & $69.2 \%(18 / 26)$ & & $76.9 \%(20 / 26)$ & \\
\hline Valve & $80 \%(24 / 30)$ & & $93.8 \%(15 / 16)$ & \\
\hline CABG\&Valve & $100 \%(23 / 23)$ & & $93.3 \%(14 / 15)$ & \\
\hline \multirow[t]{2}{*}{ All procedures } & $82.3 \%(65 / 79)$ & & $86 \%(49 / 57)$ & \\
\hline & Sotalol: - & Sotalol:: + & Sotalol: - & Sotalol: + \\
\hline CABG & $86.7 \%(13 / 15)$ & $45.5 \%(5 / 11)^{*}$ & $200 \%(16 / 16)$ & $40.0 \%(4 / 10)^{* * *}$ \\
\hline Valve & $84.6 \%(22 / 26)$ & $50.0 \%(2 / 4)$ & $100 \%(10 / 10)$ & $83.3 \%(5 / 6)$ \\
\hline CABG\&Valve & $100 \%(17 / 17)$ & $100 \%(6 / 6)$ & $100 \%(14 / 14)$ & $0 \%(0 / 1)$ \\
\hline All procedures & $89.7 \%(52 / 58)$ & $61.9 \%(13 / 21)^{\star}$ & $100 \%(40 / 40)$ & $52.9 \%(9 / 17)^{\cdots+k}$ \\
\hline
\end{tabular}

Absolute number of patients in each subgroup are given between brackets.

* $p<0.05, * *<<0.01, * * * 0<0.001$

Table 6.4. Incidence of postoperative atrial fibrillation in patients without a preoperative history of atrial fibrillation.

\begin{tabular}{|c|c|c|c|c|}
\hline & $\begin{array}{l}\text { Young } \\
80 \%(3.20 / 400)\end{array}$ & & $\begin{array}{l}\text { old } \\
71.5 \%(143 / 200)\end{array}$ & \\
\hline CABG & $31.4 \%(74 / 236)$ & & $60 \%(63 / 105)^{* \star}$ & \\
\hline Valve & $45.2 \%(19 / 42)$ & & $70 \%(14 / 20)$ & \\
\hline CABG\&Valve & $54.8 \%(23 / 42)$ & & $61.1 \%(11 / 18)$ & \\
\hline \multirow[t]{2}{*}{ All procedures } & \multicolumn{2}{|l|}{$36.3 \%(116 / 320)$} & \multicolumn{2}{|c|}{$61.5 \%(88 / 143)^{*}$} \\
\hline & Sotalol: - & Sotalol: + & Sotalol: - & Sotalol: + \\
\hline CABG & $50.8 \%(31 / 61)$ & $24.6 \%(43 / 175)^{* *}$ & * $84.0 \%(42 / 50)$ & $38.2 \%(21 / 55)^{* * * *}$ \\
\hline Valve & $63.0 \%(17 / 27)$ & $13.3 \%(2 / 15)^{* *}$ & $100 \%(10 / 10)$ & $40 \%(4 / 10)^{*}$ \\
\hline CABG\&Valve & $72.0 \%(18 / 25)$ & $29.4 \%(5 / 17) *$ & $90.9 \%(10 / 11)$ & $14.3 \%(1 / 7)^{* *}$ \\
\hline All procedures & $58.8 \%(66 / 113)$ & $24.2 \%(50 / 207)^{* * *}$ & $87.3 \%(62 / 71)$ & $36.1 \%(20 / 72)^{*+1}$ \\
\hline
\end{tabular}

Absolute numbers of patients in each subgroup are given between brackets.

* $p<0.05$, * $p_{<}<0.01$, *** $P_{<} 0.001$ 
Table 6.5. Length of postoperative hospital stay (days).

\begin{tabular}{lll} 
& Young & \\
\cline { 2 - 3 } Post-op. AF & Yes & No \\
\hline CABG & $10(92)$ & $8(170)^{* * *}$ \\
Valve & $14(43)$ & $10(29)^{* * *}$ \\
CABG\&Valve & $14(46)$ & $9(20)^{*}$ \\
All procedures & $13(181)$ & $8(219)^{* * *}$ \\
\hline
\end{tabular}

\begin{tabular}{lll} 
Post-op. AF & \multicolumn{1}{l}{$\begin{array}{ll}\text { Old } \\
\text { Yes }\end{array}$} & No \\
\hline CABG & $13(83)$ & $12(48)^{5 \$ \$}$ \\
Valve & $16(29)$ & $9(7)$ \\
CABG\&Valve & $15(25)$ & $12(8)$ \\
All procedures & $14(137)$ & $12(63)^{* \$ \$}$ \\
\hline
\end{tabular}

Median length of postoperative hospital stay: number of patients between brackets.

${ }^{*} P<0.05$, * $P<0.01$, ** $P<0.001$ for post-operative AF; $\$<<0.05, \$ 5<<0.01$, $\$ \$ \$<0.001$ between both age groups

of 14 days which was only 2 days longer than when no postoperative atrial fibrillation was detected $(P<0.05)$. The median postoperative admission time of $C A B G$ patients was shorter than of patients who underwent valvular or combined surgery. If no postoperative atrial fibrillation occurred, this procedure related difference became less pronounced in either age group. The present data suggest that postoperative atrial fibrillation is associated with an increased length of postoperative in-hospital-stay in patients younger than 75 years of age, but less so in elderly patients. However, other factors may influence the postoperative length of hospital stay even to a greater extent.

\section{ARE CONTRAINDICATIONS FOR B-BLOCKERS RISK FACTORS FOR POSTOPERATIVE ATRIAL FIBRILLATION?}

We correlated the presence of general contraindications for $\beta$-blocking agents with the occurrence of postoperative atrial fibrillation in patients who were prophylactically treated with low dose sotalol and in patients who did not receive this drug. It appeared that only postoperative ventilation lasting longer than 24 hours was associated with a significantly $(P<0.05)$ increased risk for developing postoperative atrial fibrillation (relative risk 1.23 , odds ratio 2.1 ). Treatment with low dose oral sotalol abolished this increased risk. There were no significant differences between both age groups. 


\section{DISCUSSION}

The main findings of the present study are that more than $50 \%$ of the cardiac surgery patients below 75 years of age and more than $65 \%$ of those above this age have one or more (relative) contraindications for $\beta$-blocking drugs. This may have important implications for the routine use of $\beta$-blockers to prevent postoperative atrial fibrillation. It appeared that postoperative atrial fibrillation occurs in the majority of patients, and that oral sotalol in a very low dose can reduce the incidence atrial fibrillation by more than $50 \%$. Finally, postoperative atrial fibrillation was statistically associated with a prolonged hospital admission period.

\section{STUDY DESIGN}

The main purpose of this study was to quantify the incidence of contraindications for $\beta$-blocking agents in cardiac surgery patients with special emphasis on the growing, elderly population. Since the average age of cardiac surgery patients is increasing, management and/or prevention of postoperative complications becomes more important. Risk-stratification of postoperative morbidity is mandatory for a realistic cost-benefit analysis in the era of decreased hospital resources and increasing age of cardiac surgery patients. Therefore the eldery patient population above 75 years of age was arbitrarily chosen as the primary study group. It should be realized that also this elderly study group represents a selected group of older patients with a relatively low risk profile regarding postoperative comorbidity and mortality. For age-related comparison a group of patients younger than 75 years of age was selected perfectly matching the eldery group as far as gender and surgicall procedure were concerned. Only in this way differences in incidence of contraindications for $\beta$-blockers, postoperative atrial fibrillation or hospital admission time could be studied in relation to age and type of surgery. It should be emphasized that because of this matching procedure the Young patient group did not represent the normal population of cardiac surgery patients below 75 years of age which usually contains more coronary artery bypass grafting procedures and relatively more male patients than in our matched group.

The preoperative screening data including contraindications for $\beta$-blockade were not explicitly presented to the attending physicians when deciding upon the postoperative administration of low dose oral sotalol. The use of low dose sotalol was not directed by a study protocol. In this way the impact of contraindications on the use of low dose sotalol in daily practice could be investigated. This represents the 'real life' scenario as seen in most hospitals and gives us the real incidence of 
atrial fibrillation as well as the clinical handling of contraindications for B-blockers.

Our detection criteria for postoperative atrial fibrillation were very strict. Each episode of atrial fibrillation was considened, regardless of its duration or clinical significance. To our opinion both the occurrence of nonsustained and persistent atrial fibrillation is an indicator for the presence of a pathoelectrophysiologic substrate for this arrhythmia. In other studies various AF detection criteria were applied including minimal AF durations between 16 seconds and 60 minutes, $11-14$. This may explain why reported incidences of postoperativa atrial fibrillation differ so widely.

\section{ATRIAL FIBRILLATION POST CARDIAC SURGERY}

The pathophysiological mechanisms responsible for postoperative atrial fibrillation remain unclear. Surgical trauma of the right auricle due to venous cannulation or the occurrence of postoperative sterile pericarditis may play an important role in the development of postoperative atial fibrillation. Also age-related tissue fibrosis, eventually in relation. with hypertensive heart disease or perioperative atrial ischemia, has been postulated as a substrate for increased atrial vulnerability 17: 18. Furthermore, an increased adrenergic tone due to periand postoperative stress or an elevated circulatory volume causing increased atrial wall stretch and ANF release might be important factors in the development of postoperative atrial fibrillation. Frost et al. found an increased incidence of atriall ectopy and an elevated mean heart rate in the hours preceding the onset of atrial fibrillation post $C A B G{ }^{19}$. This may explain the benificial effect of $\beta$-blocking agents.

Atrial fibrillation post cardiac surgery has also been associated with several clinical or peri-operative risk factors. Age, male gender, systemic hypertension, intra-aortic balloon pumping, postoperative pneumonia, prolonged postoperative ventilation and repeated or valvular surgery all have been identified as independent risk factors $5 ; 9$. Page et al. found a $25 \%$ AF incidence after coronary surgery and an $80 \%$ incidence after walvular procedures 20 . Lowe et al. reported a $36 \%$ incidence of postoperative atrial fibrillation 21 . In general, the conclusions from these studies were confirmed by the present findings. The fact that we found higher incidences of postoperative atrial fibrillation than in most other studies can be explained by the criteria used. We included each episode of AF, no matter its duration, and no matter its clinical significance.

\section{CONTRAINDICATIONS FOR B-BLOCKERS}

Several studies have shown that $\beta$-adrenergic blocking agents may reduce or prevent the occurrence of postoperative atrial fibrillation. Therefore routine treatment with $\beta$-blockers post cardiac surgery is recommended if contraindica- 
tions are absent. To the best of our knowledge the present literature does not provide systematic data on the incidence of contraindications for $\beta$-blocking agents in cardiac surgery patients and how these affect the routine use of $\beta$-blockers in daily practice.

Interestingly, we found that more than half of the Young and two third of the Old patients had at least one contraindication for treatment with $\beta$-blocking agents. In addition, patients of 75 years or older had more often multiple contraindications than the younger patients. This indicates that a considerable number of patients are no good candidates for prophylactic treatment with $\beta$-blockers. Therefore the efficacy of the lowest recommended dosage of sotalol is very interesting. Although the number of patients actually treated with low dose sotalol in our institution was somewhat higher than the number of patients free of contraindications, a considerable amount of patients remained unprotected against postoperative atrial fibrillation. In daily practice a number of patients with contraindications still received low dose sotalol without problems. Therefore, routine use of low dose sotalol in all patients irrespective of contraindications might turn out to be a safe and effective approach. Future studies are required to evalluate the risks and adverse effects of low dose sotalol in patients with relative contraindications for $\beta$-blocking agents and the feasibility of standard low dose sotalol use irrespective of contraindications.

\section{THE EFFECTS OF $\beta$-BLOCKERS ON POST SURGERY ATRIAL FIBRILLATION}

The prophylactic use of drugs to reduce the incidence of postoperative atrial fibrillation has been advocated by several authors. A meta-analysis by Kowey et al. ${ }^{12}$ revealed that $\beta$-blockade significantly reduces the incidence of clinically important atrial fibrillation from $20.2 \%$ to $9.8 \%$. This prophylactic action also appeared from a meta-analysis by Andrews et al. ${ }^{8}$. In other studies the efticacy of sotaloI was only evaluated for CABG $11 ; 15 ; 22 ; 23$. Janssen et al. showed that moderately high dosages of sotalol ( $80 \mathrm{mgr}$ t.i.d.) were significantly more effective than metoprolol ( 50 mgr t.i.d) in preventing postoperative atrial fibrillation ". This clifference was attributed to the additionall class III effects of sotalol. Suttorp et al. showed that even lower dosages of Sotalol ( $40 \mathrm{mgr}$ t.i.d.) were equally effective but with significantly less side effects $15 ; 16$. We showed that further lowering of the dosage of sotalol did not affect its efficacy both in younger and elderly patients.

\section{THE VALUE OF PREVENTING ATRIAL FIBRILLATION POST CARDIAC SURGERY}

The occurrence of atrial fibrillation after cardiac surgery has several consequences for postoperative management and recovery. One of the most important associations is the lenghtening of postoperative in-hospital stay ${ }^{9}$. However, 
these studies did not discriminate between different types of surgery or age groups. In patients younger than 75 years of age we found a similar increase in hospital admission length in the presence of postoperative $\mathrm{AF}$ as reported by others. However, in the elderly this difference was much less ( 2 versus 5 days). This might be explained by a higher degree of comorbidity than in Young patients or by a prolonged admission due to elderly related social or rehabilitation problems. It furthermore appeared that postoperative hospital stay shortened the most if no postoperative atrial fibrillation occurred in patients who underwent valvular surgery. In the $\mathrm{CABG}$ group the difference was only 1-2 days depending on the age group. It should be emphasized though that the statistical association between postoperative hospital admission length and the occurrence of postoperative atrial fibrillation does not implicate any causal relationship between these variables.

\section{STUDY LIMITATIONS}

The total number of patients included in the present study was sufficient to answer the primary study questions for patients with $C A B G$, valvular or combined coronary/valvular surgery. The number was too low for further differentiation between various type of valvular surgery (aortic valve, mitral valve or both; replacement or repair). Another limitation is that the duration and frequency of individual episodes of atrial fibrillation were not assessed. This could have answered the question in how many patients low dose sotalol only reduced the number and duration of postoperative episodes of atrial fibrillation without completely eliminating the arrhythmia.

\section{CONCLUSIONS}

The present findings demonstrate that contraindications for $\beta$-blockers are present in more than $50 \%$ of all patients having cardiac surgery, with a trend to a higher incidence in the elderly. Low dose sotalol ( $40 \mathrm{mgr}$. b.i.d.) prevents postoperative atrial fibrillation in more than $50 \%$ of the cases. This reduction was associated with a 5 day shortening of postoperative hospital stay in young patients, but only 2 days in the elderly. Given the high number of patients with relative contraindications for $\beta$-blockade, we conclude that new the rapies might be required to prevent post cardiac surgery atrial fibrillation. On the other hand, low dose sotalol might be used without causing serious adverse effects in the majority of patients with general contraindications for $\beta$-blockade. Future placebo-controlled studies are necessary to study this hypothesis. 


\section{ACKNOWLEDGEMENTS}

We thank the cardiosurgical staff including T. Elenbaas, G. Geskes, J. Maessen and P. Barenbrug for their contribution in this study. We are most gratefull to the carchiothoracic intensive care staff and nurses who provided us with the required study data.

\section{REFERENCES}

1. Kannel WB, Abbott RD, Savage DD, McNamara PM: Epidemiologic features of chronic atrial fibrillation: the Framingham Study. N Engl J Med. 1982;306:1018-22

2. Creswell LL, Schuessler RB, Rosenbloom M, Cox JL: Hazards of postoperative atrial. arrhythmias. Ann Thorac Surg. 1993,56:539-49

3. Hashimoto K, Ilstrup DM, SchaffHV: Influence of clinical and hemodynamic variables on risk of supraventricular tachycardia after coronary artery bypass. J Thorac Cardiovasc Surg. 1991;101:56-65

4. Leitch JW, Thomsen D, Baird DK, Harris PI: The importance of age as a predictor of atral fibrillation and futter after coronary artery bypass grafting. I Thorac Cardiovase Surg. 1990; $100: 338-42$

5. Ommen SR, Odell JA, Stanton MS: Atrial arthythmias after cardiothoracic surgery [published erratum appears in N Engl I Med 1997 17;337(3):209]. N Engl J Med 1997 $15,336: 1,429-34$

6. Talajic $M$, Lemery $\mathbb{R}$, Roy D, Pelletier LC: Management of arrhythmias in the postbypass patient. Cardiovase Clin 1991;21:211-26

7. Wellens HJ]: Atrial fibrillation its consequences., in Kulbertus HE, Wellens HJJ, Bour geois I, Sutton R (eds): Atrial fibrillation: facts from yesterday, ideas for tomorrow. Armonk, NY, Futura Publishing Comp Inc, 1994, pp 57-71

8. Andrews TC. Reimold SC, Berlin IA, Antman EM: Prevention of supraventricular arthythmias after cononary artery bypass surgery. A meta-analysis of randomized control crials. Circulation 1991;84:111236-44

9. ArankiSF, Shaw DP, Adams DH, Rizzo RJ, Couper RJ, Van der Vhet M, Collins JIr, Cohn LH. Burstin HR: Predictors of atrial fbrillation after cononary artery surgery: Current trends and impact on hospital resources. Circulation 1996;94:390-97

10. Chidambarm M, Akhtar MI. Al-Nozha M. Al-Saddique A: Relationship of arrial fibrillation to significant pericandial etfusion in valve-teplacement patients. Thorac Cardiovase Surg $1992 ; 40: 70-3$

11. Janssen J, Loonans L, Harink J, Taams $M$, Brumninkhuis L, Starte wd P, Kootstra $G$ : Prevention and treament of supraventricular tachycardia shortly after coronary artery bypass grafing: A randomized open trial. Angiology. 1986,37:601-9

12. Kowey PR. Taylor JE, Rials SJ, Marinchak RA: Meta-analysis of the effectiveness of prophylactic dug therapy in preventing supraventricular arthythmia early after coronary artery bypass grafting. Am J Cardiol 1992;69:963-5 
13. Pfisterer M, Kloeter-Weber UCD, Huber M, Osswald S, Buser P, Skarvan K, Stule P: Prevention of supraventricular tacyarhythumas after open heart operation by low-dose sotalol: a prospective, double-blind, randomized, placebo-controlled study. Ann Thorac Surg 1997;64:1113-9

14. Sitverman NA, Wright R, Levitsky S: Efficacy oflow-dose propranolol in preventing postoperative supraventricular tachyarthythmias. Ann Surg 1982;196:194-7

15. Suttorp MJ, Kingma JH, Peels HOJ, Koomen EM, Tijsen JGP, Van Hemel NM, Defauw JAM, Ernst SMPG: Effectiveness of sotalol in preventing supraventricular tachyarthythmias shortly after coronary artery bypass grafting. Am I Cardiol $1991 ; 68: 1163-9$

16. Suttorp M], Kingma JH, Gin MT], Van Hemel NM, Koomen EM, Defauw IAM, Adan AJM, Enst $S M P G$ : Efficacy and safety of low- and high-dose sotalol versus propranolol in the prevention of supraventricular tachyarrluythmias early after cononary artery bypass operations. I Thorac Cardiovasc Surg 1990;100:921-6

17. Cox JL: A perspective of postoperative atrial fibrillation in cardiac operations. ANN Thorac Surg 1993;56:405-9

18. Sato $S$, Yamauchi $S$, Schuessler RB, Boineau JP, Matsunaga $Y, C o x J L$ : The effect of augmented atrial hypothemia on atrial refractory period, conduction, and atrial flutter/fibrillation in the canine heart. J Thorac Cardiovasc Surg 1992:104:297-306

19. Frost $\mathbf{L}$, Jacobsen CJ, Christiansen EH, Molgaard H, Pilegatard H, Hjortholm $\mathrm{K}$, Thomsen PE: Hemodynamic predictors of atrial fibrillation or flutter affer coronary artery bypass grafting. Acta Anaesthesiol Scand. 1995,39:690-97

20. Page PL, Pym J: Atrial fibrillation following cardiac surgery. Can J Cardiol 1996;12 Suppl A:40A-44A.

21. Lowe JE, Hendry PJ, Hendrickson SC, Woll KR: Intraoperative identification of cardiac patients at risk to develop postoperative atrial fibrillation. Ann Surg 1991:213: 388-92

22. Nystrom U, Edvardsson N. Berggren $H$, Pizzarelli GP, Radegran K: Oral sotalol reduces the incidence of atrial fibrillation after coronary artery bypass surgery. "Thorac Cardiovasc Surg 1993:41:34-7

23. Weber UK, Pfisterer M. Osswald $S$, Huber M, Buser P, Stulz P. Low dose sorallol to prevent supraventricular arthythmias after CABG surgery and its effects on hospital stay. JACC 1996:27:309A 
CHAPTER 7

\section{Comparison of quality of life after coronary and/or valvular cardiac surgery in patients $\geq 75$ years of age to younger patients}

Jan A Heijmeriks", MD, Salima Pourrier", MS, Pim Dassen", PhD, Kees Prengert, MD, Hein JJ Wellens*, MD.

Department of Cardiology and Cardiothoracic Surgery $\$$, Academic Hospital, Maastricht, the Netherlands

Published in "American Journal of Cardiology. 1999; 83(7): 1129-32". 
Contemporary studies have indicated that open heart surgery in elderly patients can be performed with a low mortality rate ${ }^{1-5}$. However only limited information is available about the quality of life following different types of open heart surgery in elderly as compared to younger patients. The effect of cardiac surgery on quality of life was studied prospectively in 200 elderly patients aged $\geq 75$ years and 400 younger patients.

During a period of $3 \frac{1}{4}$ years, starting September 22, 1993, until December 18 , 1996. we included 200 patients who underwent open heart surgery, and were 75 years or older (Older group, mean age $=78$, range 75-91). Each of these patients was matched with 2 patients $<75$ years. (Younger group, mean age $=65$, range 35-74), having the same operative procedure, and being of the same sex (table 1). Sixty-six \% had coronary surgery, the remaining patients had valvular surgery (18\%) or combined coronary and valvular surgery (16\%). Fifty-four \% of all patients were female. The median follow-up duration of the surviving patients was 31 months and ranged from 12 to 52 months.

To evaluate quality of life, two tests were selected with a limited number of questions, easy to respond in a short time by the patient, but covering various aspects like mood, social functioning and physical condition. The first one is the Hospital Anxiety and Depression scale (H.A.D., after Zigmund and Snaith, 1983)6,7 of which an official Dutch translation is available. This questionnaire has 14 multiple choice questions dealing with anxiety and depressive complaints, with a range from $0-21$. A higher number means a worse score for that item. The second is the Nottingham Health Profile (N.H.P., after Hunt, McKenna, 1981) ${ }^{899}$, of which a Dutch translation exists since 1993. The first part of this questionnaire has six main items, consisting of energy, pain, emotional reactions, sleep, social isolation, and physical mobility, with a total number of 38 questions, that can all be answered by filling out A "yes" or "no". The range for this scale is from $0-100$. Also here a higher number means a worse score for that item. Part 2 of the NHP has seven questions concerning limitations in daily activities (work, housekeeping, social contacts in/outside home, sexual activity, hobbies and recreational activities). These items were put together into a sum score (range 0-7), in which a higher score means a higher limitation of social activities.

Both questionnaires were filled out by the patient 1) one day before surgery, 2) two months after surgery, and 3) six months after surgery. The time that is needed to fill out these questionnaires varies between 5 and 15 minutes.

Several studies have shown that these questionnaires are suitable for serial comparison, and have been useful in showing changes of quality of life after surgery. Validation studies have also been performed of the Dutch version of these questionnaires. $10 ; 11$ 
Table 7.1. Type of surgeny in the patients studied.

\begin{tabular}{|c|c|c|c|c|}
\hline & \multicolumn{4}{|c|}{ Age group } \\
\hline & \multicolumn{2}{|c|}{ Young } & \multicolumn{2}{|l|}{ old } \\
\hline & $\mathrm{Nb}$ & $\%$ & $\mathrm{Nb}$ & $\%$ \\
\hline CABG & 262 & $65.5 \%$ & 131 & $65.5 \%$ \\
\hline klep & 72 & $18.0 \%$ & 36 & $18.0 \%$ \\
\hline CABG+valve & 66 & $16.5 \%$ & 33 & $16.5 \%$ \\
\hline Total & 400 & $100.0^{\circ}$ & 200 & $100.0 \%$ \\
\hline
\end{tabular}

Abbreviations: $C A B G=$ coronary artery bypass grafting: $N b=n u m b e r$

At the end of the follow-up period (median 31 months) 161 Younger and 83 Older randomly selected patients from the study population were asked by telephone about their subjective opinion concerning the final surgical outcome. These results were graded into three categories: 1) patients felt better compared to before the operation, 2) patients without change in well-being, 3) patients who experienced permanent worsening after the operation.

Elderly patients ( 275 years) referred for coronary surgery had nore often 3-vessel disease $(81.7 \%$ vs. $66.3 \%)$, a higher incidence of severe left main stenosis $(13.7 \%$ ws. $7.7 \%$ ) and more often reported angina in rest $(69 \%$ ws. $56 \%$ ). The incidence of hypercholesterolemia $(24.7 \%$ versus $37.9 \%, P=0.002)$ and smoking $(13.8 \%$ wersus $24 \%, P=0.001$ ) was clearly lower in the elderly. This might explain why the onset of coronary insufficiency is on a more advanced age. No differences. were seen in renal function, $L \mathrm{~V}$-ejection fraction, pulmonary function. In elderly patients referred for valvular surgery a higher incidence of diabetes mellitus $(15.9 \%$ versus $12.3 \%)$, and a lower incidence of treated hypertension $20.3 \%$ versus $33.3 \%$ was found. Elderly patients had a higher incidence of urgent surgery $(53.0 \%$ versus $43.5 \%, p<0.05)$. This was defined as surgery during the sane hospital admission as the cardiac catheterisation.

The unpaired t-test was used to demonstrate differences in Interval variables between both age groups. For nominal variables chi-square analysis of contingency was used. In case of ordinal variables the Mann-Whitney rank-sum test was performed. To demonstrate changes in each treatment group after surgery the paired $t$-test was used for interval variables, McNemar"s test for nominal variables and Wilcoxon signed rank test for ordinal variables. A P-value $<0$. 05 was considered statistically significant. Analyses were conducted using SPSS for Windows, release 8.0 (OSPSS Inc, Chicago, lllinois.)

The hospital mortality (defined as mortality within 30 days following surgery) was 22 patients (5.5\%) in the Younger and 9 patients $(4.5 \%$ ) in the Older group $(P=$ n.s.). The one-year mortality (including hospital-mortality) was 32 patients (8.0\%) in the Younger and 15 patients $(7.5 \%$ in the Older group ( $P=11.5$.$) .$ 
Table 7.2. Hospital Anxiely and Depression Scale \& Nottingtham Health Profile*. All data are mean standard deviation. P-values represent differences to pre-operative values.

\begin{tabular}{|c|c|c|c|c|c|c|}
\hline & \multicolumn{3}{|l|}{ Young } & \multicolumn{3}{|l|}{ old } \\
\hline & Pre-gp & 2 months & 6 months & Prem & 2 monttis & 6 montins \\
\hline Anmety & $8.24+4.45$ & 5.46424 .28 & $5.91+4.61=$ & $7.65+4,4.0$ & $4.88 \pm 3.73^{* 2 x}$ & $5.15 \pm 4.13^{* * *}$ \\
\hline Depression" & 6.4423 .99 & $5.07 .4 .399^{*}$ & $5.26 \pm 4.54$ & $6.63 \pm 4.41$ & $5,37 \pm 4.45 \%$ & $5.19 \pm 4.36^{* *}$ \\
\hline Emargy & $48.5+40.4$ & $24.4+33,9^{-1}$ & $24.8 \pm 34.5 * *$ & $44.3 \pm 39.1$ & $27.9 \pm 34.0^{* * x}$ & $26.2 \pm 35.0^{\text {min }}$ \\
\hline Emot reactions & $29.1 \pm 25.8$ & $15 \cdot 1+21.9^{-2 x}$ & $16.9 \pm 23.1^{*}$ & 27.4125 .9 & $15.7 \pm 22.2^{m-x}$ & $16.6 \pm 22.7^{* x}$ \\
\hline Porin & $23.2 \pm 24.8$ & $14.9 \pm 23.2^{*}$ & $12.8 \pm 20.5^{* * *}$ & $22.8 \pm 23.2$ & $12.3 \pm 20.4^{* *}$ & $16.2 \pm 23.0^{* k}$ \\
\hline Slegpt & $4.3 .4 \pm 33.7$ & $35.2 \pm 34.8^{* \text { * }}$ & $32.3 \pm 33.8^{*}$ & $448 \pm 35.8$ & $33.5 \pm 35.6^{\text {tk }}$ & $33.3 \pm 37.3^{* * *}$ \\
\hline Sinciat isotarion* & $10.5 \pm 19.5$ & $6.54 \pm 15.3 *$ & $8.91: 19.3$ & $11.0 \pm 17.6$ & $8.70 \pm 17.6$ & $6.67 \pm 15.5^{*}$ \\
\hline Physical molbility & $30.8 \pm 27.1$ & $17.2 \pm 22.7^{* * 2.2}$ & $16.623 .3^{* k *}$ & $35.9 \pm 26.6$ & $23.9 \pm 24.2^{\# x}$ & $25.0 \pm 25.0^{* *}$ \\
\hline Dabily artivities." & $2.81+1.9$ & $1.71+1.89^{6 * x}$ & $1.53+1.85^{* * *}$ & $2.40+1.8$ & $1.59 \pm 1.7^{*}$ & $1.42 \pm 1.76^{* * *}$ \\
\hline
\end{tabular}

*P<0.05, "** P $<0.01$, * * $P<0.001$

The quality of life questionnaires were filled out 2 and 6 months following surgery by $352 / 373(94.3 \%)$ surviving Younger patients and 170/188 (90.4\%) surviving Older patients. Both groups showed a significant improvement of anxiety and depression scores two months following surgery. No significant changes were seen in the time between 2 and 6 months following surgery (figure 1). Patients who had pre-operative signs of depression (HAD score $\geq 12, n=44$ ) had the same 1-year mortality $(6.9 \%)$ in both age groups as patients without depression (7.9\%, $P=$ n.s.). However, general well-being at a median follow-up time of 32 months was less if signs of pre-operative depression were present, especially in the Older group (figure 2). There were no significant differences in NYHA class 6 months following surgery between depressed (76\% improvement) and non-depressed patients ( $81 \%$ improvement).

All items of the NHP except social isolation showed a clear improvement in the two months following surgery, with again no significant changes in the period between 2 and 6 months following surgery (table 2). Symptoms of social isolation before surgery were very mild in both age groups. This may explain why there are only minimal changes for that variable after surgery. Both groups showed a similar improvement of daily activities 2 months following surgery, as measured in part 2 of the NHP, which further improved 6 months following surgery. Younger patients had pre-operatively more lumitations in social activities, due to the fact that elderly patients had usually retired from working.

Questioning by telephone at the end of the follow-up (12-52, median 31 months) revealed a clear improvement of general well-being in $73.3 \%$ Younger and $69.9 \%$ Older patients. This includes depressed and non-depressed patients. No differences in well-being compared to before the operation were present in $13.7 \%$ Young and $15.7 \%$ Old patients, and a worsening of general well-being following surgery was present in $13.0 \%$ Younger and $14.5 \%$ Older patients $(P=\mathrm{ns.s}$ ). 
mean H.A.D. scores

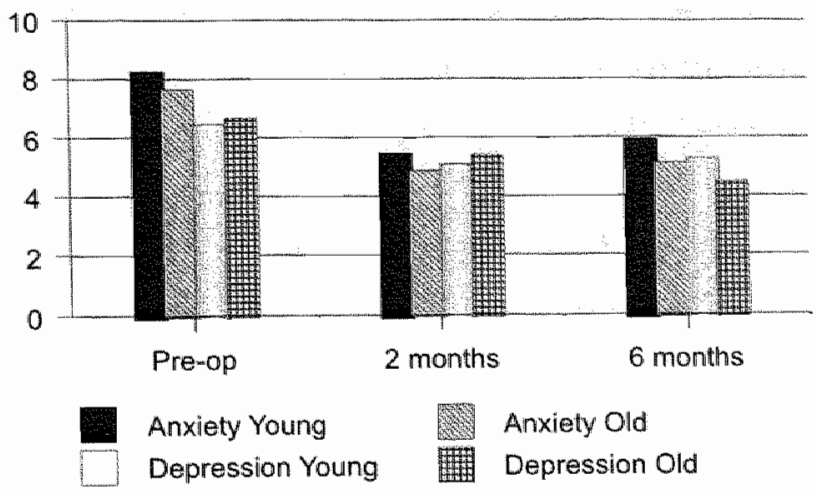

Figure 7.1. Hospital Anxiety and Depression scale.

\section{General well-being}

Young, No depression

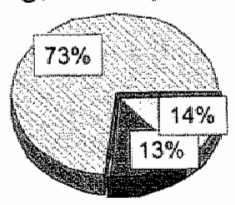

Old, No depression

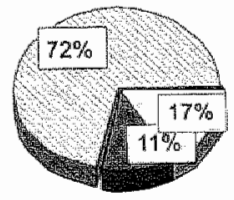

Improved

Worsened
Young, Depressed

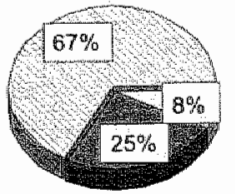

Old "Depressed

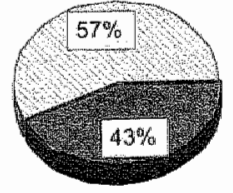

No change

Figure 7,2 . General wellbeing at the end af the follow-up period (range 12-52 months), in comparison to pre-operative situation. 


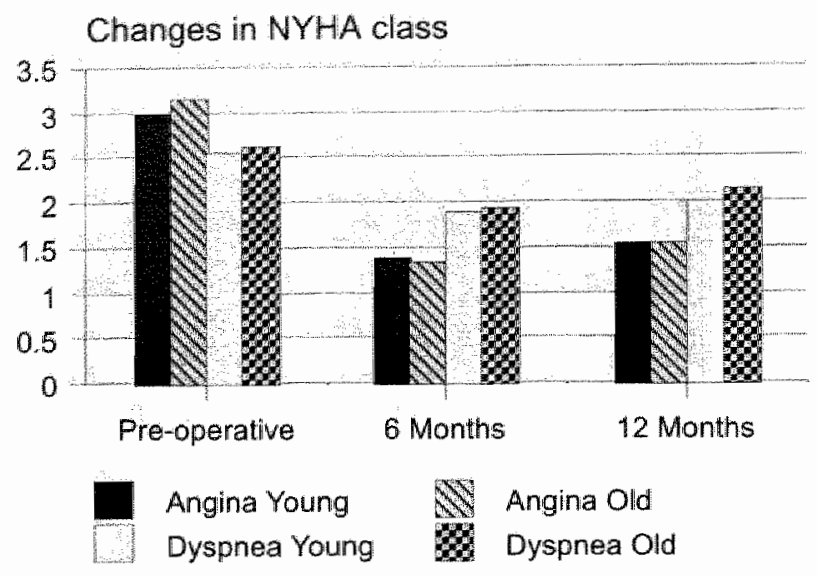

Figure 7.3. Changes in complaints of angina and dyspnea following surgery in both age groups.

Pre-operatively more elderly people had angina at rest compared to young patients $(50.5 \%$ versus $41 \%, P<0.05)$. After six and twelve months following surgery all patients were again asked about anginal and dyspnea complaints. Compared to pre-operative values there was a clear improvement of complaints in both groups $(P<0.001)$ without any differences between the age groups. In the time between 6 and 12 months following surgery a moderate increase in anginal complaints was seen $(P<0.01)$ and to a lesser extent in complaints of dyspnea $(P<0.05)$ in both age groups (figure 3$)$.

In our study we found that although elderly patients had more severe coronary artery disease and more often urgent surgery, their surgical and one-year mortality were identical to younger patients. Both quality of life questionnaires showed improvement in nearly all aspects of quality of life in both age groups. Also relief of anginal and dyspnea complaints were similar in both groups. Several studies have already shown that there is an improvement of quality of life in elderly patients $1: 12-16$. Our study indicates that this improvement is independent of the age of the patient.

Some studies suggest that pre-operative signs of depression are predictive for a worse outcome following cardiac surgery $17-19$. We found that the mortality and NYHA class were identical in depressed and non-depressed patients. However the subjective signs of general well-being were worse in elderly depressed patients.

In conclusion there is a definite improvement in quality of life following cardiac surgery, which is independent of the age of the patient. 


\section{REFERENCES}

1. Chocron S, Rude N, Dussancy A, Leplege A, Clement F, Alwan K, Viel]F, Etievent]p: Quality of life after open-heart surgery in patients over 75 years old. Age Ageing $1996 ; 25: 8-11$.

2. Deiwick M, MollhoffT, Budde $T$, Scheld HH: Cardiac surgery in patients aged 80 years and above: does outcome justify significant perioperative morbidicy? Cardology in the Elderly 1995;3:381-386

3. KatzNM, Hannan RL, Hopkins RA, Wallace RB: Cardac operations in patients aged 70 years and over: mortality, length of stay, and hospital charge. Ann Thort Surg $1995 ; 60: 96-100$

4. Shah VZ, Rosenfeldr FL, Parkin GW, Ugoni AM, Habersberger PG, Cooper E: Cardiac surgery in the very elderly. Med I Aust 1994;160:332-334

5. Subayi JB, de Brux JL, Delhumeau A, Lotfi N, Moreau X, Cottineau C, Bukowski JG, Corbeau J], Pillet ]: [Cardiac surgery in aged patients; immediate and medium-tem results in 100 patients over 75 years of age] Chirurgie cardiaque chez les parients ages; resultats immediats et a moyen teme chez 100 patients ages de 75 ans et plus. Ald Mal Coetr Vaiss 1994;87:1671-1677

6. Snaith P: Measuring anxiety and depression. Pwotitioner. 1993;237:554-559

7. Zigmund AS, Snaith RP: The hospital anxiety and depression scale. Acta Psydiatr Scand $1983 ; 67: 361-370$

8. Hunt SM, Mc Kenna SP, Mc Ewen J, Williams J, Papp E: The Nottingham health profile: Subjective health status and medical consultations. Sor So Med 1981;15A: $221-229$

9. Jenkinson $C$, Fitzpatrick $\mathbb{R}$, Argyle $M$ : The Nottingham health profile: an analysis of its sensitivity in differentiating illness groups. Sor Soi Med 1988;27:1411-1414

10. Spinhoven P, Ormel J, Sloekers PP, Kempen GI, Speckens AE, Van Hemert AM: A validation study of the Hospital Anxiety and Depression Scale (HADS) in different groups of Dutch subjects. Ps 5 chol Med 1997;27:363-370

11. Erdman RA, Passchier J, Kooijman M. Stronks DL: The Dutch version of the Notringham Health Profile: investigations of psychometric aspects. Psolol Rep $1993 ; 72: 1027-1035$

12. Bunzel B, Eckersberger F: Changes in life quality after aortocoronary bypass and valve replacement: A subjectiwe criterion for assessing operative results. Thorac Cardiowas Sugy $1987 ; 35: 242-247$

13. Caine N, Harrison SC, Sharples LD, Wallwork J: Prospective study of quality of life before and after coronary artery bypass grafting. BMJ 1991,302:511-516

14. Chocron S, Etiewent JP, Viel JF, Dussaucy A, Clement F, Alwan K, Neidhardt M, Schipman N: Prospective study of quality of life before and after open heart operations. Am Thord Surg 1996:61:153-157

15. Kumar P, Zehr KI, Chang A, Cameron DE, Baumgartner WA: Quality of life in octogenarians after open heart surgery. Ches 1995;108:919-926 
16. Olsson $M$, Janfjall $H$, Orth-Goner $K$, Unden $A$, Rosenqvist $M$ : Quality of life in octogenarians after valve replacement due to aortic stenosis. A prospective comparison with younger patients. Eur Heart J $1996 ; 17: 583-589$

17. Oxman "TE, jreman $\mathrm{DH}_{\text {, }}$ Jr, Manhemer ED: Lack of social participation or religious strength and confort as risk factors for death after cardiac surgery in the elderly. Psychosom Med 1995,57:5-15

18. Loma $\mathrm{Cay} \mathbb{E}_{\text {, Rourke }} \mathrm{O}^{\prime} \mathrm{A}$ : The emotional state of patients after coronary bypass surgery, in Walter PJ (ed): Quality of Life after Open Hean Surgery. Kluwer Academic Publishers; 1992, pp 177-183

19. Duits AA, Boeke S, Taams MA, Passchier J. Erdman RA: Prediction of quality of life after cononary antery bypass graft surgery: a review and evaluation of multiple, recent studies. Psychosom Med 1997,59:257-268 
CHAPTER 8

\section{The incidence and consequences of mental disturbances in elderly patients post cardiac surgery}

A comparison with younger patients

J.A. Heijmeriks", W. Dassen *, K. Prengert , H.J.J. Wellens"

Depiartment of Cardiology * and of Cardiopulmonary surgery'

Academic Hospital, Maastricht, the Netherlands.

P.0. Box 5800,6202 AZ Maastricht, The Netherlands

Accepted for publication, Clinical Cardiology (2000). 


\section{ABSTRACT}

Background: Limited data exists about the incidence and consequences of mental confusion following open heart surgery in different age groups. Also little is known about pre-operative predictors of mental confusion.

Methods: Two-hundred consecutive patients, aged 75 years or more (old group), and four-hundred procedure and gender-matched younger patients (Young group) who underwent coronary or valvular surgery were included in a prospective study. The relation between postoperative mental confusion, mortality, morbidity and quality of life were studied.

Results: Mental confusion was present in $11.8 \%$ Young and $22.6 \%$ old patients. The incidence was higher after valvular surgery. Pre-operative risk factors in 0ld patients were: Diabetes Meltitus, a history of heart failure, weak carotid pulsations and a re-operation. Late mortality, after a median follow-up duration of 31 months, was significantly worse in patients that were confused, which was related to the underlying disease. Recovery of quality of life was clearly diminished in ellderly patients with confusion in contrast to younger patients.

Conclusion: Postoperative mental confusion has a high incidence in the elderly population, and is associated with a diminished quality of life.

\section{CONDENSED ABSTRACT}

The incidence of postoperative mental confusion was prospectively studied in 200 subsequent patients $\geq 75$ years and 400 procedure and gender matched younger patients undergoing open heart surgery. Mental confusion was present in $22.6 \%$ of the older and $11.8 \%$ of the younger patients. Preoperative riskfactors were: valvular surgery, diabetes, heart failure, weak carotid pulsations and re-operation. Mental confusion was associated with a diminished recovery of quality of life, and a higher late mortality rate. 


\section{INTRODUCTION}

It is well known that elderly people are more prone to develop mental confusion after a surgical procedure, which is also called the postoperative delirium syndrome. Only limited data exists about the incidence and the predisposing factors of mental confusion after open heart surgery in different age groups. Pre-operative screening with the "Mini Mental State Exam" appeared to be of no value in predicting which patient will develop mental confusion. ${ }^{1}$ Also the consequences of mental confusion on the final outcome of the procedure including quality of life have not been studied so far.

In order to investigate the incidence and outcome of patients developing mental confusion after open heart surgery we performed a prospective study in 200 consecutive patients of 75 years or older, and 400 younger patients.

\section{MATERIALS AND METHODS}

In order to investigate the incidence of mental confusion following cardiac surgery in elderly patients as compared to younger patients we designed a prospective observational study. During a period of $31 / 4$ years, starting September $22^{\text {nd }} 1993$ until December $18^{\text {th }} 1996$ we included 200 patients who underwent open heart surgery, and were 75 years or older (Old group, range 75-91 years, median $=77.3$ years). Each of these patients were matched with two patients less than 75 years ( $Y$ oung group, range $35-74$ years, median $=66.5$ years), having the same operative procedure, and being of the same sex. The data analyzed include medical data, information about admission duration, and assessment of the quality of life. The follow up duration of all surviving patients was at least one year. All patients were operated upon in the Academic Hospital of Maastricht (Department of Cardio Thoracic surgery). Two-third of all patients had cononary surgery, the others having valvular or combined valvulat and coronary surgery (table 1).

Mental confusion following surgery was defined as a mental state in which the patient had signs of disorientation in time, place or person, with or without hallucinations. The incidence of mental confusion was registered from the first day following surgery until discharge from hospital. It's appearance however, was nearly always in the first days following surgery, and the duration of symptoms varied between 1 and 7 days. All patients were mentally healthy and not confused prior to surgery.

Quality of life assessment was done using the Dutch version of the Nottingham Health Profile (NHP) $)^{2-4}$ and the Hospital Anxiety and Depression scale 


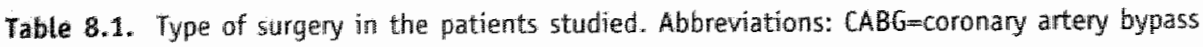
grafting; Nbmumber.

\begin{tabular}{|c|c|c|c|c|}
\hline & \multicolumn{4}{|c|}{ Age group } \\
\hline & \multicolumn{2}{|c|}{ Young: } & \multicolumn{2}{|l|}{ old } \\
\hline & $\mathrm{Nb}$ & $\%$ & $\mathrm{Nb}$ & $\%$ \\
\hline CABG & 262 & $65.5 \%$ & 131 & $65.5 \%$ \\
\hline klep & 72 & $18.0 \%$ & 36 & $18.0 \%$ \\
\hline CABG+valve & 66 & $16.5 \%$ & 33 & $16.5 \%$ \\
\hline Tatal & 400 & $100,0 \%$ & 200 & $100.0 \%$ \\
\hline
\end{tabular}

(HAD $)^{5-7}$. These questionnaires were filled out by the patient one day before surgery, and repeated two and six months following surgery.

Data recorded from the clinical history included: cardiac risk factors (smoking, hypercholesterolemia, diabetes mellitus, hypertension), presence of an old or recent myocardial infarction ( $<2$ months old), history of congestive heart failure, previous cardiac operation, history of non-cardiac atherosclerotic vascular disease (cerebral, peripheral, kidney), history of arrhythmias, hypertension, chronic obstructive pulmonary disease and medication use.

An echocardiogram was performed one day prior to surgery to evaluate left ventricular function and the hemodynamic status of the patients.

\section{OPERATIVE PROCEDURE}

The operative technique included a standard median sternotomy, and routine aortic and right atrial canulation.

Data was collected on type of surgery, first or re-operation, use of intra-aortic balloon pump (JABP), quantity and type of grafts (arterial, venous), quality of vein grafts and native vessels, types of valve surgery (mechanical, biological, or reconstruction).

\section{ANESTHESIA AND MYOCARDIAL PERFUSION DURING SURGERY}

Standard anesthetic (lorazepam, fentanyl citrate, sufentanil citrate, alfentanil hydrochloride, midazolam hydrochloride, pancuronium bromide) and monitoring techniques (electrocardiogram, central venous/pulmonary and arterial pressure monitoring, urinary output, rectal and skin temperature monitoring) were used in both groups.

The main components in the extra corporeal circuit consisted of a hollow fiber membrane oxygenator (Univox; Bentley/Baxter Inc.), a venous reservoir (BMR-1900), a cardiotomy reservoir: William Harvey $\mathrm{H} 4700$ and an arterial line filter. The standard priming of the extra corporeal circuit was $1300 \mathrm{ml}$ Haemaccel $3.5 \%, 200 \mathrm{ml}$ Mannitol 20\%, $100 \mathrm{ml}$ Human-Albumin $20 \%, 50 \mathrm{ml} \mathrm{NaHCO}_{3}$ 
$8.4 \%, 20 \mathrm{ml} \mathrm{KCl} 7.45 \%$ and $6500 \mathrm{IU}$ Heparin Leo. After institution of cardiopulmonary bypass at a flow rate of $2.4 \mathrm{~L} / \mathrm{min} / \mathrm{m}^{2}$, and after reaching a blood temperature below $28^{\circ} \mathrm{C}$, the heart was topically cooled till fibrillation using cold saline $0.9 \%$ at $4^{\circ} \mathrm{C}$. The aorta was then cross clamped and a single dose of approximately $800 \mathrm{ml}$ of St. Thomas I cardioplegic solution at $4^{\circ} \mathrm{C}$ was infused into the aortic root in a period of 4 minutes (3-5 minutes) to provide nyocardial preservation. Topic cooling was maintained during the infusion of the cardioplegic solution. Target flow rates of $2.4 \mathrm{~L} / \mathrm{min} / \mathrm{m}^{2}$ were maintained at normothermia and correspondingly lower rates of $2.0 \mathrm{~L} / \mathrm{min} / \mathrm{m}^{2}(1.8-2.2$ $\mathrm{L} / \mathrm{min} / \mathrm{m}^{2}$ ) were maintained at moderate hypothermia of $28^{\circ} \mathrm{C}$, depending on the venous oxygen saturation and the arterial pressure. Pulsatile perfusion was used throughout the period of aorta cross clamping.

Data was collected about bypass time, aortic cross clamping time, arterial blood pressure, central venous pressure, diastolic pulmonary artery pressure, circulatory arrest time, lowest temperature, lowest hematocrit during perfusion, cardioplegia, venous $\mathrm{O}^{2}$ saturation, and the need for inotropic support, temporary pacing or intra-aortic balloon pumping (IABP) at the end of the procedure.

\section{POSTOPERATIVE COURSE}

Information was collected about mortality and morbidity. "The last one included the need for inotropic support, use of IABP, duration of ventilatory support, occurrence of post operative arrhythmias especially atrial fibrillation or flutter. Data on complications were divided in cardiac complications (infarction, heart failure, conduction disturbances) and non-cardiac complications (e.g. bleeding, infections, renal failure, need for rethoracotomy).

\section{STATISTICAL METHODS}

The Unpaired -test was used to demonstrate differences in Interval variables between both age groups. For Nominal variables Chi-square analysis of contingency was used. In case of Ordinal variables, or in case of no nomal distribution of the interval variables (e.g. Age-group) the Mann-Whitney rank-sum test was performed. To demonstrate changes in each treatment group after surgery the Paired t-test was used for Interval variables, McNemar"s test for Nominal variables and Wilcoxon signed rank test for Ordinal variables. To analyze predictors of mortality Stepwise Logistic regression was performed. Survival analysis was done using the Kaplan-Meier method, with differences calculated using the Log rank test. Analyses were conducted using SPSS for Windows, release 8.0 (OSPSS Inc, Chicago, Illinois.) 


\section{RESULTS}

The overall incidence of mental confusion following surgery in all procedures was $11.8 \%$ in the Young group and $22.6 \%$ in the Old group $(P=0.001)$. As shown in table 2 the incidence was higher in case of valve surgery. 399 Young and 199 Old patients could be analyzed in our study ( 2 patients excluded because of peri-operative mortality).

Table 8.2. Incidence of Mental Confusion following surgery. ( ${ }^{*}$ a bioprosthesis in the mitral position was only implanted in 2 Young and 1 old patient). P-values represent differences in incidence of merital confusion between both age groups. The percentages mentioned refer to the total number of patients in the sub-groups.

\begin{tabular}{lcl}
\hline Mental Confusion & Young & Old \\
\hline Total study group & $47(11.8 \%)$ & $45(22.6 \%)$ \\
Coronary surgery & $29(11.1 \%)$ & $22(16.9 \%)$ \\
Valve surgery & $12(16.7 \%)$ & $11(30.6 \%)$ \\
Combined valve + coronary surgery & $6(9.2 \%)$ & $12(36.4 \%)^{* *}$ \\
Aortic valve (mechanical) & $11(13.3 \%)$ & $10(34.5 \%)^{*}$ \\
Aortic valve (biological) & $2(20.0 \%)$ & $10(37.0 \%)$ \\
Mitral valve (mechanical) & $7(15.9 \%)$ & $5(50 \%)^{*}$ \\
Mitral valve (reconstruction) & $1(8.3 \%)$ & $1(16.7 \%)$ \\
\hline
\end{tabular}

$* P<0.05, * P_{0}<0.01$

Risk factors for mental confusion in elderly people were: prolonged bypass time, aortic cross clamp time, together with increased use of cardioplegic solution and prolonged duration of surgery (table 3 ). Also a lower temperature during perfusion appeared to be a risk factor. In the Young group a prolonged bypass time, a higher diastolic pullmonary artery pressure at the end of surgery and a lower $L V$-ejection fraction were predictors for mental confusion.

Insulin dependent diabetes mellitus was an independent risk factor for mental confusion in both age groups. Non-insulin dependent diabetes mellitus was only a riskfactor in the Old group (table 4 ).

Other pre-operative predictors in elderly patients were: a history of heart failure, presence of weak carotid pulsations and a re-operation (table 5).

A complicated post-operative course resulting in prolonged mechanical ventilation, imotropic support, heart-failure, rethoracotony or acute tubular necrosis was also associated with a higher incidence of mental confusion, especially in the elderly patient (table 5 ). 
Table 8.3. Riskfactors for mental confusion in both age groups.

\begin{tabular}{|c|c|c|c|c|c|c|}
\hline \multirow{2}{*}{\multicolumn{2}{|c|}{ Age group }} & \multicolumn{3}{|c|}{ Confusion } & \multirow{2}{*}{$\begin{array}{l}\text { Std. } \\
\text { Dowation }\end{array}$} & \multirow{2}{*}{$\begin{array}{l}\text { Std Error } \\
\text { Mean }\end{array}$} \\
\hline & & present & $\mathrm{N}$ & Mean & & \\
\hline \multirow[t]{26}{*}{ roung } & Bypass time & Mo & 348 & 101.39 & 47.13 & $2.520^{*}$ \\
\hline & & Yes. & 47 & 115.05 & 44.30 & 6.46 \\
\hline & cross clamp time & No & 347 & 67.73 & 35.49 & 1.91 \\
\hline & & Yes & 47 & 77.43 & 37.75 & 5.51 \\
\hline & Duration of surgery & No & 352 & 201.49 & 72.65 & 3.27 \\
\hline & & Yes & 47 & 220.40 & 60.71 & 8.86 \\
\hline & Cardiop?egic solution (my) & $\mathrm{No}$ & 347 & 943.62 & 4.73 .93 & 25.44 \\
\hline & & Yes & 47 & 1021.28 & 524.27 & 76.47 \\
\hline & Lowest hematocrit during surgery & No & 349 & 22.12 & 3.20 & .18 \\
\hline & & Yes & 47 & 21.83 & 3.21 & .47 \\
\hline & Lowest temperature during perfusion $\left({ }^{\circ} \mathrm{C}\right.$ ) & No & 350 & 23.56 & 4.35 & 23 \\
\hline & & Yes & 47 & 22.91 & 4.23 & .62 \\
\hline & Lowest venous 02-sat duning sulfgery & No & 349 & 77.19 & 7.76 & .42 \\
\hline & & Yes & 47 & 77.51 & 7.17 & 1.05 \\
\hline & $\begin{array}{l}\text { Diastolic Pulmonary Art. Pres. ate end } \\
\text { of surgery }\end{array}$ & No & 324 & 15.57 & 4.34 & $0.241^{*}$ \\
\hline & & Yes & 46 & 27.04 & 5.24 & .77 \\
\hline & Lowest ABP during surgery ( $\mathrm{mmHg}$ ) & No & 349 & 44.37 & 9.27 & .50 \\
\hline & & Yes & 47 & 44.15 & 13.57 & 1.98 \\
\hline & Creatin pre-opherative (HMol/l) & No & 352 & 95.62 & 42.27 & 2.25 \\
\hline & & yes & 47 & 103.68 & 31.01 & 4.52 \\
\hline & UWEF pre-operative & No & 351 & 55.59 & 11.23 & 0.599 \\
\hline & & Yes & 47 & 51.62 & 13.16 & 1.92 \\
\hline & Syst. Rv-pressule pre-operative & No & 351 & 28.49 & 10.55 & .56 \\
\hline & & Yes & 47 & 30.60 & 14.77 & 2.15 \\
\hline & Forced Expiratory 1 second Volume $(1)$ & No & 178 & 2.4375 & .8812 & $6.605 \mathrm{E}-02$ \\
\hline & & Yes & 24 & 2.2371 & 5257 & .1073 \\
\hline \multirow[t]{26}{*}{ old } & Bypass time & No & 153 & 96.05 & 35.09 & 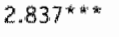 \\
\hline & & Yes & 45 & 128.71 & 54.81 & 8.17 \\
\hline & Cross clamp time & No & 152 & 61.99 & 25.16 & $2.041 \cdots$ \\
\hline & & Yes & 4.4 & 85.66 & 42.52 & 6.41 \\
\hline & Duration of surgery & $\mathrm{No}$ & 154 & 180.71 & 51.16 & 4. $122^{* w * x}$ \\
\hline & & Yes & 45 & 230.13 & 75.33 & 11.23 \\
\hline & Cardioplegic solution (mi) & No & 151 & 914.57 & 355.74 & $28.96 \times$ \\
\hline & & Yes & 4.4 & 1204.55 & 6387.20 & 95.91 \\
\hline & Lowest hematocrit during surgery & No & 154 & 21.20 & 2.86 & .23 \\
\hline & & Yes & 45 & 21.09 & 3.00 & .45 \\
\hline & Lowest temperature during perfusion ( $\left.{ }^{6} \mathrm{C}\right)$ & No & 154 & 23.58 & 4.32 & $0.3 .488^{4 * x}$ \\
\hline & & Yas & 4.5 & 21.62 & 3.61 & .54 \\
\hline & Lowest venous 0a-sat diring surgery & No & 153 & 78.54 & 8.05 & .65 \\
\hline & & Yes & 45 & 76.84 & 7.95 & 1.19 \\
\hline & $\begin{array}{l}\text { Diastolic Pultionary Ant. Pres. } \\
\text { at end of surgery }\end{array}$ & No & 144 & 15.94 & 4.46 & .37 \\
\hline & & Yes & 40 & 16.27 & 5.41 & .86 \\
\hline & Lowest ABP wiuring surgery (mmHg) & Wo & 153 & 43.31 & 9.20 & .74 \\
\hline & & Yes & 45 & 4.2 .16 & 9.46 & 1.41 \\
\hline & Geatin pre-operative (uMol/l) & No & 154 & 100.22 & 38.40 & 3.09 \\
\hline & & Ves & 45 & 101.98 & 24,90 & 3.71 \\
\hline & LVEF pre-opeliative & No & 1.52 & 53.83 & 10.38 & .84 \\
\hline & & Yes: & 44 & 53.86 & 12.11 & 1.82 \\
\hline & Syst. RW-pressure pre-operative & No & 150 & 29.38 & 9.24 & .75 \\
\hline & & Yes & $4 x_{4}$ & 32.41 & 12,12 & 1.83 \\
\hline & Forced Expliratory 1 second Wolume (1) & Wo & 67 & 1.9803 & .5572 & $6.808 \mathrm{E}-02$ \\
\hline & & Yes & 24 & 2.8933 & .6225 & .1271 \\
\hline
\end{tabular}


Table 8.4. Effect of the presence of Diabetes on the incidence of mental confusion $(P<0.01)$.

\begin{tabular}{lll} 
Mental confustion & Young & old \\
No Diabetes & $33 / 330(10 \%)$ & $30 / 162(18.5 \%)$ \\
Mon Insulin Dependent DM & $5 / 42(11.9 \%)$ & $12 / 33(36.4 \%)$ \\
Insulin Dependent DM & $9 / 27(33.3 \%)$ & $3 / 4(75 \%)$ \\
\hline
\end{tabular}

Table 8.5. Pre- and postoperative predictors for mental confusion in both age groups.

\begin{tabular}{|c|c|c|c|}
\hline Mental confusion & & Young & Old \\
\hline \multirow[t]{2}{*}{ History of congestive heart failure } & Wo & $32 / 299(10.7 \%)$ & $27 / 146(18.5 \%)$ \\
\hline & Yes & $15 / 100(15.0 \%)$ & $18 / 53(34.0 \%)^{*}$ \\
\hline \multirow[t]{2}{*}{ Re - operation } & No & $41 / 333(12.3 \%)$ & $35 / 177(19.8 \%)$ \\
\hline & Yes & $6 / 66(9.1 \%)$ & $10 / 22(45.5 \%)^{* *}$ \\
\hline \multirow[t]{2}{*}{ Histary of cerebro-vascular disease } & No & $40 / 361(11.1 \%)$ & $38 / 178(21.3 \%)$ \\
\hline & Yes: & $7 / 38(18.4 \%)$ & $7 / 21(33.3 \%)$ \\
\hline \multirow[t]{2}{*}{ Weak carotid pulsations } & No & $49 / 352(13.9 \%)$ & $26 / 154(16.9 \%)$ \\
\hline & Yes & $9 / 47(19.1 \%)$ & $14 / 45(33.4 \%)^{*}$ \\
\hline \multirow[t]{2}{*}{ Carotid bruit present } & No & $24 / 352(6.9 \%)$ & $8 / 154(5.1 \%)$ \\
\hline & Yes & $7 / 47(14.9 \%)$ & $3 / 45(6.6 \%)$ \\
\hline \multirow[t]{2}{*}{ Inotropic support $>24$ hours } & No & $34 / 356(9.6 \%)$ & $31 / 175(17.7 \%)$ \\
\hline & Yes & $13 / 43(30.2 \%)^{* * *}$ & $14 / 24(58.3 \%)^{* * *}$ \\
\hline \multirow[t]{2}{*}{ Mech. ventitation $>24$ hours } & No & $24 / 324(7.4 \%)$ & $21 / 152(13.8 \%)$ \\
\hline & Yes & $23 / 75(30.7 \%)^{* * *}$ & $24 / 47(51.1 \%)^{* * *}$ \\
\hline \multirow[t]{2}{*}{ Atrial fibrillation post operative } & No & $16 / 218(7.3 \%)$ & $8 / 62(12.9 \%)$ \\
\hline & Yes & $31 / 181(17.1 \%)^{\star *}$ & $37 / 137(27.0 \%)^{*}$ \\
\hline \multirow[t]{2}{*}{ Killip 3-4 heart failure post operative } & No & $36 / 358(10.1 \%)$ & $37 / 185(20.0 \%)$ \\
\hline & Yes & $11 / 41(26.8 \%)^{*}$ & $8 / 14(57.1 \%)^{* *}$ \\
\hline \multirow[t]{2}{*}{ Rethoracotomy required } & No & $36 / 353(10.2 \%)$ & $36 / 182(19.8 \%)$ \\
\hline & Yes & $11 / 46(23.9 \%)^{*}$ & $9 / 17(52.9 \%) * *$ \\
\hline \multirow[t]{2}{*}{ Acute Tubular Necrosis } & No & $39 / 3.67(10.6 \%)$ & $33 / 181(18.2 \%)$ \\
\hline & Yes & $8 / 31(25.8 \%)^{*}$ & $12 / 18(66.7 \%)^{* *}$ \\
\hline \multirow[t]{2}{*}{ Cerebrovascular accident post-op. } & No & $2 / 351(0.6 \%)$ & $4 / 154(2.5 \%)$ \\
\hline & Yes & $7 / 47(14.9 \%)^{* * *}$ & $4 / 45(4.0 \%)$ \\
\hline
\end{tabular}

* $P_{<0.05}$, * $p_{<<0.01, * * *} P_{<} 0.001$

\section{CONSEQUENCES OF MENTAL CONFUSION}

The hospital mortality (defined as mortality within 30 days following surgery or during the initial admission) in the Young / Old group was $4.5 \% / 2.6 \%$ if no confusion was present and $10.6 \% / 8.9 \%$ in case of mental confusion $(P=n, s$.$) . The late mortality was measured after a median follow-up duration of$ 29 months. The minimal follow-up duration of the surviving patients was 12 


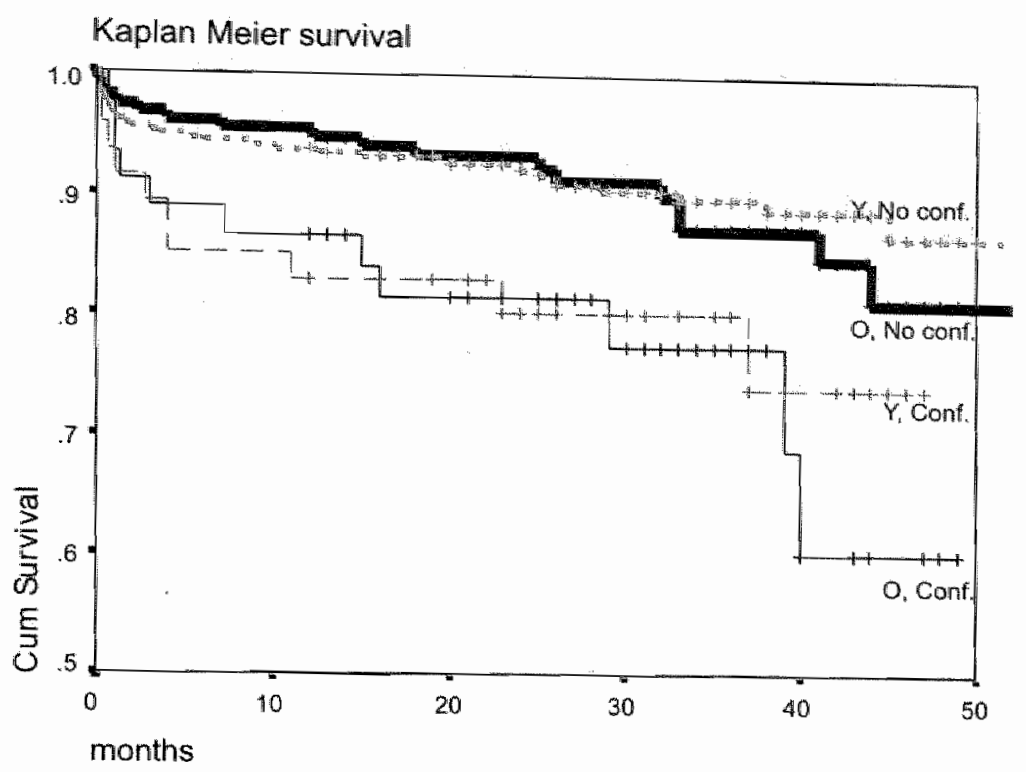

Figure 8.1. Four year survival in both age groups, and the effect of mental confusion $(P<0.01)$. $Y=$ Young group, $0=0$ ld group, conf.=confusion present.

months (maximum $=52$ months). The late mortality was significantly worse in both age groups if mental confusion has occurred (figure 1).

\section{QUALITY OF LIFE}

Both quality of life questionnaires were filled out by $352 / 373(94.3 \%)$ surviving Young patients and $170 / 188(90.4 \%)$ surviving Old patients. The Hospital Anxiety and Depression scale has two items (anxiety and depression) with a range from 0-21. A higher number means a worse score for that item. Patients with mental confusion in both age groups showed no improvement of symptoms from depression following surgery, in contrast to non-confused patients (table 6). The Nottingham Health Profile has six items (energy, emotional reactions, pain, sleep, social isolation and physical mobility) with a range from 0-100. Also here a higher number means a worse score for that item. Elderly patients with mental confusion showed no significant improvement in symptoms of emotional reactions, pain, sleep disorders, and physical mobility following surgery, in contrast to younger or non-confused patients (table 6). 


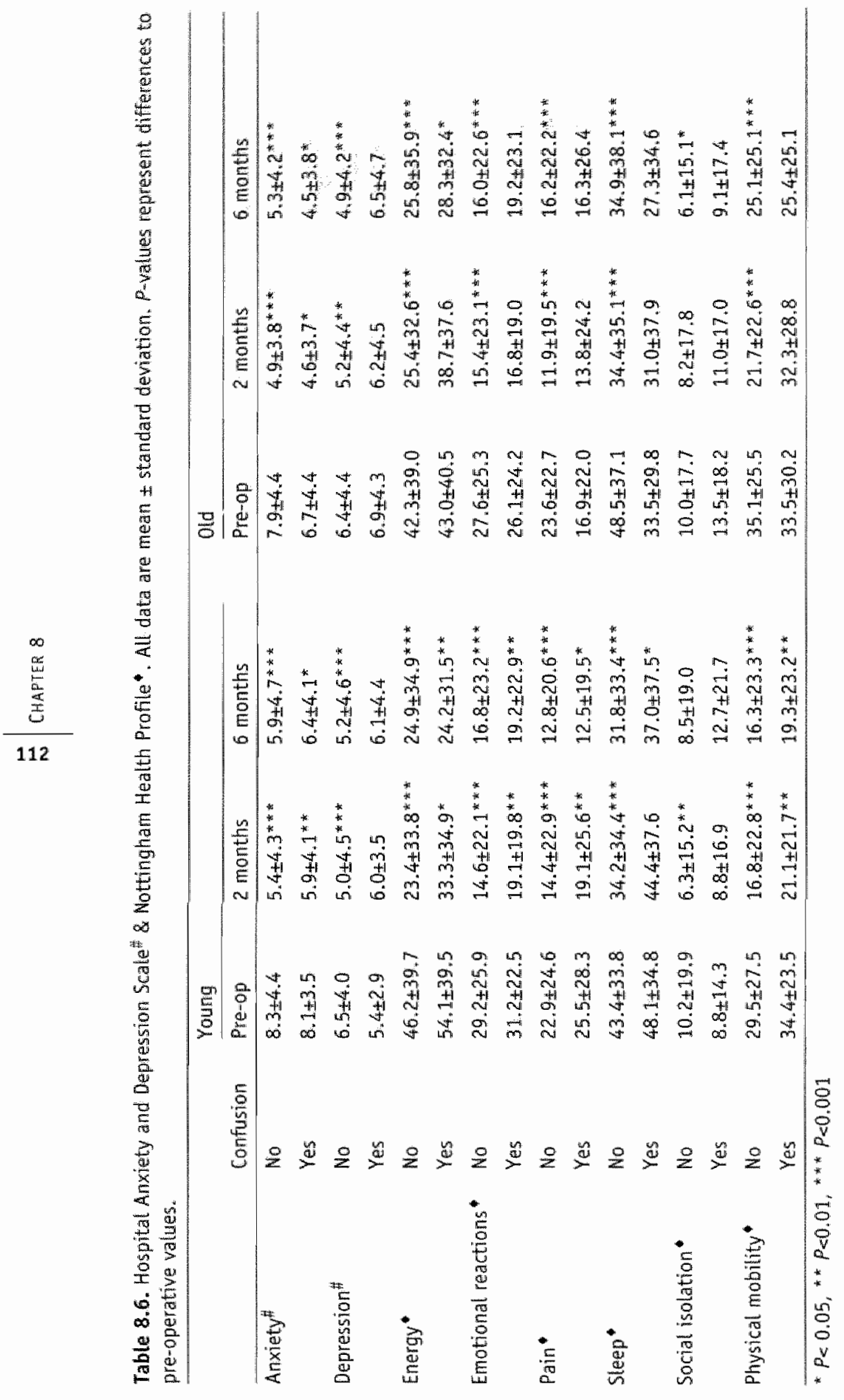


Table 8.7. Value of mental confusion as a separate risk factor for one year mortality in patients with different risk profiles.

\begin{tabular}{|c|c|c|c|c|}
\hline \multirow[b]{2}{*}{ Subgroup } & \multicolumn{2}{|l|}{ Mortality Young } & \multicolumn{2}{|l|}{ Mortality old } \\
\hline & No confusion & Confusion & No confusion & Confusion \\
\hline All patients & $23 / 352(6.5 \%)$ & $8 / 47(17 \%)^{*}$ & $8 / 154(5.2 \%)$ & $6 / 45(13.3 \%)$ \\
\hline Pre-operative heartfailure & $14 / 85(16.5 \%)$ & $3 / 15(20 \%)$ & $4 / 35(11.4 \%)$ & $3 / 18(16.7 \%)$ \\
\hline Creatinin > 140 $\mu$ Molll pre-op & $5 / 32(15.6 \%)$ & $1 / 6(16.7 \%)$ & $4 / 14(28.6 \%)$ & $2 / 5(40 \%)$ \\
\hline Valvular surgery & $15 / 119(12.6 \%)$ & $2 / 18(11.1 \%)$ & $4 / 46(6.7 \%)$ & $4 / 23(17.4 \%)$ \\
\hline Re=-operation & $7 / 60(11.7 \%)$ & $1 / 6(16.7 \%)$ & $0 / 12(0 \%)$ & $2 / 10(20 \%)$ \\
\hline Diabetes Melliturs & $3 / 55(5.5 \%)$ & $3 / 14(21.4 \%)$ & $3 / 22(13.6 \%)$ & $1 / 15(6.7 \%)$ \\
\hline Acute tubular necrosis post-op & $10 / 23(43.5 \%)$ & $3 / 8(37.5 \%)$ & $2 / 6(33.3 \%)$ & $2 / 22(16.7 \%)$ \\
\hline Mechanical ventilation $>1$ day & $13 / 52(25 \%)$ & $7 / 23(30.4 \%)$ & $5 / 23(21.7 \%)$ & $4 / 24(16.7 \%)$ \\
\hline Inotropic support > 1 day & $13 / 30(43.4 \%)$ & $6 / 13(46.2 \%)$ & $2 / 10(20 \%)$ & $2 / 14(14.3 \%)$ \\
\hline Re-thoracotomy needed & $10 / 35(28.6 \%)$ & $3 / 11(27.3 \%)$ & $0 / 8(0 \%)$ & $2 / 9(22.2 \%)$ \\
\hline
\end{tabular}

* $P<0.05$

\section{MENTAL CONFUSION AS A SEPARATE RISKFACTOR IN DIFFERENT PATIENT GROUPS}

To evaluate the additional effect of mental confusion on one-year mortalty we performed a subgroup analysis in patients with several risk profiles (table 7). It appeared that the presence of mental confusion within these subgroups was not an independent predictor for mortality.

\section{DISCUSSION}

In a prospective study by Gokgoz 8 in 50 patients following coronary bypass surgery a significantly reduced perfusion of certain cerebral lobes using single photon emission computed tomography was found in those patients developing a postoperative delirium syndrome. Possible risk tactors in that study were: advanced age, long aortic cross-clamp time, high dose inotropic support and excessive blood transfusion. Newman ${ }^{9}$, who did a study on cerebral autoregulation during cardiopulmonary bypass, found thac an increased age predisposes to impaired cognition atter cardiac surgery. This decline in cognitive function in the elderly however was not associated with age-related changes in cerebral blood flow auto regulation. Hofstell found that a pathologic intra-operative quantitative electroencephalogram and an intra-operative hemoglobin value of less than $5 \mathrm{mMol} / 1$ were predictors for delirium following surgery. Christenson"l found a higher incidence of mental confusion in elderly parients after a reoperative $C \mathrm{ABG}$. 
In our study we found that insulin dependent diabetes mellitus was an independent pre-operative predictor for mental confusion in all patients. In addition to this we found that walvular surgery (especially mitral valve surgery or combined surgery), a history of congestive heart failure and a re-operation were pre-operative predictors in patients more than 75 years old. Peri-and postoperative predictors for confusion were variables that were related to the duration of the surgical procedure, hemodynamic status, and post-operative complications. Surprisingly a longer cross clamp time was only a risk factor in the Old group.

The presence of weak carotid pulsations was the only neurologic pre-operative factor in the elderly patient that was predictive. A carotid bruit was not helpful for predicting postoperative confusion (radiated bruits from aortic stenosis or sclerosis were excluded). Apparently the presence of a bruit does not sufficiently reflect the severity of a carotid stenosis. A doppler examination of the carotid arteries was not routinely performed in our study. However this might more accurately discriminate patients at risk for mental confusion.

A history of a transient ischemic attack or a cerebrovascular accident before surgery was not a significant predictor for postoperative confusion. A reason for this might be that the incidence of ischemic cerebrovascular disease in our study population was only $8.5 \%$.

The duration of the operative procedure (and perfusion time) was more important for predicting confusion than a lower oxygen saturation, a lower hematocrit level or a lower blood pressure during the procedure. The reduced perfusion of the brain during aortic cross clamping during a longer time is probably the major cause of mental confusion. Postoperative cerebrovascular accidents of ischemic origin were also associated with mental confusion in both age groups. However its incidence is rather low, which makes this a less important etiologic factor.

Mental confusion was associated with a 2.4 times higher hospital mortality in the Young group, and a 3.4 times higher mortality in the Old group. The four years survival dropped from $87 \%$ to $74 \%$ in the Young and from $81 \%$ to $58 \%$ in the Old group when mental confusion was present following surgery. However this excess in mortality is due to the underlying riskfactors and morbidity of these patients and is not the result of mental confusion itself. However the recovery of quality of lite following surgery in elderly patients who are confused is clearly diminished in the first six months following surgery.

Considering the act the number of elderly patients that is undergoing open heart surgery is increasing, more attention should be paid to the mentioned risk factors for postoperative confusion. Postoperative confusion has a higher incidence in the elderly population and is clearly related to quality of life following surgery. A risk stratification can be made in the elderly patient summarizing the number of risk factors for confusion. In cases of multiple risk factors a conservative approach in treating the patient might be considered. Since the length of the surgical proce- 
dure is a major factor, more attention should be paid in short r surgical technigues in the elderly parient.

\section{REFERENCES}

1. Burker EJ, Blumenthal JA, Lewis ], Feldman M, Croughwell N, Thyrum E, at. Tho mini mental state exam as a predictor of neuropsychological functioning after cardiac surgery. Int.J.Psychiatry Med. 1995; 25:263-276.

2. Erdman RA, Passchier J, Koojiman $M$, Stronks DL. The Dutch version of the Nottingham Health Profile: investigations of psychometric aspects. Psychol Rep. 1993; 72:1027-1035.

3. Hunt SM, MC Kenna SP, Mc Ewen J, Willams ], Papp E. The Nottingham healu profile: Subjective health status and medical consultations. Soc.SciMed. 1981; 15A:221-229.

4. Jenkinson C, Fitzpatrick R, Argyle M. The Nottinglam thealth profile: an analysis of its sensitivity in differentiating illness groups. Soc.Sci.Med. 1988; 27:1411-1414.

5. Spinhoven P, Omel J, Sloekers PP, Kempen GL, Speckens AE, Van Hemert AM. A validation study of the Hospital Anxiety and Depression Scale (HADS) in different groups of Dutch subjects. Psychol.Med. 1997; 27:363-370.

6. Snaith P. Measuring anxiety and depression. Practitionex. 1993; 237:554-559.

7. Zigmund AS, Snaith RP. The hospital anxiety and depression scale. Acta psychiatr.scand. 1983; 67:361-370.

8. Gokgoz L, Gunaydin S, Sinci V, Unlu M, Bonatav C. Babacan A, et al. Psychiatic complications of cardiac surgery postoperative delinium syndrome. Scand. Cardiovasc J. 1997; $31: 217-222$.

9. Newman MF, Croughwell ND, Blumenthal JA, White WD, Lewis.JB, Smith LR, et al. Effect of aging on cerebral autoragulation during cardiopulnonary bypass. Association with postoperative cognitive dysfunction. Circulation 1994; 90:11243-11249

10. Hofsté WJ, Linssen CA, Boezenan EH, Hengeveld JS. Leusink JA, de-Boer A. Delirium and cognitive disorders after cardiac operations: rehationship to pre- and intraoperative quantitntive electroencephalogram. Int.J.Clin. Monit.Comput 1997. Feb. 97 A.D.; 14:29-36.

11. Christenson JT, Simonet F, Schmuziger M. The influence of age on the results af reoperative coronary artery bypass grafting. Coron. Artery Dis. $1997 ; 8: 91-96$. 
CHAPTER 9

\section{Observations on the effect of cardiac surgery on long-term survival patterns}

A comparison with the general population

Jan A. Heijmeriks, MD** Pim Dassen, PhD*, Kees Prenger, MD*, Salima Pourrier, MS*, Hein J.. Wellens, MD*

Department of Cardiology* and of Cardiopulmonary surgery

Academic Hospital, Maastricht, the Netherlands ${ }^{\dagger}$

Submitted for publication 


\section{ABSTRACT}

Background: The number of aged people referred for open heart surgery is gradually increasing. Only limited data exists about the long-term survival of elderly patients after open heart surgery, in comparison to the general population.

Methods: Two-hundred consecutive patients, aged 75 years or more (Old group), and four-hundred procedure and gender-matched younger patients (Young group) who underwent coronary or valvular surgery were included in a prospective study. The median follow-up duration was 31 months. Survival curves from each age group were compared with survival curves for the Dutch population in general.. Results: In the first three years no significant differences in mortality are seen in both age groups. After that an increased mortality is seen in patients over 80 years, which is equal to the general population. After 36 months the survival of the elderly (70-80y) male patient is better, and the elderly female patient is equal to that of the general population. Mitral valve surgery was associated with a higher mortality in patients $>65$ years.

Conclusion: Apart from a higher initial mortality due to the surgical procedure, the survival of elderly patients undergoing open heart surgery in the first three years is comparable to that of the general population. 


\section{INTRODUCTION}

The relative number of patients older than 75 years that have undergone open heart surgery has increased 4-6 times in the last decade 1.2. Several studies have indicated that the initial results are good regarding surgical mortality and morbidity ${ }^{3-8}$. The late mortality is always higher in elderly patients. This can be due to a lower life expectancy of elderly patients, or may reflect a worse surgical outcome in the elderly. Cane 9 already suggested in a retrospective study in octogenarians after coronary surgery that the long-term prognosis was worse than from an age, sex, and race-matched general population. To analyze differences in outcome between various age groups we performed a prospective study in 600 patients undergoing open heart surgery. Of these patients 200 were 75 years or older. The remaining 400 patients were younger patients. The survival curves of these patients were compared to the survival curves of the general Dutch population, which were available from the Dutch National Institute of Statistics $(\mathrm{CBS})^{10,11}$.

\section{METHODS}

During a period of $3 \frac{1 / 4}{4}$ years, starting September $22^{\text {nd }} 1993$ until December $18^{\text {th }} 1996$ we included 200 consecutive patients who underwent open heart surgery, and were 75 years or older (Old group). During the inclusion period 290 old patients were operated. The remaining 90 patients were not included for logistic reasons (mostly because of matching problems). In that period 2499 younger patients were operated. Each of the old patients were matched with two patients less than 75 years (Young group), having the same operative procedure, and being of the same sex. These variables were chosen to analyze procedure related mortality, and the fact that life expectancy is gender dependent. Because of a relative small number of patients no further variables were used for matching. For matching the first young patient was chosen with the same gender and type of operation as the included old patient. $66 \%$ had coronary surgery, the remaining patients had valvular surgery $(18 \%)$ or combined coronary + valvular surgery (16\%). $53.5 \%$ of all patients were female (table 1). These female patients were relatively older than male patients. The majority of patients being operated was between 60 and 80 years old (figure 1). The median follow-up duration of the surviving patients was 31 months and ranged from 12 to 52 months. Due to intensive follow-up techniques no patients were lost to follow-up. In case the patient could not be reached, data from follow-up were obtained from the general physician. Pre-operative data were collected one day prior to surgery by interviewing and examining the patient, together with data 
Table 9.1. Patient population

\begin{tabular}{lcccc}
\hline & \multicolumn{1}{c}{ Young } & & \multicolumn{1}{l}{ Old } & \\
\cline { 2 - 5 } & male & female & \multicolumn{1}{l}{ male } & female \\
\hline CABG & $132(71.0 \%)$ & $130(60.7 \%)$ & $65(71.0 \%)$ & $65(60.7 \%)$ \\
Valve & $24(12.9 \%)$ & $48(22.4 \%)$ & $12(12.9 \%)$ & $24(22.4 \%)$ \\
CABG+Vatve & $30(16.1 \%)$ & $36(16.9 \%)$ & $15(16.1 \%)$ & $18(16.9 \%)$ \\
Total & $186(100 \%)$ & $214(100 \%)$ & $93(100 \%)$ & $107(100 \%)$ \\
\hline
\end{tabular}

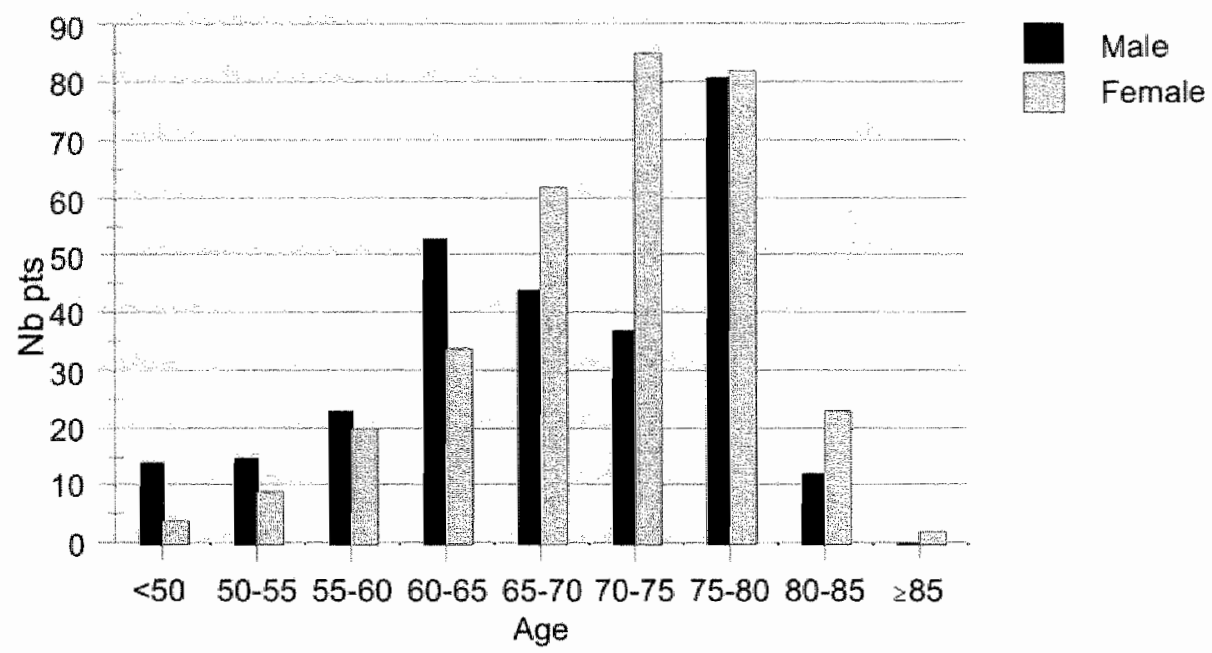

Figure 9.1. Age and gender of the patients studied. Abbreviations: Nb pts = Number of patients.

from the clinical chart. Data on follow-up were retrieved by calling the patient by telephone, after checking the hospital computer system that the patient did not die in the meantime. Since this is a prospective study data from clinical history, physical examination, ECG, and laboratory values were available from all patients. A pre-operative echocardiogram was available in 593/600 (98.8\%) patients, and a pre-operative LV ejection fraction in 596/600 (99.3\%) patients.

All patients were operated in the academic hospital of Maastricht. Due to its unique geographical location this hospital is the only hospital in the wide neighborhood that offers cardiac surgery. Therefore many centers refer patients to Maastricht, which could make the study population representative for a major part of the general Dutch population. 


\section{STATISTICAL METHODS}

The Unpaired $t$-test was used to demonstrate differences in Interval variables between both age groups. For Nominal variables Chi-square analysis of contingency was used. In case of Ordinal variables the Mann-Whitney rank-sum test was performed. To demonstrate changes in each treatment group after surgery the Paired t-test was used for Interval variables and WiJcoxon signed rank test for Ordinal variables. Survival analysis was done using the Kaplan-Meier method, with differences calculated using the Log rank test. Analyses were conducted using SPSS for Windows, release 8.0 SPSS Inc, Chicago, Illinois.)

\section{BASELINE DIFFERENCES}

Elderly patients $(275$ years) referred for coronary surgery had more often 3-vessel disease ( $81.7 \%$ vs $66.3 \%)$, had a higher incidence of severe left main stenosis $(13.7 \%$ vs $7.7 \%)$ and had more often angina in rest $(69 \%$ vs $56 \%)$. The incidence of hypercholesterolemia (24.7\% versus $37.9 \%)$ and smoking $(13.8 \%$ versus $24 \%$ was clearly lower in the elderly. No differences were seen in renal function, LV-ejection fraction, pulmonary function. In elderly patients referred for valvular surgery a higher incidence of diabetes mellitus $(15.9 \%$ versus $1.2 .3 \%$ ), and a lower incidence of treated hypertension (20.3\% versus $33.3 \%$ ) was found (table 2). Elderly patients had a higher incidence of urgent surgery $(53.0 \%$ versus $43.5 \%, P<0.05)$. This is defined as surgery within 2 weeks following referral, and during the same hospital admission.

\section{RESULTS}

The operative mortality (within 30 days following surgery) in the Young group was $10 / 186(4.3 \%)$ in the Male, and $14 / 214(6.5 \%)$ in the Female population. In the Old group this was $5 / 93(5.4 \%)$ in the Male, and $4 / 107(3.7 \%)$ in the Female population ( $P=n . s$.).

When comparing the two age groups (Young and Old) no significant differences were found in mortality in the first three years following coronary, valvular or combined surgery. Even if more age categories are created no significant changes in mortality are seen in the first 40 months following surgery (figure 2). Only after 42 months there is a tendency to a higher mortality in patients older than 80 years. The youngest age group had the best long-term prognosis.

The same pattern is seen for coronary surgery and aortic valve surgery (figure $3+4)$. Only for mitral valve surgery a higher mortality rate is found $(P<0.001)$ compared to other types of surgery (figure 5). 
Table 9.2. Biaseline characteristics.

\begin{tabular}{|c|c|c|}
\hline CABG patients & Young $(n=262)$ & old $(n=131)$ \\
\hline Age (yrs) & $65.0 \pm 7.2$ & $77.8 \pm 2.3$ \\
\hline Angina in rest, NYHA=4 $(n)$ & $146(56 \%)$ & $90(69 \%)^{\pi}$ \\
\hline Hypercholesterolemia $(\geq 6.5 \mathrm{~m} M$ ol/ $/)$ & $99(37.9 \%)$ & $32(24.7 \%)^{m}$ \\
\hline Smoking & $63(24 \%)$ & $18(13.8 \%)^{* *}$ \\
\hline Body mass index $\left(\mathrm{g} / \mathrm{m}^{2}\right)$ & $27.4 \pm 4.2$ & $25.7 \pm 3.4^{* * *}$ \\
\hline Anti-aniginal triple medication & $134(51.1 \%)$ & $71(54.2 \%)$ \\
\hline LV Ejection Fraction pre-op (\%) & $54.9 \pm 10.6$ & $53.0 \pm 9.9$ \\
\hline Syst RV-press. pre-op $(\mathrm{mmHg})$ & $24.8 \pm 5.8$ & $26.2 \pm 5.8^{*}$ \\
\hline 3 Vessel disease $(n)$ & $173(66.3 \%)$ & $107(81.7 \%)^{*}$ \\
\hline Left Main stenosis $>70 \%(n)$ & $20(7.7 \%)$ & $18(13.7 \%)^{*}$ \\
\hline Creatinin $>200,1 \mathrm{Mol} / \mathrm{l}(\mathrm{n})$ & $6(2.3 \%)$ & $3(2.3 \%)$ \\
\hline Pulmonary Vital capacity \% / norm & $101.1 \pm 15.6$ & $99.5 \pm 19.7$ \\
\hline Hemoglobim pre-op (mMol/l) & $8.6 \pm .9$ & $8.1 \pm .8^{* * *}$ \\
\hline Number of anastomosis & $3.6 \pm 1.3$ & $3.95 \pm 1.2^{* *}$ \\
\hline Left internal mammary used $(n)$ & $233(89 \%)$ & $100(76 \%)^{* * *}$ \\
\hline Re-operation & $40(15.2 \%)$ & $15(11.5 \%)$ \\
\hline Valvular surgery & Young $(n=138)$ & Old $(n=69)$ \\
\hline Age (yrs) & $64.8 \pm 7.5$ & $78.2 \pm 3.1$ \\
\hline Dyspnea in rest. NYHA 4 (n) & $36(26.1 \%)$ & $15(21.7 \%)$ \\
\hline History of congestive Heart Failure & $74(53.6 \%)$ & $40(57.9 \%)$ \\
\hline Diabetes Mellitus (type 1 or 2 ) & $17(12.3 \%)$ & $11(15.9 \%)^{* * * *}$ \\
\hline Systemic Hypertension (treated with drugs) & $46(33.3 \%)$ & $14(20.3 \%)^{* * *}$ \\
\hline Smoking & $43(31.1 \%)$ & $11(15.9 \%)^{*}$ \\
\hline Body mass index $\left(\mathrm{g} / \mathrm{m}^{2}\right)$ & $26.3 \pm 4.5$ & $25.7 \pm 3.3$ \\
\hline LV Ejection Fraction pre-op (\%) & $55.6 \pm 13.1$ & $55.5 \pm 12.0$ \\
\hline Posterior wall enddiast wall thickness (mm) & $10.4 \pm 1.4$ & $11.2 \pm 1.5^{* * *}$ \\
\hline Syst RV-press. pre-op (mmHg) & $36.6 \pm 14.7$ & $37.0 \pm 13.8$ \\
\hline Pulmonary Vital capacity \%/ norm & $95.2 \pm 19.9$ & $101.6 \pm 19.9$ \\
\hline Use of bioprosthesis & $10(11 \%)$ & $27(48 \%)^{* * *}$ \\
\hline Re-operation & $26(18.8 \%)$ & $7(10.1 \%)$ \\
\hline
\end{tabular}

*P<0.05, ** $p<0.01$, ** $P<0.001$ 


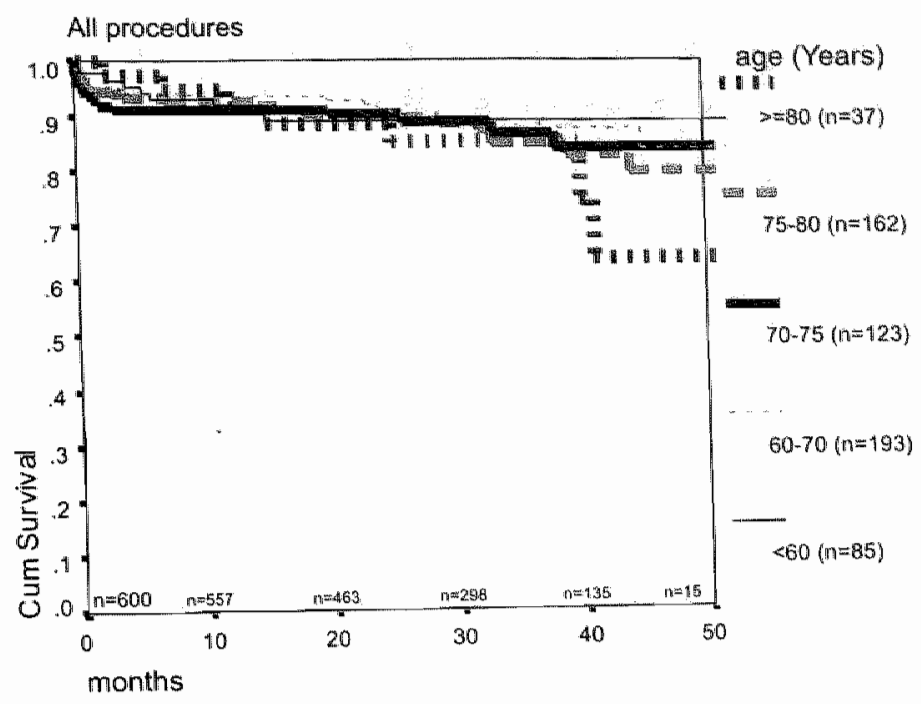

Figure 9.2. Life table showing survival in all age categories in all procedures $\left(P=n . s_{.}\right)$, including number of patients at risk during follow up.

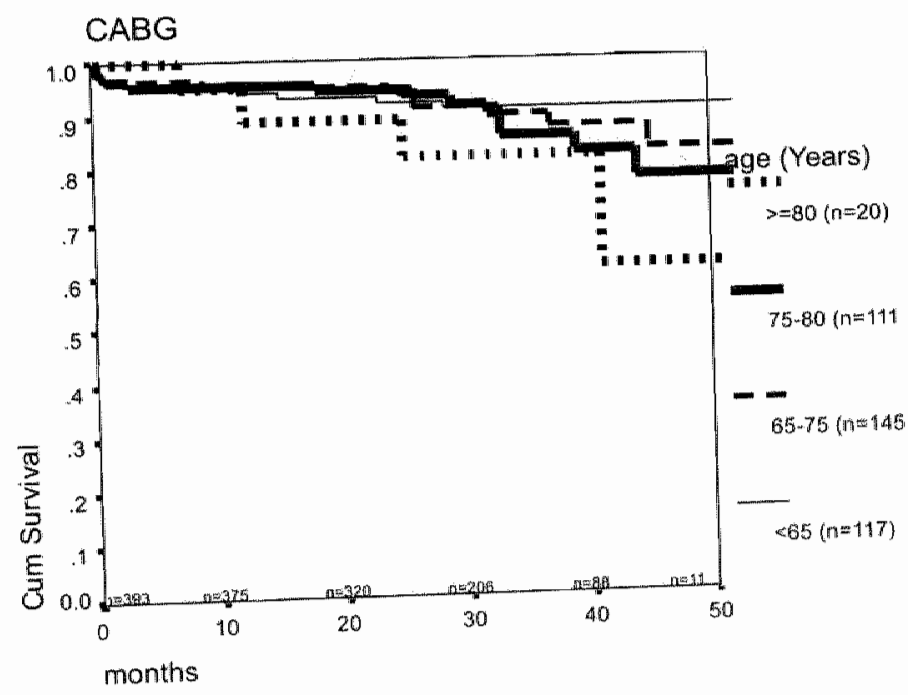

Figure 9.3. Coronary surgery $(n=393, P=n .5$. 


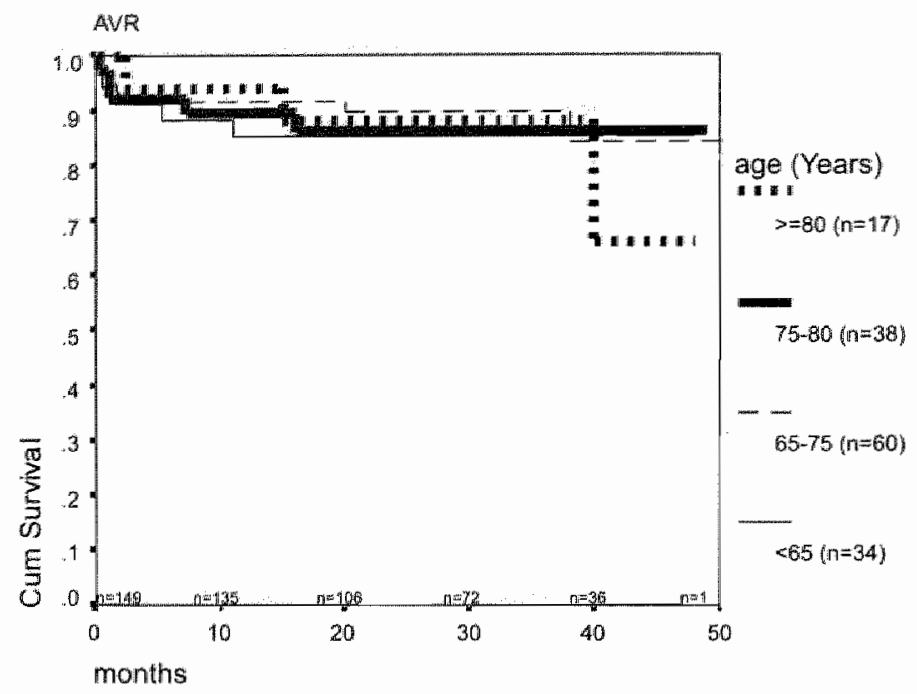

Figure 9.4. Aortic valve surgery. $(n=149, P=n .5$.

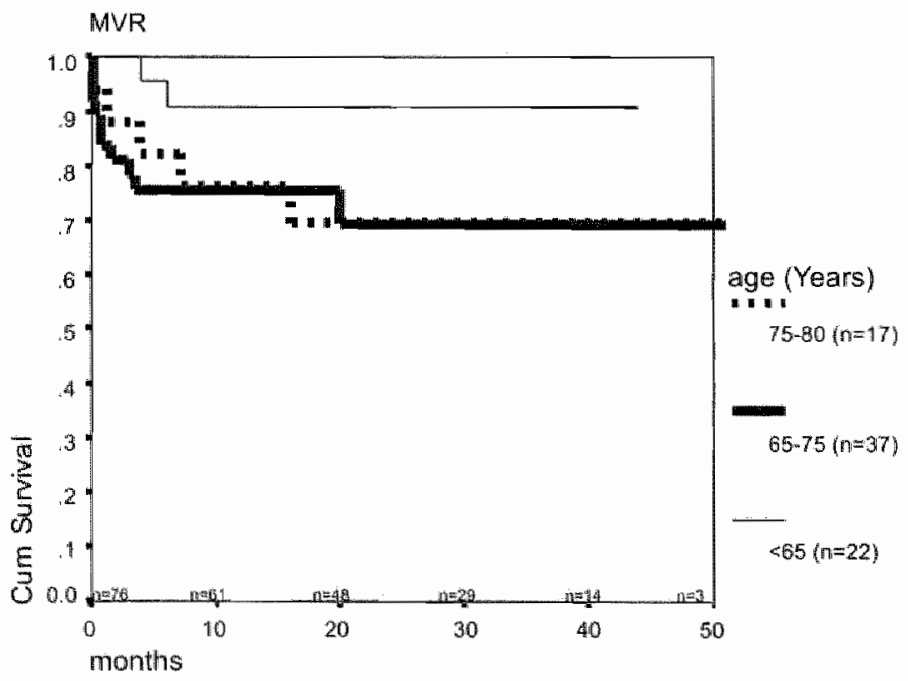

Figure 9.5. Mitral valwe surgery. (n=76, $P=n . s$, within age groups, $P<0.001$ compared to coronary and aortic valve surgery), no pts>80years. 
Table 9.3. Pre-operative Predictors of 1-year mortality after cardiac surgery.

\begin{tabular}{|c|c|c|}
\hline Coronary surgery & Young $(n=262)$ & Otd $(n-131)$ \\
\hline Pre-operative Creatinin $>140 \mu \mathrm{Mol} / \mathrm{L}$ & $4 / 22(18.2 \%) *$ & $2 / 13(15.4 \%)$ \\
\hline Previous Myocardial infarction & $9 / 135(6.7 \%)$ & $7 / 77(9.1 \%)^{* *}$ \\
\hline Diabetes Mellitus & $4 / 52(7.7 \%)$ & $2 / 26(7.79 \%)$ \\
\hline LNEF $<53 \%$ & $8 / 103(7.8 \%)$ & $6 / 71(8.5 \%)$ \\
\hline Re-operation & $3 / 40(7.5 \%)$ & $1 / 15(6.7 \%)$ \\
\hline Pre-operative Heart-failure & $6 / 27(2.2 .2 \%)^{* * *}$ & $1 / 13(7.7 \%)$ \\
\hline Congestion on chest $X$-ray & $2 / 9(22.2 \%)^{*}$ & $1 / 8(12.5 \%)$ \\
\hline One-sided carotid murmur & $4 / 13(30.8 \%)^{* \ldots}$ & $1 / 7(14.3 \%$ \\
\hline Ischemia on pre-operative ECG & $11 / 95(11.6 \%)^{* *}$ & $5 / 73(6.8 \%)$ \\
\hline Emergency surgery & $1 / 16(6.3 \%)$ & $0 / 9(0 \%)$ \\
\hline Valvular surgery & Young $(n=138)$ & Old $(n=69)$ \\
\hline Pre-operative Creatinin $>140 \mu \mathrm{Mol} / \mathrm{l}$ & $2 / 15(13.3 \%)$ & $4 / 5(80 \%) * *$ \\
\hline FEV $1<1$ liter & $11 / 36(30.6 \%)^{*}$ & $2 / 19(10.5 \%)$ \\
\hline Previous Myocardial infarction & $7 / 24(29 \%)^{* *}$ & $1 / 11(9.1 \%)$ \\
\hline Diabetes Mellitus & $2 / 17(11.8 \%)$ & $2 / 11(18.2 \%)$ \\
\hline LVEF $<53 \%$ & $10 / 44(22.7 \%)^{*}$ & $5 / 25(20 \%)$ \\
\hline Re-operation & $5 / 26(19.2 \%)$ & $1 / 7(14.3 \%)$ \\
\hline RV Syst. $>45 \mathrm{mmHg}$ Pre-operative & $5 / 30(16.7 \%)$ & $6 / 11(55 \%) *$ \\
\hline Additional coronary surgery & $12 / 66(18.2 \%)$ & $6 / 33(18.2 \%)$ \\
\hline Mitral valve surgery & $11 / 59(18.6 \%)$ & $4 / 17(23.5 \%)$ \\
\hline Emergency surgery & $0 / 1(0 \%)$ & $0 / 2(0 \%)$ \\
\hline
\end{tabular}

Abbreviations: $L V E F=$ Left Ventricular Ejection Fraction, FEV1 $=$ First Expiratory 1-Second Volume, RV Syst $=$ Right Ventricular Systolic Pressure. ${ }^{*} P<0.05^{* * *} P<0.01^{* * * *} P<0.001$

Major pre-operative predictors for 1 year mortality including hospital mortality in the $\mathrm{CABG}$ patients were: $\mathrm{A}$ history of pre-operative heartfailure, an increased Creatinin value $>140 \mu \mathrm{Mol} / 1$, persisting ischemia on the last pre-operative $\mathrm{ECG}$, previous myocardial infarction, and a one-sided carotid murmur (table 3 ). In the group with valvular heart surgery major pre-operative predictors for mortality were: An increased Creatinin value $>140 \mu \mathrm{Mol} / 1$, previous myocardial infarction, poor pulmonary function with a FEV $1<1$ liter, and increased right sided pressures $>45 \mathrm{mmHg}$ systolic (table 3 ).

Patients aged 75 years or older had a higher incidence of postoperative atrial fubrillation. In case of coronary surgery the postoperative admission duration was longer and the incidence of postoperative heartfailure was higher. In case of valvular surgery a higher incidence of post-operative mental confusion was found (table 4). There was no difference in stroke incidence. 
Table 9.4. Postoperative morbidity.

\begin{tabular}{|c|c|c|}
\hline Coronary surgery & Young $(n=262)$ & Old $(n=131)$ \\
\hline Atrial fibrillation & $92(35.1 \%)$ & $83(63.4 \%)^{* * *}$ \\
\hline Ventricular tachycardia/fibrillation & $6(2.3 \%)$ & $5 .(3.8 \%)$ \\
\hline Myocardial infarction & $33(12.6 \%)$ & $22(16.8 \%)$ \\
\hline Congestive heart failure (killip 2-4) & $81(30.9 \%)$ & $56(42.7 \%)^{*}$ \\
\hline AV-conduction disturbances requining pacing & $20(7.6 \%)$ & $19(14.5 \%)^{*}$ \\
\hline Rethoracotomy performed & $24(9.2 \%)$ & $11(8.4 \%)$ \\
\hline Respiratory infection & $16(6.1 \%)$ & $13(9.9 \%)$ \\
\hline Mediastinitis & $6(2.3 \%)$ & $6(4.6 \%)$ \\
\hline Acute Tubular Necrosis & $13(5.0 \%)$ & $7(5.3 \%)$ \\
\hline Cerebrovaliscular accidents & $6(2.3 \%)$ & $5(3.8 \%)$ \\
\hline Mental confusion & $29(11.1 \%)$ & $22(16.9 \%)$ \\
\hline Postoperative admission duration (median/std) & $9 \pm 9$ & $12 \pm 10^{* * *}$ \\
\hline Valvular surgery & Young (n=:138) & Old $(n=69)$ \\
\hline Atrial fibrillation & $89(64.5 \%)$ & $54(78.3 \%)^{*}$ \\
\hline Ventricular tachycardia/fibrillation & $6(4.3 \%)$ & $1(1.4 \%)$ \\
\hline Myocardiall infarction & $16(11.6 \%)$ & $8(11.6 \%)$ \\
\hline Congestive heart failure (Killip 2-4) & $61(44.5 \%)$ & $34(49.3 \%)$ \\
\hline AV-conduction disturbances requiring pacing & $44(32.1 \%)$ & $23(33.3 \%)$ \\
\hline Rethoracotomy performed & $22(16.1 \%)$ & $7(10.1 \%)$ \\
\hline Respiratory infection & $25(18.2 \%)$ & $13(18.8 \%)$ \\
\hline Mediastinitis & $5(3.7 \%)$ & $1(1.4 \%)$ \\
\hline Acute Tubular Necrosis & $18(13.2 \%)$ & $11(15.9 \%)$ \\
\hline Cerebrowascular Accidents & $5(3.7 \%)$ & $4(5.8 \%)$ \\
\hline Mental confusion & $18(13.1 \%)$ & $23(33,3 \%)^{* * *}$ \\
\hline Postoperative admission duration (median \pm std) & $13 \pm 16$ & $14 \pm 12$ \\
\hline
\end{tabular}

$* p_{\leq} 0.05 * p_{0}<0.001$

\section{GENERAL POPULATION LIFE TABLES}

To compare the long tem results regarding survival with the general population, we analyzed period life tables from the Netherlands (1992-1996), obtained from C.B.S. (Dutch National Institute for Statistics) 10.11. From that data we constructed two survival curves for a period of 5 years using the life table method, one for men and one for women (figure 6.7). The lines plotted in each of these age categories represent the survival curve for the median age of our study population in that age group. 


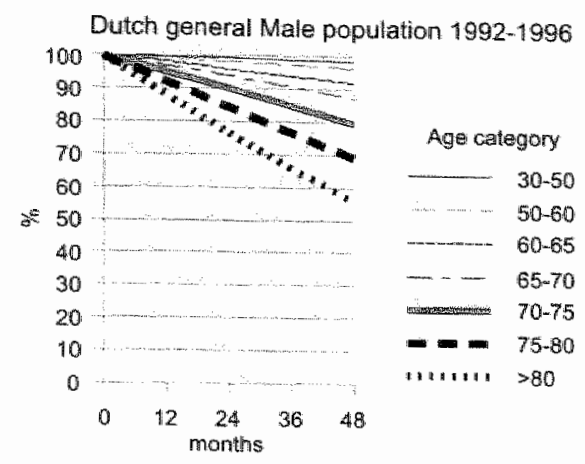

Figure 9.6. Survival curves from the Dutch general Male population (source: C.B.S. 1997).

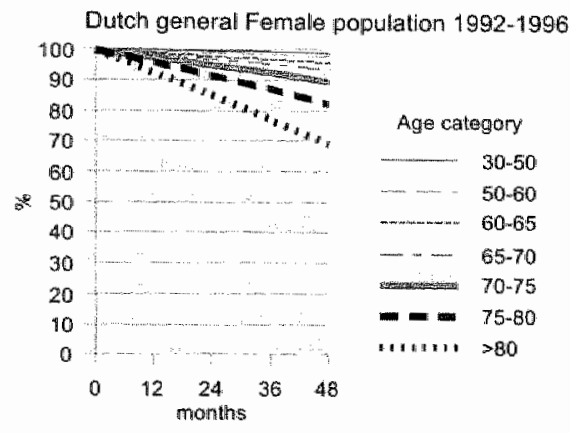

Figure 9.7. Survival curves from the Dutch general female population (source: C.B.S. 1997).

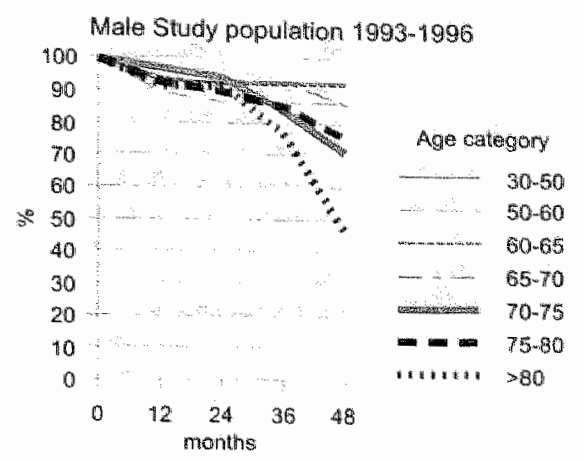

Figure 9.8. Survival curves of Male study population, all procedures $(n=279)$.

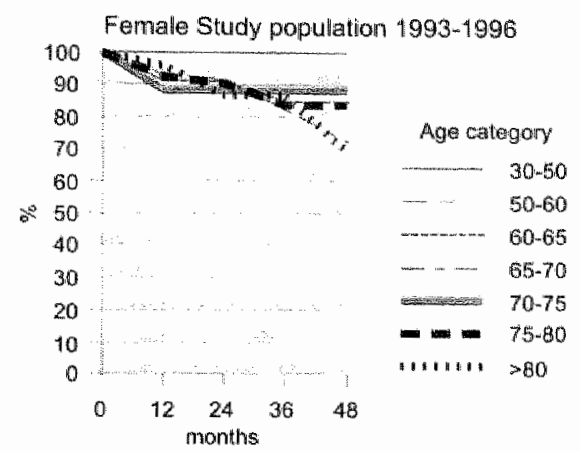

Fìgure 9.9. Survival curves of Female study population, all procedures $(n=321)$.

Below these two figures we plotted the same graphs, also divided by gender, but now for our study population, which includes both coronary surgery and valvular surgery (figure 8,9).

Comparing these figures reveals a higher early mortality in nearly each age group in the study population, due to the surgical mortality. After 36 months following surgery the survival of the elderly patient is better than the general population for both men and women. After 48 months the survival of female patients over 80 years is equal to the general population, for male patients over 80 years the prognosis looks slightly worse, but is statistically also not different from the general population. For patients between 70 and 80 years old the prognosis is still better after 48 months than in the general population. 


\section{DISCUSSION}

No significant differences in operative mortality were found between both age groups and between both genders. This is in contrast to the observations of Edwards et $a^{12}$ who found a higher operative mortality in female patients. Also several studies report a higher surgical mortality in elderly patients ${ }^{9.13,14}$. This might be explained by a more careful selection of the elderly patient presented for surgery. Since only $1 / 600(0.2 \%)$ patients had acute surgery and $27 / 600$ (4.5\%) patients had emergency surgery (within 2 days) with only 3 deaths $(11.1 \%)$, we could not confirm this as a risk-factor.

Our study demonstrates that the mortality after 36 months of male patients older than 75 years was lower than from the general population (figure 6,8 ). In female elderly patients the mortality after 36 months was equal to that of the general population (figure 7,9). This difference can be explained by the lower life expectancy of male subjects. In octogenarians the mortality rate dramatically increased after three years following surgery, but that appeared to be in concordance with the general. life expectancy of octogenarians. Since the number of octogenarians in our study was relatively low, the presented increase of mortality between 36 and 48 months could be overestimated.

The mortality in patients younger than 60 years was al ways higher than that of the general population. The explanation for this is probably the low mortality rate of the general (young) population, and the effect of the surgical mortality.

This study however has several limitations. The relative small number of the study population makes subgroup analysis less reliable. Especially because there are also some biases in the baseline characteristics between the age groups. Also a median follow-up duration of 31 months has limitations for predicting long term prognosis.

\section{CONCLUSIONS}

Apart from a higher initial mortality due to the surgical procedure, the survival of elderly patients undergoing open heart surgery in the first three years is comparable to that of the general population.

Mitral valve surgery in patients over 65 years is associated with a $>40 \%$ higher mortality in the first year. Therefore a cautious approach in this patient group should be considered. 


\section{REFERENCES}

1. Acinapura AJ, Rose DM, Cunningham JN, J1, Jacobowitz IJ, Kramer MD, Zisbrod Z Coronary artery bypass in Septuagenarians. Analysis of montility and morbidicy. Circulation $1988 ; 78: 1-179-1-184$

2. Curtis JJ, Walls JT, Boley TM, Schmaltz RA, Demmy TL, Salam N. Coronary revascularization in the elderly: detemanants of operative mortality. Ann. Thorac Surg. $1994 ; 58: 1069-1072$

3. Bashour TT, Hanna ES, Myler RK, Mason DT, Ryan C, Feeney J, et al. Cardiac surgery in parients over the age of 80 years. Clin. Cardiol. 1990; 13:267-270.

4. BoucherJM, Dupras A, Jutras N, Page V, Lelorier J, Gagnon RM. Long-term survival and functional status in the elderly after cardiac surgery. Can.J Cardiol.1997.Jul. 13:646-652.

5. Chocron S, Rude N, Dussaucy A, Leplege A, Clement F, Alwan K, etal. Quality of hife after open-heart surgery in patients over 75 years old. Age. Ageing 1996; 25:8-11.

6. Katz NM, Haman RL, Hopkins RA, Wallace RB. Cardiac operations in patients aged 70 years and over: mortality, length of stay, and hospitat charge. Ann. Thorac. Surg. $1995 ; 60: 96-100$.

7. Shah VZ, Rosenfeldt FL, Parkin GW, Ugoni AM, Habersberger PG, Cooper E. Cardiac surgery in the very elderly. Med.J.Aust. 1994; 1.60:332-334.

8. Subayi JB, de Brux JL, Delhumeau A, Lotfi N, Moreau X, Cottineau C, et al. FCardiac surgery in aged patients; immediate and medium-tem results in 100 patients over 75 years of agel Chirurgie cardiaque chez les patients ages; resultats immediats et a moyen terme chez 100 patients ages de 75 ans et plus. Arch.Mal.Coeur. Vaiss. 1994; 87:1671-1677.

9. Cane ME, Chen C, Bailey BM, Fernandez J, Laub GW, Anderson WA, et al. CABGin octogenarians: early and late events and actuarial survival in comparison with a matrched population. Ann. Thorac Surg. 1995; 60:1033-1037.

10. anonymous. Life tables, 1996 and $1992-1996$. Mandstatistiek van de bevolking 1997 ; $45: 46-50$.

11. Tas RFJ. Period life tables for the Netherlands by sex and age, 1991-1995. Maandstatistiek wan de bevolking 1998; 46:8-13.

12. Edwards FH, Carey IS, Grover FL, Bero JW, Hart RS. Impact of gender on coronary bypass operative mortallity. Ann. Thorac Surg. 1998; 66:125-131.

13. Fremes $\mathrm{SE}$, Goldman BS, Ivanov J, Weisel RD, David TE, Salemo T. Valvular surgery in the elderly. Circulation 1989; 80:177-190

14. Hannan EL, Burke J. Effect of age on mortality in coronaryartery bypass surgery in New York, 1991-1992. Am. Heart J. 1994; 128:1184-1191 



\section{General discussion}

\section{INTRODUCTION}

From the data described in this thesis and from the literature it can be concluded that the results from cardiac surgery in the elderly patient are favorable in many aspects. This resulted in a larger number of elderly patients currently referred for open heart surgery. ${ }^{1-4}$

However success of a surgical procedure can be measured in many ways. Most studies from the literature were retrospective, and their data limited to mortality rates and description of complications. ${ }^{5-14}$ Also the majority of those studies did mot include a control group. Since results may also vary between surgical centers, a control group with younger patients from the same center is needed to examine differences in results between the younger and the elderly population.

The unique aspect of our study is that we prospectively analyzed 200 patients aged 75 years or older referred for CABG and/or valve surgery and that they were matched with 400 gender and procedure matched younger patients as a control group. Besides the collection of medical data also quality of life analysis was performed before and after surgery.

\section{PATIENT CHARACTERISTICS}

Elderly patients referred for cardiac surgery are more compromised than younger patients. They have more angina in rest $(69 \%$ vs $56 \%$ ), a higher incidence of 3-vessel disease ( $82 \%$ vs $66 \%$ ) and left main stenosis (14\% vs $8 \%$ ), and a higher incidence of urgent surgery ( $53 \%$ vs $44 \%$ ). On the other hand the number of risk factors is clearly lower in the elderly. Smoking is less (14\% vs $24 \%$ ), obesity (BMI>30) is less (13\% vs 23\%, hypercholesterolemia is less (25\% vs $38 \%$ ), and also hypertension ( $20 \% \mathrm{vs} 33 \%$, in the valve surgery group). The incidence of concomitant diseases (COPD, renal failure, diabetes) was low in our study group, with no clear differences with the young group. Also the incidence of heart failure was low (10\%, CABG group). 


\section{MORTALITY AND MORBIDITY}

The low incidence of risk factors and concomitant diseases makes the study population except for cardiac disease relatively healthy, compared to the general population. This might explain why the surgical mortality had a tendency to be lower in the elderly ( $4.5 \%$ vs $6 \%$ ). As can be seen in chapter 9 the long term surwival after surgery is similar or even better than that from the general elderly population. This can be explained by patient selection with a higher incidence of chronic diseases in the elderly population in general. ${ }^{15}$

Atrial fibrillation is the most common complication after open heart surgery in the elderly patient. Since the size of the left atrium, which was measured pre-operatively in all patients, did not differ between the age groups, other age-related factors have to explain this finding. Probably the most important factor is age-related myocardial fibrosis. Another important factor we found in our study is the low incidence of prophylactic use of betablockers to prevent atrial fibrillation due to a higher incidence of contra-indications for $\beta$-blockade. Since atrial fibrillation results in a longer admission duration, there is a need for the development of anti-arrhythmic agents with less side-effects for the elderly population, which can be given prophylactically.

Mental confusion following open heart surgery is more common in the elderly. Its incidence is especially high after long operative procedures (bypass-time $>114$ minutes, cross-clamp time $>76$ minutes) as in vallvular surgery. We also found that diabetes, pre-operative heart failure, weak carotid pulsations and a re-operation were risk factors. Probably diabetes causes some cerebral vasculopathy which enhances the occurrence of confusion in case of hypoperfusion of the brain. Also the presence of heart failure causes lower arterial oxygen saturations, which causes worsening of hypoxemia of the brain during surgery. Weak carotid pulsations can be a sign of carotid stenosis. Since this is a known risk factor for surgery, several authors suggest pre-operative carotid screening by duplex scanning if a carotid stenosis is suspected. The presence of a carotid stenosis $>75 \%$ is associated with a $15 \%$ chance of a postoperative cerebrovascular accident. ${ }^{16 ; 17}$ A re-operation is a time-consuming procedure which because of its longer duration might explain the higher incidence of mental confusion.

The results of mitral valve surgery were less good in the elderly. The 1-year mortality was higher ( $24 \%$ vs $19 \%$, and also the number of re-admissions within one year ( $47 \%$ v $15 \%)$. A possible explanation for this can be a higher incidence of mitral annulus calcification in the elderly $(56 \%$ vs $34 \%) .{ }^{18}$ This makes the surgical procedure more difficult. Also the possibilities to do a mitral valve reconstruction are limited in the presence of annular calcification. Elderly patients also had a higher incidence of inadequate functioning of the mitral val ve when measured 6 months later by echocardiography. That finding was present in $29 \%$ vs $16 \%$. This 
was especially the case when mitral valve reconstruction was performed $(75 \%$ vs 45\%). These results suggest that mitral valve reconstruction is less successul in the elderly, and its use should probably be limited.

\section{QUALITY OF LIFE}

Both age groups showed a significant and similar improvement of the quality of life variables measured after surgery. The only pre-operative difference was a higher incidence of physical immobility in the elderly, which is a nomal age-related phenomenon. The presence of pre-operative signs for depression appeared to be a predictor for less improvenent of general well being in the elderly patient (57\% vs $72 \%$ ). In another study it has been described that pre-operative depression has a bad influence on rehabilitation after cardiac surgery, which will contribute to a poor outcome. ${ }^{19}$

\section{CONCLUSIONS}

Using the current selection criteria for open heart surgery in the elderly excellent results can be achieved regarding surgical mortality, morbidity and quality of life.

Further improvement is needed in the development for new anti-arthythmic drugs for the prevention of atrial fibrillation following surgery. Also the development of surgical techniques resulting in shortening of the perfusion time are needed to diminish mental confusion in the elderly. Alternative surgical techniques for the management of mitral valve incompetence in the elderly patient should be considered.

Advancedage should not be a contra-indication for open heart surgery, especially when there is little comorbidity.

\section{REFERENCES}

1. Katz NM, Wolfe-Pearce $\int L$, Chase GA: Comparison of results and risk factors of cardiac surgery in two 3-year time periods in the 1990s. Am. J. Condiol. 1998.Jum. 15.

2. Keon WJ: Operative results and risk factors over the past three decades, in Walter PJ (ed): Coronary bypass surgery in the eldery. Kluwer Acadenvic Publishers, 1995, pp 27-40

3. Naunheim KS, Fiore AC, Wadley JJ, Kanter KR, McBride LR, Pennington DG, Barner HB, Deligonul U, Kern MJ, Vandormael M, Wilman VL, Kaiser GC: The changing mortality of myocardial revascularization: Coronary artery bypass and angioplasty. Awn. Thorac. Surg. 1988;46:666-674

4. Schneider M: Denographic and economic trends in Europe and the need for coronary bypass surgery., in Walter PJ (ed): Coronary bypass surgery in the elderly. the Netherlands, Kluwer Acadenic Publishers, $1995, \mathrm{pp} 3-12$ 
5. BashourTT, Hanna ES, Myler RK, Mason DT, Ryan C, Feeney J, Iskikian J, Wald SH, Antonini C, Sr., Malabed LL: Cardiac surgery in parients over the age of 80 years. Clin. Cardiol. 1990, 13:267-270

6. Boucher JM, Dupras A, Jutras N, Page V, LeLorier J, Gagnon RM: Long-term survival and functional status in the elderly after candiac surgery. CanJ. Cardiol. 1997.Jul. $13.646-652$

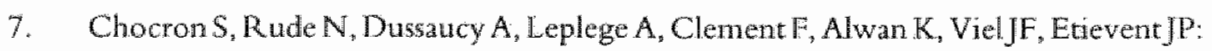
Quality of life after open-heart surgery in patients over 75 years old. Age.Ageing 1996;25:8-11

8. Dewick M, MollhoffT, Budde $T$, Scheld HH: Cardiac surgery in patients aged 80 years and above: does outcome justify significant perioperative morbidity? Cardiology in the clderly $1995,3: 381-386$

9. Edmunds LH, Jr, Stephenson LW, Edie RN, Ratcliffe MB: Open-heart surgery in octogenarians. New Engl.J.Med. 1988;319:131-136

10. Freeman WK, SchafHV, O'Brien PC, Orsalak TA, Naessens JM, Tajik AJ: Cardiac surgery in the octogenarian: perioperative outcome and clinical follow-up. J.Am. Coll. Cardiol. 1991:18:29-35

11. Katz NM, Hannan R. I, Hopkins RA, Wallace RB: Cardiac operations in patients aged 70 years and over: mortality, length of stay, and hospital charge. Anm. Thorac Sury. $1995 ; 60 ; 96-100$

12. Kumar P, Zehr KJ, Chang A, Cameron DE, Baumgartner WA: Quality of life in octogenarians after open heart surgery. Chest 1995;108:919-926

13. Shab VZ, Rosenfeldt FL, Parkin GW, Ugoni AM, Habersberger PG, Cooper E: Cardiac surgery in the very elderly. Med I. A ust. 1994;160:332-334

14. Tsai TP, Chaux A, Matloff JM, Kass RM, Gray RJ, DeRobertis MA, Khan SS: Ten-year experience of cardiac surgery in patients aged 80 years and over. Alm. Thorac. Surg. 1994;58:445-450

15. Nusselder WJ. Bos wan den GAM, Lenior ME, Sonsbeek van JLA, Velden van der J: Prevalentiecifers en gezonde levensverwachting, in Nusselder WJ (ed): Gezonde

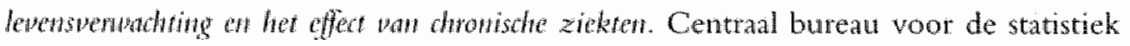
(CBS), 1.995, pp 51-76

16. Berens ES, Kouchoukos NT, Murphy SF, Wareing TH: Preoperative carotid artery scresning in elderly patients undergoing cardiac surgery.J. Vase. Surg. 1992,15:313-323

17. Faggioli $G L$, Curl GR, Ricotta J]: The role of carotid screening before coronary artery bypass. J.VASC.SURG. 1990;12:724-731

18. Cammack PL, Edie RN, Edmunds LH, Jr.: Bar calcification of the mitral anulus. A risk factor in mitral valwe operations. J. Thorac Cardiowasc. Surg. 1987;94:399-404

19. Loma Cay E, Rourke $O$ " A: The emotional state of patients after coronary bypass surgery, in Walter PJ (ed): Qmaliry of Life affer Open Hean Surgery. Kluwer Academic Publishers, 1992, pp 177-183 


\section{Summary}

The number of patients older than 75 years that have undergone open heart surgery has increased significantly during the last decade. To answer the question if there are differences in outcome of open heart surgery in eldedy patients we prospectively studied 200 patients aged 75 years or older in comparison to 400 procedure and gender matched younger patients. Data were collected regarding clinical parameters and quality of life.

\section{BASELINE DIFFERENCES}

Gender: As shown in chapter 3 female patients were relatively older at the time of surgery compared to male patients.

Senerity of the disease: Elderly patients ( $\geq 75$ years) referred for coronary surgery had more often 3-vessel disease ( $81.7 \%$ vs $66.3 \%)$, had a higher incidence of severe left main stenosis $(13.7 \%$ vs $7.7 \%$ ) and had more often angina in rest $(69 \%$ vs $56 \%)$. The incidence of diabetes, renal disease and COPD did not differ. Risk factors for coronary artery disease (hypercholesterolemia and smoking) were less present in elderly patients. Elderly patients also had a higher incidence of pre-operative mitral insufficiency, a higher $R V$-systolic pressure and a higher LV-end diastolic pressure.

In elderly patients referred for valvular surgery the incidence of hypertension and smoking was less compared to younger patients. The incidence of left ventricular hypertrophy was slightly higher in the elderly. Findings on hemodynamic measurements were similar in both groups.

\section{SURVIVAL}

When comparing two age groups (above and below 75 years) no signifcant differences were found in mortality in the first three years following coronary, valvular and combined surgery. Hospital mortality (up to 30 days following surgery) was $4.5 \%$ in the Old group and $6.0 \%$ in the Young group. The One-year mortality (including hospital mortality) was $7.5 \%$ of the Old and $8.0 \%$ of the Young group. Only after 42 months a higher mortality rate was found in elderly patients, especially in those older than 80 years. This can be explained by 
the lower life expectancy of octogenarians. In agreement with this observation is the fact that the youngest age group always had the best long-term prognosis. When the type of surgery was taken in account, the same pattern is seen for coronary surgery and aortic valve surgery. Only for mitral valve surgery a higher one year mortality rate is found in patients older then 75 years (23.5 vs $18.6 \%$ ).

Major pre-operative predictors for 1 year mortality including hospital mortality in the CABG patients were: A history of cardiac asthma, the presence of pleural fluid on a chest $X$-ray, persisting ischemia on the last pre-operative ECG and symptomatic cerebrovascular disease. In the group with valvular heart disease major pre-operative predictors for mortality in the elderly were: An increased creatinin value $>140 \mu \mathrm{Mol} / 1$ and increased right sided pressures $>45 \mathrm{mmHg}$ systolic.

\section{DIFFERENCES IN HOSPITAL MORBIDITY}

One of the major differences in morbidity was a higher incidence of post-operative atrial fibrillation in the elderly patient. The incidence was especially higher when valvular surgery was performed. The presence of atrial fibrillation was associated with a longer admission duration. The higher incidence of atrial fibrillation can be partly explained by a higher incidence of atrial fibrillation in elderly people, because of a higher incidence of age-related myocardial fibrosis. However as shown by the high incidence of atrial fibrillation in valve surgery, other factors like atrial enlargement play a role. We also found that elderly patients were considered to have more contra-indications for prophylactic use of beta-blocking diugs.

Another striking difference is a 2.5 times higher incidence of temporary mental confusion of elderly patients after valvular surgery (found in $1 / 3$ of patients). Mental confusion was associated with a significantly longer aortic cross clamp time (mean $=103.8$ minutes in confused patients versus 79.89 minutes without confusion). The mean aortic cross clamp time in elderly patients undergoing coronary surgery was only 56.2 minutes, which can explain the relatively low incidence of $17.2 \%$ mental confusion following that operation. Other riskfactors for mental confusion were: diabetes mellitus, pre-operative heartfailure and a re-operation.

Another difference in morbidity include a median of four days longer postoperative admission duration of the elderly patient with coronary surgery (13 versus 9 days), but no significant difference in case of valvular surgery (14 versus 13 days). In the elderly group with coronary surgery the incidence of postoperative congestive heart failure (Killip class $2-4$ ) was higher (41.9\% versus $31.1 \%$ ) and also the incidence of postoperative $\mathrm{AV}$-conduction disturbances requiring pacing was higher ( $14.7 \%$ versus $7.6 \%$ ). 


\section{DIFFERENCES DURING FOLLOW-UP}

Elderly patients with valvular surgery had a 2.9 times higher incidence of readmissions ( $29.7 \%$ ws $10.4 \%$ ) because of procedure related or new cardiac problems in the first year following surgery. This was especially the case in elderly patients with mitral valve surgery of whom $47 \%$ had readmissions. No differences in readmissions were seen in patients with coronary surgery.

A routine echocardiogram which was performed 6-7 months following surgery demonstrated a larger decrease of LV-end diastolic diameter following valvular surgery in the young patient. No differences were seen regarding LV and valvular function.

Elderly patients showed a similar improvement in anginal and dyspnea complaints 6 and 12 months following surgery. When compared to preoperatively, general well-being improved one year after surgery in $73.3 \%$ of the Young and $69.9 \%$ of the Old patients ( $P=$ n.s.).

Quality of life assessment using the Nottingham Health Profile and Hospital Anxiety and Depression scale pre-operatively and two and six months after surgery, showed improvement in both age groups. However in case of valvular: surgery the amount of improvement was less in the elderly, especially regarding energy, sleep and social functioning which did not significantly improve in the first 2 months following surgery. In case of coronary surgery all items regarding quality of life improved significantly in both groups. Elderly patients who were pre-operatively depressed, had less improvement of general well-being compared to younger depressed patients following surgery (57\% versus $67 \%$ ). The improvement of the non-depressed patients were similar in both groups $(72-73 \%)$.

\section{COSTS OF HOSPITAL. STAY}

Based on fxed prices for one day admission on a general care or an intensive care unit we calculated the approximate admission costs for each patient, including pre-operative admission duration and re-admissions until one year following surgery, and excluding costs of surgery and diagnostic procedures. For this calculation we used an amount of $f 850$.- per day for a bed of general care, and $f 2500$.- per day for an intensive care or coronary care unit bed. The costs for coronary surgery were significantly higher in the Old age group (table 1), because of a longer postoperative admission duration. Surprisingly no differences were seen in the other patient groups. 
Table 1. Calculated costs (Mean \pm Std in DFL) for admission duration and re-admissions within one year.

\begin{tabular}{lll}
\hline & Young & old \\
\hline CABG & $24818 \pm 20444$ & $29860 \pm 21176^{*}$ \\
Valve & $27028 \pm 21670$ & $27749 \pm 20984$ \\
CABG + Valve & $35105 \pm 37876$ & $33812 \pm 31773$ \\
AVR & $27212 \pm 23162$ & $27656 \pm 17783$ \\
MVR & $37452 \pm 37365$ & $39153 \pm 42935$ \\
All procedures & $26913 \pm 24589$ & $30132 \pm 23152$ \\
\hline
\end{tabular}

$* 0 \times 0.05$

\section{CONCLUSIONS}

Elderly patients admitted for coronary revascularisation or aortic valve surgery have excellent results regarding mortality, morbidity and quality of life, comparable to younger patients. An important factor explaining these results is the pre-operative selection of patients. The results of mitral valve surgery in elderly patients are more disappointing because of higher mortality and morbidity. These findings should be taken into account when cardiac surgery in the elderly is considered.

The finding that the overall life expectancy after cardiac surgery is similar to that of the general population, indicates that advanced age should not be seen as a contra-indication for surgery, especially when not too many riskfactors predicting mortality are present. 


\section{Samenvatting}

Het aantal patiënten ouder dan 75 jaar dat open hart chirurgie heeft ondergaan in de laatste tien jaar is in belangrijke mate toegenomen. Om de vraag te beantwoorden of er verschillen zijn in de uitkomst van open hart chirurgie bij oudere patiënten, hebben wij een prospectieve studie verricht bij 200 patiënten van 75 jaar en ouder, en 400 jongere patiënten met overeenkonnstige procedure en geslacht. Gegevens werden verzameld betreffende klinische paramerers en kwaliteit van leven.

\section{BASIS KENMERKEN}

Geslach: Zoals aangetoond in hoofdstuk 3 zijn vrouwelijke patiënten relatief ouder op het tijdstip van de operatie vergeleken met mannelijke patiënten.

Emst van de ziekte: Oudere patiënten $(\geq 75$ jaar) verwezen voor coronaire bypass chirurgie hadden vaker 3 -taks lijden ( $81.7 \%$ vs $66.3 \%)$, hadden een hogere incidentie van ernstige hoofdstam stenose (13.7\% vs $7.7 \%)$ en hadden vaker angina pectoris in rust (69\% vs $56 \%)$. De incidentie van diabetes mellitus, nierfunctie stoornissen en CARA verschilde niet. Risico factoren voor coronaria lijden (hypercholesterolemie and roken) waren in mindere mate aunwezig bij oudere patiënten. Oudere patiënten hadden ook een hogere incidentie van een pré-operatieve mitralisïnsufficiëntie, een hogere RV-systolische druk, en cen hogere LV-einddiastolische druk.

Oudere patiënten verwezen voorklepchirurgie hadden een lagere incidentie van hypertensie en roken, vergeleken met jonge patiënten. De incidentie van linker ventrikel hypertrofie was iets hoger bij ouderen. Hemodynamische metingen waren identiek in beide groepen.

\section{OVERLEVING}

Wanneer we beide leeftijdsgroepen (ouder en jonger dan 75 jaar) vergelijken, dan zijn er geen verschillen in sterfte in de eerste 3 jaar na coronair, klep, en gecombineerde operaties. De ziekenhuis sterfte (tot 30 dagen na operatie) was $4.5 \%$ in de oude en $6.0 \%$ in de jonge groep. De 1 -jaars sterfte (inclusief ziekenhuis sterfte) was $7.5 \%$ in de oude en $8.0 \%$ in de jonge groep. Alleen na 42 maanden werd een hogere sterfte gevonden bij oudere patiënten, met name in de leeftijds- 
groep ouder dan 80 jaar. Dit kan verklaard worden door de lagere levensverwachting van 80 -plussers. In overeenstemming met deze bevinding is het feit dat de jongste leeftijdsgroep altijd de beste lange-termijn prognose had.

Wanneer er gekeken wordt naar het type operatie, dan is hetzelfde patroon zichtbaar voor coronair chirurgie en aortaklep chirurgie. Alleen bij mitraalklep chirurgie werd een hogere 1-jaars sterfte gevonden bij patiënten ouder dan 75 jaar (23.5 vs $18.6 \%)$.

Bellangrijke pré-operatieve voorspellers voor 1-jaars sterfte alsmede ziekenhuis sterfte bij coronair chirurgie zijn: Een astma cardiale in de voorgeschiedenis, de aanwezigheid van pleuravocht op een thoraxfoto, persisterende ischemie op het laatste pré-operatieve ECG, en symptomatisch cerebrovasculair lijden. In de groep met kleplijden waren de belangrijkste pré-operatieve voorspellers voor sterfte: Een verhoogd serum kreatinine van $>140 \mu \mathrm{Mol} / 1$ alsmede verhoogde rechter ventrikel drukken van $>45 \mathrm{mmHg}$ systolisch.

\section{VERSCHILLEN IN ZIEKENHUIS MORBIDITEIT}

Een van de grootste verschillen in morbiditeit was een hogere incidentie van post-operatief boezemfibrilleren bij de oudere patiënt. De incidentie was met name hoger na klep-operaties. Het optreden van boezemfibrilleren ging gepaard met een langere opnameduur. De hogere incidentie van boezemfibrilleren kan gedeeltelijk worden verklaard door een hogere incidentie van boezemfibrilleren bij ouderen, ten gevolge van een hogere incidentie van leeftijdsgebonden hartspier fibrose. Echter zoals blijkt uit de hogere incidentie van boezemfibrilleren na klepoperaties, spelen ook andere factoren zoals boezem vergroting een rol. Tevens vonden we dat oudere patiënten meer contraindicaties hadden voor het profylactisch gebruik van bèta-blokkers.

Een ander opvallend verschil is een 2.5 keer hogere incidentie van tijdelijke mentale verwardheid bij oudere patiënten na klepchirurgie (bij $1 / 3$ van de patiënten). Verwardheid was geassocieerd met een significant langere aorta klemtijd (gemiddeld $=103.8$ minuten bij verwarde patiënten versus 79.89 minuten zonder verwardheid). De gemiddelde aorta klemtijd bij oudere patiënten tijdens coronairchirurgie was slechts 56.2 minuten, hetgeen de relatief lage incidentie van $17.2 \%$ verwardheid kan verklaren bij die ingreep. Andere risicofactoren voor verwardheid waren: diabetes mellitus, pré-operatief pompfalen en een reoperatie.

Een ander verschil in morbiditeit is een vier dagen langere postoperatieve opnameduur bij de oudere patiënt na coronairchirurgie (13 versus 9 dagen), doch er is geen significant verschil na klepchirurgie (14 versus 13 dagen).

In de oudere groep met coronairchirurgie werd een hogere incidentie gevonden van postoperatief pompfalen in Killip klasse $2-4$ (41.9\% versus $31.1 \%)$. Ook de 
incidentie van postoperatieve AV-geleidingstoomissen warwoor pacing noodzakelijk is was hoger $(14.7 \%$ versus $7.6 \%$.

\section{VERSCHILLEN TIJDENS FOLLOW-UP}

Oudere patiënten na klepchirurgie hadden een 2.9 keer hogere incidentie van heropnames $(29.7 \%$ vs $10.4 \%)$ ten gevolge van procedure gerelateerde of nieuwe cardiale problemen in het eerste jaar na de operatie. Dit was met name het geval bij mitraalklep-chirurgie waarbij er $57 \%$ heropnames waren. Er waren geen verschillen in heropnames bij coronairchirurgie.

Een routine echocardiogram dat 6-7 maanden postoperatief werd verricht toonde een grotere afname van de LV-eind diastolische diameter bij jongere patiënten na een klepoperatie. Er waren geen verschillen zichtbaar in linker ventrikel en klepfunctie.

Oudere patiënten lieten een identieke verbetering zien van angina pectoris en dyspneu klachten 6 en 12 maanden na de operatie. Ten opzichte van pré-operatief is het allgemene welbevinden na 1 jaar verbeterd bij $73.3 \%$ van de jonge en $69.9 \%$ van de oude patiënten ( $P=$ n.s.).

Kwaliteit van leven, gemeten met de Nottingham Health Profile en de Hospital Anxiety and Depression scale, zowel pré-operatief als twee en zes maanden postoperatief, liet verbetering zien in beide leeftijdsgroepen. Echter bij klepoperaties is de mate van verbetering minder bij de oudere groep, met name factoren zoals energie, slaap, en sociaal functioneren verbeterden niet significant in de eerste 2 maanden na de operatie. Bij coronairchirurgie trad er in alle gemeten variabelen een verbetering op van kwaliteit van leven in beide groepen. Oudere patiënten die pré-operatief depressief waren, toonden een geringere verbetering van het algemene welbevinden dan jongere depressieve patiënten na de operatie ( $57 \%$ versus $67 \%$. De verbetering van niet depressieve patiënten was identiek in beide groepen $(72-73 \%)$.

\section{KOSTEN VAN ZIEKENHUISOPNAME}

Uitgaande van vaste bedragen voor een dag opname op een algemene afdeling en een intensive care unit hebben we een berekening gemaakt van de geschatte opname kosten per patiënt. Hierbij werd gekeken naarzowel de pré-en post-operatieve opnameduur, alsmede de heropnames tot een jaar na de operatie (exclusief kosten van ingrepen en diagnostiek). Voor deze berekening werd een bedrag van $f 850$,- per dag gebruikt voor een bed op de algemene afdeling, en $f 2500$, - per dag op een intensive care of hartbewakings afdeling. De kosten voor coronair chirurgie waren significant hoger bij de oudere leeftijdsgroep (tabel 1), ten gevolge van een langere postoperatieve opnameduur. Opvallend genoeg waren er geen verschillen bij de andere patiënten groepen. 
Tabel 1. Berekende kosten (Gemiddelde \pm Std in DFL) voor opnamedur en heropnames binnen kên jaar.

\begin{tabular}{lll}
\hline & Jong & Oud \\
\hline Bypass & $24818 \pm 20444$ & $29860 \pm 21176^{*}$ \\
Klep & $27028 \pm 21670$ & $27749 \pm 20984$ \\
Bypass+Klep & $35105 \pm 37876$ & $33812 \pm 31773$ \\
Aartaklep & $27212 \pm 23162$ & $27656 \pm 17783$ \\
Mitraalklep & $37452 \pm 37365$ & $39153 \pm 42935$ \\
Alle ingrepen & $26913 \pm 24589$ & $30132 \pm 23152$ \\
\hline
\end{tabular}

* P $<0.05$

\section{CONCLUSIES}

Oudere patiënten opgenomen voor coronair chirurgie of aortaklep vervanging hebben uitstekende resultaten betreffende mortaliteit, morbiditeit, en kwaliteit van leven, hetgeen vergelijkbaar is met jongere patiënten. Een belangrijke factor die deze resultaten verklaard is de pré-operatieve selectie van patiënten. De resultaten van mitraalklep chirurgie bij oudere patiënten zijn meer teleurstellend in verband met een hogere mortaliteit en morbiditeit. Met deze bevindingen dient rekening te worden gehouden indien open hart chirurgie wordt overwogen bij oudere patiënten.

De bevinding dat de levensverwachting na open hart chirurgie identiek is aan die van de algemene bevolking, geeft aan dat gevorderde leeftijd niet gezien mag worden als een contra-indicatie voor operatie, met name indien er niet te veel risicofactoren woor een slechte operatie uitkomst aanwezig zijn. 


\section{Dankwoord}

Graag wil ik iedereen bedanken die op enigerlei wijze heeft bijgedragen aan de totstandkoming van dit proefschrift. Zonder iemand te kort te willen doen, wil ik een aantal betrokkenen met name noemen.

Een speciaal woord van dank richt ik graag tot jou, Professor Wellens, beste Hein. Zonder jou was dit proefschrift er niet gekomen. Jouw belangstelling en ideeën voor dit onderwerp, alsmede je intensieve begeleiding zijn voor mij van onschatbare waarde geweest.

De leden van de beoordelingscommissie dank ik voor de moeite die zij hebben willen nemen voor de beoordeling van het manuscript en voor de nuttige adviezen.

Simon Braat bedank ik voor de wijze warop hij de patiëntenzorg op zich genomen heeft, waardoor ik in staat werd gesteld on elders aan het werk te gaan.

Salima Pourrier ben ik zeer erkentelijk voor het vele werk dat ze gedaan heeft met het telefonisch follow-up gegevens te verzamelen van alle patiënten.

Charles. Kirchhof ben ik zeer dankbaar voor de inspanning die hij gedaan heeft voor de totstandkoming van hoofdstuk 6 .

Alle medewerkers van de afdeling cardiopulmonale chirurgie, inclusief secretariaat en medische staf dank ik voor alle hulp en ondersteuning die ik gekregen heb.

Tot slot dank ik jou, Jeannette, mijn steun en toeverlaat, alsmede Christian en Ame, voor jullie liefde, begrip en vertrouwen. 



\section{Publications}

"Electrophysiological and clinical effects of propafenone in supraventricular arrhythmias". Ivo Kersschot, Pedro Brugada, Manfred Zehender, Bernd Waldecker, Anette Geibel, Jan Heijmeriks, Hein J.J. Weilens. Circulation 1985; 72(III): 128 .

'D-Sotalol, a new class III antiarrhythmic agent, in the treatment of supraventricular tachycardia'. Manfred Zehender, Pedro Brugada, Annette Geibel, Ivo Kersschot, Bernd Waldecker, Jan Heijmeriks, Hein JJ Wellens. Abstract NASPE 1986.

'Evaluation of rate response to exercise by the activitrax pacemaker'. Karel den Dulk, Pedro Brugada, Jan Heijmeriks, Ian Rankin, Fred Lindemans, Hein JJ Wellens. Abstract PACE 1986; a: 295.

'Lack of clinically significant betablocking effect of propafenone'. Emile C Cheriex, Ruud Krijne, Pedro Brugada, Jan Heijmeriks, Hein JJ Wellens. European Heart Joumal, 1986.

'Effects of early reperfusion in acute myocardial infarction on inducibility of ventricular arrhythmias. A prospective, randomized study'. Ivo Kersschot, Pedro Brugada, Mercedes Ramentol, Manfred Zehender, Bernd Waldecker, Annette Geibel, Jan Heijmeriks, Hein JJ Wellens. Circulation 1985; 72(III):360.

'Clinical course and long term follow-up of 60 patients with symptomatic idiopathic ventricular tachycardia or ventricular fibrillation'. Robert Lemery, Pedro Brugada, Adri v.d. Dool, Jan Heijmeriks, Paolo Della Bella, Thieny Dugemier, Hein JJ Wellens. Circulation 1986; 74(II): 188.

'A transventricular lead system for the identification and termination of tachycardias'. Paolo Della Bella, Pedro Brugada, Robert Lemery, Thierry Dugernier, Mario Talajic, Jan Heijmeriks, Hein J.J. Wellens. American Journal of Cardiology 1987; 60:1043-1050. 
"The Long-term clinical efficacy of oral propafenone in patients with ventricular tachyarrhythmia'. Thierry Dugernier, Pedro Brugada, Simon Braat, Jan Hejmeriks, Jan Herre Kingma, Joep Smeets, Hein JJ Wellens.

'Polymyositis, Een ongebruikelijke presentatie'. Jan Heijmeriks, W. Hart. Medisch journaal Delft, 1990; 3:158-163.

Prophylaxis with sotalol against atrial fibrillation post-cardiac-surgery in the elderly'. J.A. Heijmeriks, A. Meijer, H.J. Wellens. Abstract en voordracht op najaarsvergadering van NvvC in Garderen, 1995.

'Changes in quality of life after open heart surgery in elderly patients as compared to younger patients'. J. Heijmeriks, H. J. Wellens. Abstract en poster op XVIIIth Congress of the European Society of Cardiology, Birmingham 1996.

'Results of cardiac reoperations in elderly patients as compared to younger patients. A prospective study". J.A. Heijmeriks, H.J.J. Wellens. Abstract en poster op Voorjaarsvergadering van NvvC in Amsterdam, 1997.

'Prevention of Atrial Fibrillation Post Cardiac Surgery by low dose Sotalol in different Age Groups'. Jan Heijmeriks, Charles Kirchhof, Hein J.J. Wellens. Abstract en poster op 7 th International Symposium on Cardiovascular Pharmacotherapy, Jerusalem, Israel, 1997.

"Atrial Fibrillation following cardiac surgery in the elderly. Incidence, outcome of $\beta$-blocker use and effect on length of hospital stay'. Jan A Heijmeriks, Charles J Kirchhof, HeinJ Wellens. Abstract en poster op American Heart Association $70^{\text {th }}$ Scientific Sessions, 1997.

Differences in outcome of open heart surgery in elderly patients as compared to younger patients. A prospective study'. J.A. Heijmeriks, E.C. Cheriex, K. Prenger, H.J.J. Wellens. Abstract en poster op XX ${ }^{\text {th }}$ Congress of the European Society of Cardiology, Vienna, 1998.

"Treatment of recent onset atrial fibrillation with intravenous sotalol and/or flecainide'. F.P.J. Peters, S.H. Braat, J. Heymeriks and H.J.J. Wellens. Netherlands Journal of Medicine, 1998; 53: 93-96.

'Comparison of Quality of Life after Coronary and/or Valvular Cardliac Surgery in Patients $\geq 75$ Years of Age to Younger Patients'. Jan A Heijmeriks, Salima 
Pourrier, Pim Dassen, Kees Prenger, Hein JJ Wellens. American Journal of Cardiology, 1999; 83(7): 1129-32.

'The incidence and consequences of mental disturbances in elderly patients post cardiac surgery. A comparison with younger patients'. J.A. Heijmeriks, W. Dassen, K. Prenger, H.J.J. Wellens. Clinical Cardiology, 2000; in press.

'Observations on the effect of cardiac surgery on long-term survival patterns. A comparison with the general population'. Jan A. Heijmeriks, MD, Pim Dassen, PhD, Kees Prenger, MD Salima Pourrier, MS, Hein J. Wellens, MD; Submitted. 



\section{Curriculum vitae}

Name Jan (Johannes Alexander) Heijmeriks

Born Brunssum, Netherlands, June 29, 1962

Nationality Dutch

EDUCATION

1974 - 1979 H.A.V.O. Romboutscollege, Brunssum.

$1979-1981$ Atheneum. Romboutscollege, Brunssum.

$1981-1987$ Medicine study, Rijksuniversiteit Limburg, Maastricht.

$1983-1987$ Student Assistent at the department of clinical electrophysiology, Academic Hospital of Maastricht, the Netherlands.

$1988-89 \&$

1991-93 Training in Cardiology, Academic Hospital Maastricht

1989 - 1991 Training in Internal Medicine, Reinier de Graaf gasthuis, Delft

\section{WORKING EXPERIENCE}

1993 - 1998 Department of Cardiology, Academic Hospital Maastricht 1998 Department of Cardiology. Westeinde Hospital, The Hague 1999 Department of Cardiology, Bovenly Hospital, Ansterdam 